\title{
Myosin II in early Xenopus morphogenesis
}

\author{
Ana Isabel Cosme Nunes Rolo \\ Lisboa, Portugal
}

B.S., Universidade de Lisboa, 1998

M.S., Universidade Lusófona, 2000

A Dissertation presented to the Graduate Faculty of the University of Virginia in Candidacy for the Degree of Doctor of Philosophy

\section{Department of Biology}

\section{University of Virginia} January, 2007

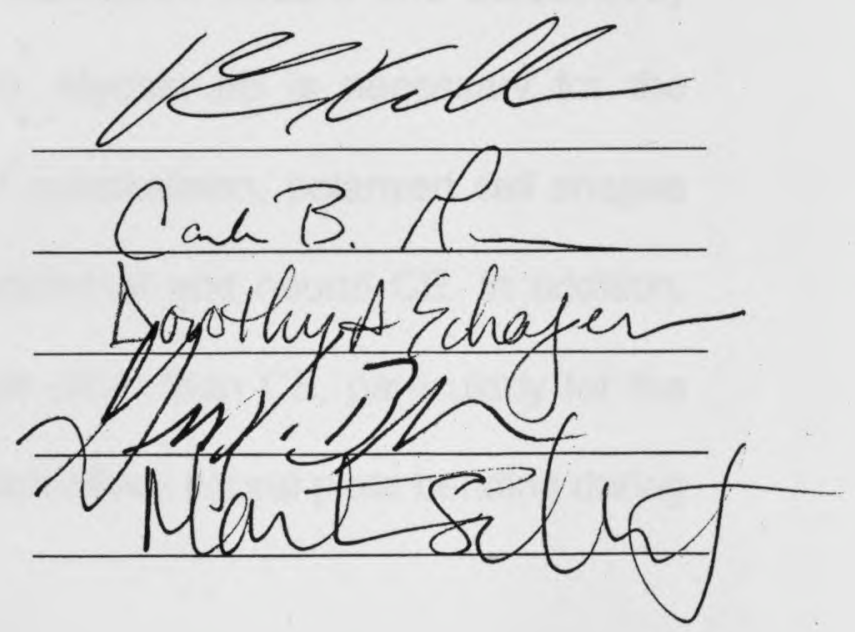




\section{ABSTRACT}

This thesis focuses on demonstrating the relative roles of cytoskeletal myosins IIA and IIB in early Xenopus morphogenesis. Cytoskeletal myosin II is a motor protein implicated at a cellular level in functions such as cell motility, adhesion and cortical integrity, and at a tissue level in diverse morphogenetic events, such as Drosophila germ band extension and dorsal closure. Vertebrates have different isoforms of myosin II, including myosins IIA and IIB, which have distinct subcellular localizations, as well as different biochemical properties, suggesting that they may have separate roles in vertebrate morphogenesis. I show that in Xenopus these isoforms also have distinct localizations in the embryo, with IIB expressed predominantly in the dorsal tissues, and IIA ubiquitously throughout the embryo, suggesting region-specific functions. With morpholino-oligonucleotide reduction or knock-down of myosins IIA and IIB, I show that myosin IIB is necessary for dorsal morphogenesis, particularly the convergence and extension (CE) of the dorsal mesodermal and neural tissues, which produce the main force that drives blastopore closure and dorsal body elongation in the normal Xenopus embryo. Myosin IIB is necessary for the organization of the contractile actin cortical cytoskeleton, polarized cell shapes and protrusive activity that drive both mesodermal and neural CE. In addition, myosin IIB is required for neurulation events other than $\mathrm{CE}$, particularly for the apical constriction of neurepithelial cells, which drives neural plate bending during 
neural tube closure. Myosin IIB is also necessary for antero-posterior elongation of the dorsal side of the embryo. In contrast, myosin IIA functions mostly in ventral morphogenetic events. During gastrulation, myosin IIA is involved in the process of convergent thickening that occurs in the ventral marginal zone of normal embryos and that aids in closure of the ventral blastoporal lip. Later, myosin IIA is involved in elongation of the ventral side of the embryos during body axis elongation. 
TABLE OF CONTENTS

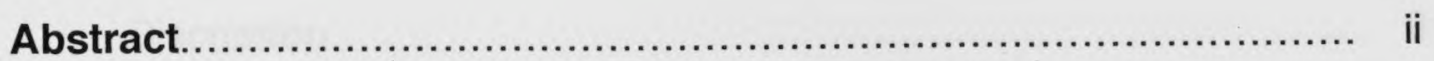

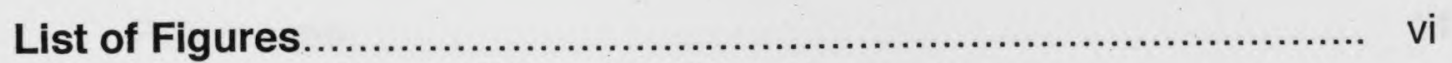

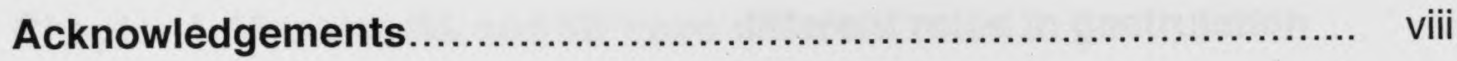

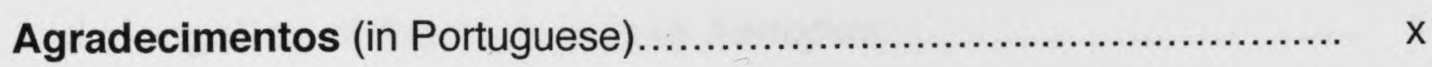

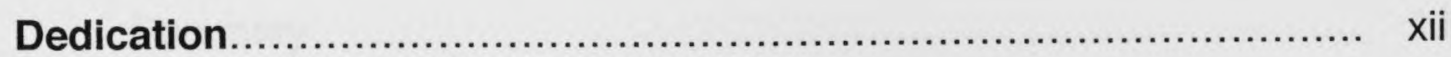

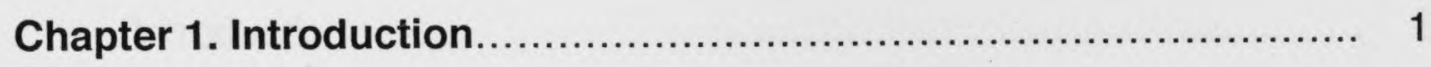

References.................................................... 18

Chapter 2. Myosin IIB is required for convergence and extension

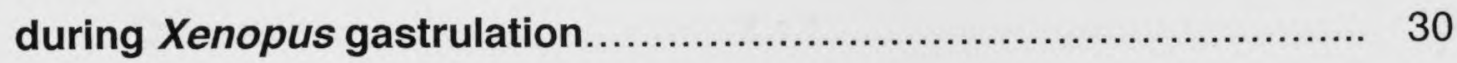

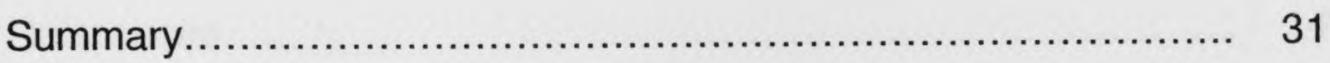

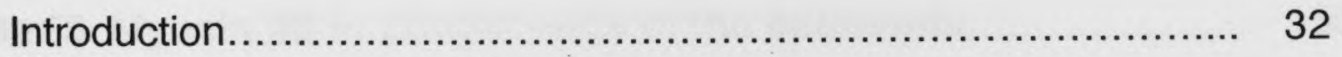

Materials and Methods.......................................... 34

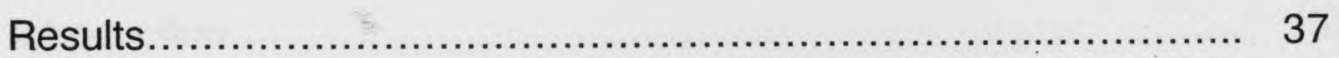

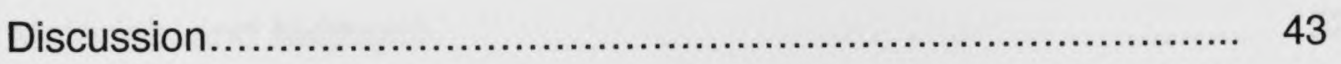

References..................................................... 58

Chapter 3. Myosin IIB has multiple roles in Xenopus neural plate

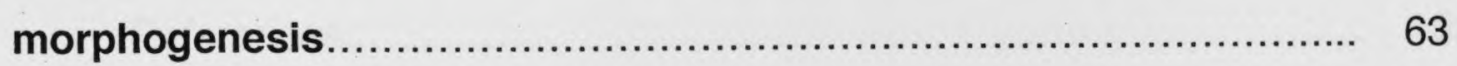

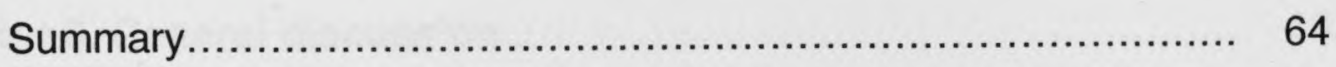

Introduction.................................................... 65 
Materials and Methods............................................ 69

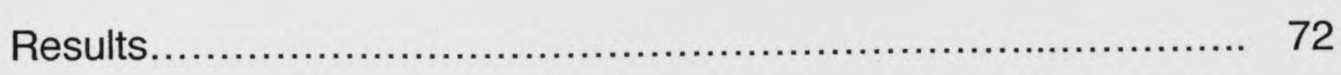

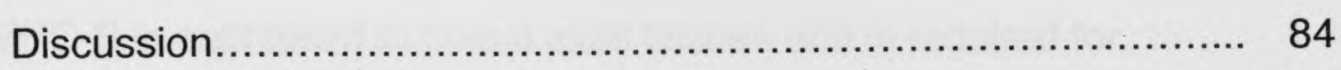

References..................................................... 111

Chapter 4. Myosins IIA and IIB have different roles in gastrulation and elongation of the body axis in Xenopus........................ 118

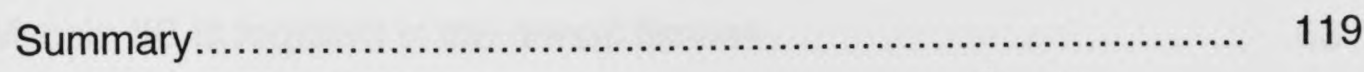

Introduction.................................................... 120

Materials and Methods........................................ 123

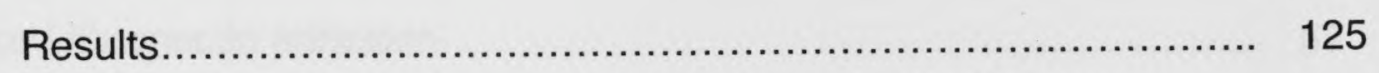

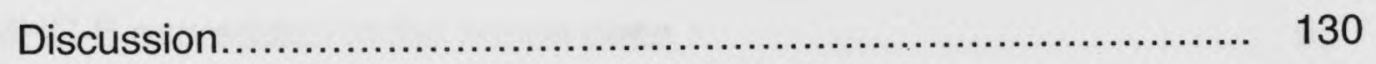

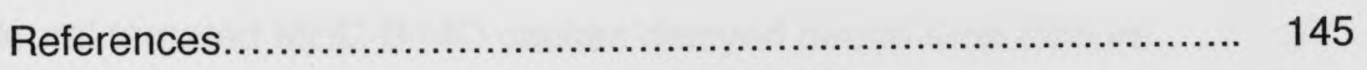

Chapter 5. Myosin IIB in ciliated cells of the epidermis ............... 150

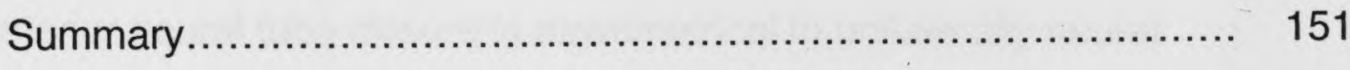

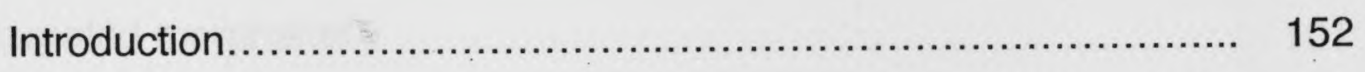

Materials and Methods......................................... 153

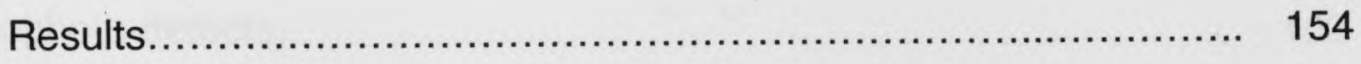

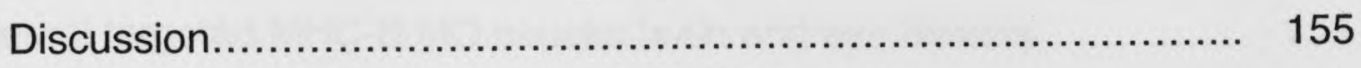

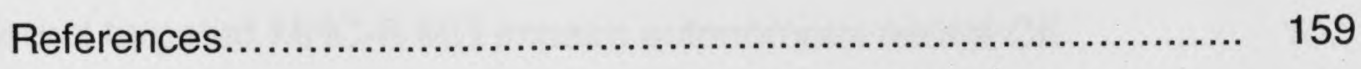

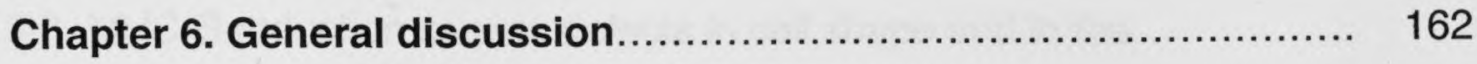

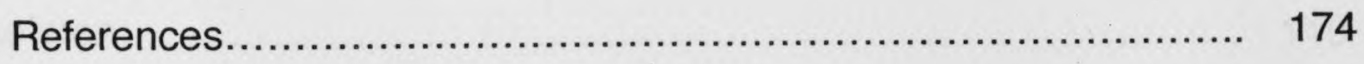




\section{LIST OF FIGURES}

2-1. MHC-B is expressed in dorsal axial tissues and is required for blastopore closure

2-2. MHC-B MO does not alter dorsal mesodermal cell fates.

2-3. MHC-B MO causes a dose-dependent phenotype.

2-4. Myosin IIB is required in the dorsal tissues 53

2-5. MHC-B depleted cells have aberrant morphology and motility. 55

2-6. MHC-B MO causes reduced levels of fibronectin matrix as well as reduced fibronectin adhesion.

3-1. MHC-B expression in the neural plate 95

3-2. Neural targeted MHC-B MO causes delayed neural tube closure 97

3-3. Neural targeted MHC-B MO does not alter neural cell fates 99

3-4. Anterior neural tube closure is asymmetrical in unilaterally neural plate targeted morphants. 101

3-5. Neural targeted MHC-B MO causes dorsal flexure, eye and melanophore defects.

3-6. Neural targeted MHC-B MO causes brain and eye defects. 105

3-7. Neural targeted MHC-B MO impairs autonomous neural CE. 107

3-8. MHC-B reduction causes defects in cell shape and in the cytoskeleton 
4-1. MHC-A is expressed ubiquitously and is required for ventral extension.

4-2. MHC-A MO causes worse defects in ventral than in dorsal tissues.... 138 4-3. MHC-A MO prevents blastopore closure in UV-ventralized embryos... 140 4-4. UV-ventralization rescues blastopore closure in MHC-B morphant embryos.

4-5. Myosins IIA and IIB synergize in blastopore closure and cell adhesion.

5-1. MHC-B is highly expressed in ciliated cells of the epidermis.

6-1. Mechanisms of blastopore closure in normal and perturbed Xenopus embryos. 


\section{ACKNOWLEDGEMENTS}

I thank my advisor, Ray Keller, for always allowing me the freedom to choose what I wanted to work on, and for his enthusiasm about morphogenesis. Over the years, we've had many invaluable discussions that shaped my way of thinking about cells, tissues and embryos.

I thank George Bloom, Carla Green, Dorothy Schafer, and Martin Schwartz, who were great committee members. They always posed good questions, had valuable criticism and gave me good ideas to pursue. I particularly thank Carla Green, my first reader, for guidance and advice during the stressful last months of my graduate career. I am also very grateful to Dorothy Schafer, for receiving me in her lab as a rotation student during my first year in the $\mathrm{PhD}$ program. In her lab, I learned a lot about the world of actin and cell motility, and that knowledge was very useful during the rest of my graduate career.

There are no words that can express my gratitude to my dear friend and labmate, Paul Skoglund. Without him, this thesis would not have been possible. He was always a great source of support and friendship, both inside and outside the lab. Paul provided me with guidance when I needed it, and with his help I learned how to think of new questions and how to design experiments. Over the years, he helped me gain confidence in myself as a scientist. Plus, it was great fun working with him. And, of course, the Skoglund jokes are a quintessential part of life in the Keller Lab - they lighten our mood and help us get through the day. Paul has always been a great friend outside the lab as well, a great person to 
hang out with and have a lot of fun, and a dear friend in dire times. I feel very lucky to have met him, to have worked with him, and, most of all, to have him as friend.

Besides Paul, other Keller Lab members were always great teammates and friends, I will always have fond memories of all of them: Lance Davidson, Max Ezin, Caroline Flournoy, Toshi Goto, Crystal Scott, Janelle Smith, and Dave Shook. I am very thankful to Crystal for being a good friend, always ready to help others, and for baking goodies and bringing them to the lab.

I thank Ammasi Periasamy and Ye Chen at the W. M. Keck Center for Cellular Imaging for their help with confocal microscopy and for always being so friendly.

With my friends, Lorena Benseñor and Ignacio Demarco, I shared the whole graduate school experience, from the first day of class until graduation. They were a great source of moral support and encouragement, as well as the hosts of many fantastic dinner parties. I will miss them terribly, as well as their adorable daughter, Paula Demarco.

Silvia Carraro is a dear friend, whom I had the luck to meet in Charlottesville, and who, even at a distance, always gave me strong support. I am very thankful to her.

I will miss all my friends from the Movie Club, who helped me get through each week by providing great company every Wednesday evening. I will miss all the heated discussions about films and about a myriad of other exciting things. 
And I especially thank Cristian Bodo for being a good friend over the years, and for being a loving and caring partner over the last several months, including tremendous patience, love and moral support during the writing of this thesis.

\section{AGRADECIMENTOS}

Agradeço apoio financeiro à Fundação para a Ciência e a Tecnologia, da qual fui bolseira número SFRH/BD/4851/2001.

O meu melhor amigo, Paulo Teixeira, sabe o quão importante ele foi durante todo este processo. Toda a ajuda, amizade, carinho e apoio moral por ele prestados foram imprescindíveis para a concretização deste projecto. As suas visitas a Charlottesville sempre me animaram, e, inúmeras vezes, longas conversas em telefonemas intercontinentais ajudaram a animar-me o espírito e a ter sempre força para seguir em frente. You're my best friend.

A Filipa Mendes é uma grande amiga que tive o prazer de conhecer em Charlottesville, com quem passei muitos bons momentos e com quem pude sempre contar para os maus momentos também. Mesmo depois da sua saída da Virgínia, continuei sempre a ter o seu apoio. Mas sinto a falta das nossas idas a museus.

Outra amiga que conheci na Virgínia foi a Alexandra Pacheco, uma excelente e prestável pessoa, sempre pronta a ajudar, e de quem vou sentir muita falta. 
Finalmente, quero agradecer aos meus pais, Maria de Lourdes e Joaquim Rolo, assim como à minha restante família, Luís Rolo, Matilde Martins, Duarte Rolo, Maria da Conceição Cosme, Maria Luísa Cosme, Maria da Purificação Cosme, Joaquim Cosme, Maria Clara Veríssimo, David Cosme e Inês Ribeiro por toda a ajuda, carinho e apoio incondicional. Sem vós, isto não teria sido possível. 
To my parents

Aos meus pais 
Chapter 1

Introduction 


\section{Early morphogenesis}

Embryonic development relies on the concerted actions of cell and tissue specification and morphogenesis. Cellular and tissue fates are established by inductive events and cytoplasmic determinants. Induction results from interactions between signaling and responding tissues and lead to the specification of the responding tissues (Gurdon, 1987; Spemann, 1938). Cytoplasmic determinants are specific mRNAs and proteins that are asymmetrically distributed in the cytoplasm and are unequally shared between daughter cells upon cell division (Jeffery, 1988). Cell and tissue differentiation involves not only tissue specification, whether by inductive interactions, or by localization of cytoplasmic determinants, but also morphogenetic behaviors.

Morphogenesis, from its Greek etymology, means the creation of shape it is the process that shapes the body and its organs through cellular and tissue movements and rearrangements. This thesis will focus on the early morphogenetic events of gastrulation, neurulation, and elongation of the body axis.

Gastrulation is the stage of development during which the three germ layers - ectoderm, mesoderm and endoderm, are formed. The ectoderm, or outer layer, will later give rise to the skin and to the nervous system. The middle layer, the mesenchymal mesoderm, forms the circulatory system, the kidneys, most of the musculature, the skeleton, the dermis of the skin, and the matrix of most of the internal organs. The inner layer, the endoderm, gives rise to the lining 
of the gastrointestinal tract. Gastrulation is an extremely varied process (Stern, 2004a). In most amniotes, it involves epithelial-to-mesenchymal-transitions (EMTs) and ingression of presumptive endodermal and mesodermal cells through the primitive streak to form the definitive mesodermal and endodermal layers (Stern, 2004b; Tam and Gad, 2004). In amphibians, these layers are brought inside by a combination of involution movements in which the tissues roll over a blastoporal lip, and, in urodeles (tailed amphibians), an EMT and ingression similar to that seen in amniotes (Keller and Shook, 2004). In these cases, gastrulation also involves closure of a blastopore.

Neurulation is a developmental stage in vertebrates that follows gastrulation and during which a thickened ectodermal plate, the neural plate, forms above the dorsal mesoderm and then becomes separated from the nonneural ectoderm by rolling into a tube - the neural tube, which will later give rise to the brain and spinal cord (Schoenwolf and Smith, 1990). The neural tissues are induced from presumptive ectoderm by the Organizer, the dorsal lip of the blastopore in amphibians (Spemann, 1938), or the node in amniotes (Hunt, 1929; Waddington, 1936).

\section{Xenopus as a model system}

This thesis will explore the cellular movements underlying gastrulation and neurulation in the African clawed frog, Xenopus laevis. Xenopus is the common model system for amphibian development, including gastrulation. It is excellent 
for studies of cell movements by video-recording of cell behaviors during early morphogenesis. The embryo is amenable to microsurgical manipulations that allow explantation of embryonic tissues, which will undergo morphogenetic movements in culture, thus facilitating the imaging of cellular movements that would otherwise be difficult to access in the whole embryo. This property also makes it advantageous for tissue interaction studies and biomechanical studies (Adams et al., 1990; Moore et al., 1995). Other advantages of using Xenopus include the fact that ovulation can be easily induced artificially, producing large spawnings, and in vitro fertilization allows synchronicity in development of large batches of embryos.

\section{Xenopus gastrulation}

Gastrulation in amphibians consists of the internalization of the presumptive mesodermal and endodermal tissues by involution of the region that initially lies just outside the blastopore of the early gastrula, called the involuting marginal zone (IMZ). As involution of the $I M Z$ occurs, the $I M Z$ also undergoes convergence movements that close the blastopore, and extension movements that elongate the embryo. As the IMZ involutes, spreading of the ectoderm by epiboly fills the space vacated on the outside (Keller and Shook, 2004). The involuting endoderm will form the lining of the archenteron, or primitive gut, but there is another endodermal component - the vegetal endoderm, which becomes internalized when the blastopore closes over it. Thus, at the end of gastrulation 
we have a typical triploblastic embryo completely covered by ectoderm, with a gut lined mostly by endoderm and with a mesodermal layer placed in between.

The first external sign of gastrulation is the appearance of bottle cells at the vegetal limit of the dorsal IMZ. In pigmented embryos, these can be easily seen by a concentration of pigment, which is due to dramatic apical constriction of these cells as they become wedge shaped, and as a result, there is a high density of pigment granules at their apices. Bottle cell formation begins dorsally and forms the dorsal blastopore lip, and then it proceeds bilaterally until bottle cells have formed at the ventral blastopore lip, by the mid-gastrula stage. Bottle cells, however, are not necessary for blastopore closure, but they may contribute to initiation of involution and the reliability of gastrulation (Hardin and Keller, 1988; Keller, 1981). The major force, however, driving rotation and initiation of involution of the $I \mathrm{MZ}$ is the vegetal rotation movement of the large mass of vegetal endoderm (Winklbauer and Schurfeld, 1999).

During the first half of gastrulation the dorsal IMZ, as well as the prospective spinal cord, undergo radial intercalation, a process by which multiple deep, mesenchymal layers intercalate along the radius of the embryo and thus form a thinner array that spreads over a larger area (Keller, 1980). Since this increase in area occurs in an anisotropic fashion - it is oriented along the future antero-posterior axis - it results in a longer and thinner array, a movement called thinning and extension (Wilson and Keller, 1991; Wilson et al., 1989). 
In the second half of gastrulation the dorsal tissues undergo convergence and extension (CE) movements that narrow the tissue in the mediolateral direction and lengthen its anterior-posterior axis. Concomitantly, these movements also aid the involution of the IMZ and the closing of the blastopore (Keller et al., 1992a; Keller, 1984; Shih and Keller, 1992b). CE is an active, independent, force-producing mechanism, since dorsal tissues can be explanted and cultured separated from the remainder embryonic tissues, and such explants will undergo CE autonomously and produce force as they do so (Keller and Danilchik, 1988; Keller et al., 1985; Moore et al., 1995).

$\mathrm{CE}$ is achieved by means of mediolateral intercalation, a process by which cells intercalate along the mediolateral axis, thus forming a longer and narrower array (Keller, 1984). This cell intercalation is accompanied by a specific motile behavior, called mediolateral intercalation behavior (MIB) (Keller et al., 1992a; Shih and Keller, 1992a; Shih and Keller, 1992b). Before midgastrula, cells of the dorsal mesoderm are roughly isodiametric and show isodiametric, multipolar protrusive behavior, in that they will extend protrusions in multiple directions without a statistical predominance of direction; after the midgastrula stage, however, they restrict large lamelliform protrusions to their medial and lateral ends, and hence become bipolar (Shih and Keller, 1992a; Shih and Keller, 1992b). As they do so, these cells also elongate in the mediolateral direction, presumably by traction of the large protrusions at their medial and lateral ends (Shih and Keller, 1992a; Shih and Keller, 1992b). Similar movements and cell 
behaviors have been described recently in the teleost fish (Glickman et al., 2003; Topczewski et al., 2001). The posterior neural tissues of the non-involuting marginal zone (NIMZ) also undergo mediolateral intercalation (Keller et al., 1992b), albeit using a monopolar type of protrusive behavior, which will be discussed below. It is thought that the intercalating mesodermal cells pull themselves in between one another by using their bipolar protrusions to exert traction on their neighbors (Keller et al., 2000). Another mechanism that aids in extension of the axial mesoderm is what is known as "boundary capture". As the second half of gastrulation is underway, a notochord-somite boundary develops, and the ends of notochordal cells that contact this boundary become "captured", in that they cease their characteristic lamelliform protrusive activity on the end that contacts the boundary, spread on the boundary and do not leave it (Shih and Keller, 1992b). As these cells spread on the boundary, they maintain their mediolateral elongation and characteristic MIB behavior at their interior ends (Shih and Keller, 1992b). Because mediolateral intercalation occurs in arcs across the dorsal lip of the blastopore, and because it progresses from anterior to posterior tissues (Shih and Keller, 1992b), it generates hoop stresses that progressively pull the involuting tissues over the lip, eventually closing the blastopore.

The arcs of tension that are generated around the lip have to be continuous in order to achieve blastopore closure (Keller et al., 1992a; Keller, 1984; Schechtman, 1942). However, at this stage CE occurs only in the dorsal 
IMZ. The continuity of these arcs on the ventral side of the embryo is due to the process of convergent thickening $(\mathrm{CT})$ that takes place ventrally (Keller and Danilchik, 1988; Keller and Shook, 2004). CT is the mechanism by which the ventral IMZ converges, thus aiding in blastopore closure, but instead of extending as it converges, the ventral region thickens to form a collar of mesoderm around the ventral lip (Keller, 1975; Keller, 1976). CT is an active, force-producing process that occurs in explants of ventral IMZ (Keller and Danilchik, 1988). The cellular behaviors driving CT are not yet known.

In summary, blastopore closure in Xenopus is driven by convergence movements of the IMZ. The dorsal IMZ undergoes CE by mediolateral cell intercalation, whereas the ventral IMZ undergoes $C T$, driven by a yet unknown mechanism. However, the bulk of convergence is achieved by $C E$, which also extends the dorsal tissues posteriorly over the vegetal endoderm, and thus blastopore closure in Xenopus occurs in an anisotropic fashion, biased towards the ventral side. My studies show that these mechanisms of blastopore closure will involve the myosin II isoforms that I have investigated.

\section{Xenopus neurulation}

Neurulation is the process by which the neural plate is shaped and then rolls up to form the neural tube, and becomes separated from the non-neural ectoderm. It occurs by elevation of the lateral edges of the neural plate, the neural folds, which will move medially and meet at the midline, where they will 
fuse and complete the formation of a tube (Jacobson, 1981; Jacobson and Gordon, 1976; Schoenwolf and Smith, 1990). For this process to be completed successfully, the initially short and wide neural plate must converge and extend, bringing the neural folds closer to the midline, but also to bend into a trough which will bring the neural folds into apposition (Schoenwolf and Smith, 1990).

\section{Neural CE}

In the Xenopus embryo, the dorsal mesoderm and the overlying neural plate converge and extend simultaneously, thus achieving the antero-posterior elongation of the dorsal aspect of the embryo. Because the axial and paraxial mesoderm are powerful CE machines, and because the neural and mesodermal tissues are tightly bound at the midline, it is likely that CE of the neural plate is partly achieved by towing force generated by the underlying mesoderm. In urodeles (tailed amphibians), the extension of the neural plate appears to be totally passive, and driven by extension of the underlying notochord, due to the tight connection of the notochord to a specialized region that overlies it, the notoplate (Jacobson, 1981; Jacobson and Gordon, 1976). However, in cultured Xenopus explants, where neural and mesodermal CE are mechanically uncoupled, autonomous CE of the neural plate has been shown to occur (Elul et al., 1997; Keller and Danilchik, 1988; Keller et al., 1992b; Keller et al., 1992c). $\mathrm{CE}$ in a neural plate without underlying mesoderm occurs by mediolateral intercalation of cells of the deep layer, which involves a bipolar mediolateral 
protrusive activity (Elul et al., 1997), similar to the behavior of intercalating mesodermal cells described above. On the other hand, when neural CE occurs in the presence of underlying mesoderm, this bipolar protrusive behavior is replaced by a monopolar, medially-directed behavior, in which cells extend lamelliform protrusions mainly in one direction, which is towards the midline. This monopolar protrusive behavior is more efficient in producing CE of the neural plate, and it also leads to a less promiscuous intercalation pattern, in that cells undergo minimal exchange of neighbors. This may be important in maintaining proper patterning of the different cell types specified in the neural plate (Elul and Keller, 2000). The establishing of the directionality of this monopolar protrusive behavior is dependent on an unknown signal or signals from the midline tissues, i.e., the notoplate and the notocord (Ezin et al., 2003; Ezin et al., 2006).

\section{Bending of the neural plate}

Bending of the neural plate in vertebrates is driven by apical constriction of the neuroepithelial cells, which converts them from columnar to wedge-shaped. In this way, the apical surface of the neural plate (future luminal surface of the neural tube) becomes narrower than its basal surface, forcing it to bend inwards (Burnside and Jacobson, 1968). The neural plate of Xenopus is multilayered, consisting of a superficial epithelial layer and deep mesenchymal layers. Whereas active neural CE in Xenopus is mostly driven by the deep layers, as 
described above, the apical constriction that bends the neural plate occurs in the superficial, epithelial layer (Baker and Schroeder, 1967; Schroeder, 1970).

In higher vertebrates (birds, mammals) bending of the neural plate occurs mainly at three localized hinge points, a medial one located directly above the notochord, present all along the length of the neural plate, and two dorsolateral ones present mostly at brain levels (Colas and Schoenwolf, 2001). In Xenopus, however, discrete hinge points at which neural plate bending occurs have not been seen, and instead it appears that apical constriction and bending occur more or less evenly throughout the width of the neural plate (Baker and Schroeder, 1967; Schroeder, 1970).

Disruptions of genes that regulate apical constriction in the neural plate primarily result in exencephaly both in mouse (Brouns et al., 2000; Hildebrand and Soriano, 1999) and in frog (Haigo et al., 2003). Exencephaly is the equivalent of human anencephaly, a birth defect that results from failure of anterior neural tube closure, thus these data suggest that apical constriction is more relevant in closure of the anterior or rostral portion of the neural tube (Wallingford, 2005).

\section{Myosin II}

Myosins are motor proteins that move along actin filaments by hydrolyzing ATP and coupling this reaction to conformational changes. All myosins have one or two heavy chains and several light chains. The heavy chains are composed of 
three different domains: a globular head that binds actin and ATP, a neck region that binds the light chains and a tail that contains binding sites specific to each myosin type (Lodish et al., 2001).

The movement of myosin heads along actin filaments occurs in discrete steps, each coupled to the hydrolysis of one ATP molecule. The head undergoes a series of conformational changes during each step, in repeated cycles that cause the myosin to move along actin. When not bound to nucleotide, myosin binds tightly to actin in what is known as the rigor state. Upon binding to ATP, myosin uncouples from the actin filament and proceeds to hydrolyze the ATP, which causes a conformational change in the head and moves it to a new position along the actin filament, where it rebinds to it. As the phosphate is released, the myosin head undergoes another conformational change - the power stroke, which brings it back to its rigor state. Release of the ADP nucleotide completes this cycle (Rayment and Holden, 1994).

Myosin IIs, or conventional myosins, are hexameric proteins composed of two heavy chains that dimerize through their tail domains forming $\alpha$-helical coiled coils, two essential light chains and two regulatory light chains. Through the coiled coil domains of their heavy chains, myosin Ils can also form bipolar thick filaments with myosin heads at both ends. Other features that set myosin IIs apart from unconventional myosins are their rate-limiting phosphate release and low duty ratio (Geeves and Holmes, 1999; Holmes and Geeves, 2000). 
Lower eukaryotes have only one type of myosin II, whereas higher animals have several myosin II isoforms. Some of them are specific to muscle tissues, where myosin II was first identified, but another kind of myosin II, called "non-muscle" or "cytoskeletal" myosin II is widely expressed in various embryonic and adult tissues. All vertebrates have at least two different cytoskeletal myosin IIs, myosin IIA and IIB (Katsuragawa et al., 1989; Kawamoto and Adelstein, 1991; Kelley et al., 1995). A third isoform has been described in mouse and humans, myosin IIC, which is expressed mostly in fully differentiated adult tissues (Golomb et al., 2004).

Cytoskeletal myosin IIs have been implicated in several cell biological functions, such as cytokinesis (Matsumura, 2005), cortical stiffness (Egelhoff et al., 1996; Laevsky and Knecht, 2003; Xu et al., 2001), cell adhesion (Shewan et al., 2005) and cell migration (Bridgman et al., 2001; Gupton et al., 2005; Lo et al., 2004; Svitkina et al., 1997).

\section{Myosin II in morphogenesis}

As expected from a motor protein implicated in the aforementioned cell biological functions, myosin II is necessary for several morphogenetic events. Particularly in Drosophila gastrulation, myosin II is involved in multiple events. During ventral furrow formation, the presumptive mesodermal and endodermal cells undergo apical constriction, which is driven by contraction of an apical actomyosin network under the control of the patterning protein, Twist, and its 
target Fog (folded gastrulation) (Dawes-Hoang et al., 2005). Germ band elongation, a process that occurs after ventral furrow internalization, also requires myosin II. Germ band elongation occurs by convergence of the dorso-ventral axis and extension of the antero-posterior axis, and it is driven by cell intercalation (Irvine and Wieschaus, 1994). The intercalation of germ band cells, which are epithelial cells, results from remodeling of cell-cell junctions and it requires myosin II and the scaffolding protein Bazooka (Bertet et al., 2004; Blankenship et al., 2006; Zallen and Wieschaus, 2004). Finally, Drosophila dorsal closure, a process in which the ectoderm covers the amnioserosa, also requires myosin II. It is needed for the contractility of a "supra-cellular purse string" formed at the leading edge of epidermal cells (Franke et al., 2005; Jacinto et al., 2002), which is dependent on the protein kinase Misshapen (Koppen et al., 2006). It is also required for apical constriction of the amnioserosa cells, which is under control of the transmembrane protein Crumbs (Harden et al., 2002).

Besides Drosophila, myosin II is also needed for gastrulation in other organisms. In $C$. elegans, it functions in apical constriction of ingressing cells, which is regulated by Wnt/Frizzled signaling (Lee et al., 2006). During epiboly of the enveloping layer in Zebrafish gastrulation, myosin II is necessary for actomyosin-mediated contractility of the underlying yolk syncytial layer, which, like contractility of the Drosophila epidermal purse string at dorsal closure, is dependent on Misshapen (Koppen et al., 2006). Myosin II is thus implicated in 
several early morphogenetic events, many of which are quite distinct and are regulated by completely separate pathways.

\section{Myosins IIA and IIB}

Cytoskeletal myosins IIA and IIB have different heavy chains that are encoded by different genes - myosin heavy chain $A(M H C-A)$ and $M H C-B$ (Katsuragawa et al., 1989; Kawamoto and Adelstein, 1991; Kelley et al., 1995). Most tissues express both MHC-A and MHC-B isoforms, with varying relative amounts. There are a few examples of tissues that express a single isoform, such as platelets, which exclusively express the A isoform (Maupin et al., 1994), or cardiac myocytes, which only express B (Conrad et al., 1995). In various cultured cells that express both myosins IIA and IIB, the two isoforms show distinct subcellular localizations (Kelley et al., 1996; Kolega, 1998; Kolega, 2003), which suggests that they may have different functions. Also, in cultured migrating endothelial cells, the distributions of myosin II isoforms can be independently regulated, with localization of myosin IIB in the rear of the cell being dependent on Rho kinase (Kolega, 2003), and localization of myosin IIA to the front dependent on its motor activity (Kolega, 2006).

Biochemically, myosins IIA and IIB also have distinct properties that suggest different cell biological functions. Myosin IIB has an unusually high duty ratio for a conventional myosin and a rate-limiting ADP release, signifying that this isoform spends a high proportion of its kinetic cycle strongly bound to actin, a 
feature that suggests a possible role as an actin cross-linker responsible for maintenance of cortical tension (Rosenfeld et al., 2003; Wang et al., 2003). Myosin IIA, on the other hand, has a low duty ratio, which is typical of conventional myosins, and more consistent with a role in generating force through rapid translocation of actin filaments (Kovacs et al., 2003).

Further evidence for different roles for myosin II isoforms comes from genetic ablation of either myosin IIA or IIB in mouse, which cause distinct phenotypes. Homozygous mice ablated for MHC-A die by embryonic day 7.5 and show defects in cell adhesion and in the formation of the visceral endoderm (Conti et al., 2004). On the other hand, homozygous mice ablated for MHC-B die between embryonic day 15 and the day of birth, and display major defects in cardiac and brain development, including abnormal migration of developing neurons (Bridgman et al., 2001; Takeda et al., 2003; Tullio et al., 1997; Tullio et al., 2001).

\section{Outline of this thesis}

In this thesis, I investigate the different roles of Xenopus myosin IIA and IIB in early morphogenetic events by interdicting their expression using two morpholino-oligonucleotides (MOs) that target MHC-A or MHC-B, respectively.

In Chapter 2, I show that myosin IIB is necessary for the CE movements that occur in the dorsal mesoderm and that are involved in blastopore closure and in antero-posterior elongation of the dorsal aspect of the body. Cellular level 
analysis reveals that myosin IIB is necessary for correct mediolateral protrusive activity and cell shape and boundary capture behaviors, as well as for cell-cell and cell-fibronectin adhesion.

In Chapter 3, I analyze the role of myosin IIB in the neural tissue by targeting MHC-B MO to the presumptive neural plate. Myosin IIB depletion affects both neural plate bending by inhibiting apical constriction of neurepithelial cell, as well as neural plate CE. Cellular analysis of the defects underlying impaired neural CE reveals defects in cell shape and in the cortical actin cytoskeletal network. Other neural tissue specific defects include absent eyes, malformed brains and diminished swimming behavior.

In Chapter 4, I describe the roles for myosin IIA in early development, and compare and contrast them with the roles for myosin IIB. Myosin IIA is necessary for the CT movements that contribute to ventral blastopore closure, whereas these same movements do not require myosin IIB. After gastrulation, myosin IIA is also involved in ventral morphogenetic events, being that it is necessary for the process of antero-posterior elongation of the ventral aspect of the body.

In Chapter 5, I show preliminary data indicating that myosin IIB may be involved in morphogenesis of the ciliated cells, a specialized cell type of the Xenopus epidermis that is responsible for water movement across the surface of the embryo.

Chapter 6 provides an overview and discussion of the whole work. 
REFERENCES

Adams, D. S., Keller, R. and Koehl, M. A. (1990). The mechanics of notochord elongation, straightening and stiffening in the embryo of Xenopus laevis. Development 110, 115-30.

Baker, P. C. and Schroeder, T. E. (1967). Cytoplasmic filaments and morphogenetic movement in the amphibian neural tube. Dev Biol 15, 432-50.

Bertet, C., Sulak, L. and Lecuit, T. (2004). Myosin-dependent junction remodelling controls planar cell intercalation and axis elongation. Nature 429, 667-71.

Blankenship, J. T., Backovic, S. T., Sanny, J. S., Weitz, O. and Zallen, J. A. (2006). Multicellular rosette formation links planar cell polarity to tissue morphogenesis. Dev Cell 11, 459-70.

Bridgman, P. C., Dave, S., Asnes, C. F., Tullio, A. N. and Adelstein, R. S. (2001). Myosin IIB is required for growth cone motility. J Neurosci 21, 6159-69.

Brouns, M. R., Matheson, S. F., Hu, K. Q., Delalle, I., Caviness, V. S., Silver, J., Bronson, R. T. and Settleman, J. (2000). The adhesion signaling molecule p190 RhoGAP is required for morphogenetic processes in neural development. Development 127, 4891-903.

Burnside, M. B. and Jacobson, A. G. (1968). Analysis of morphogenetic movements in the neural plate of the newt Taricha torosa. Dev Biol 18, 537-52. 
Colas, J. F. and Schoenwolf, G. C. (2001). Towards a cellular and molecular understanding of neurulation. Dev Dyn 221, 117-45.

Conrad, A. H., Jaffredo, T. and Conrad, G. W. (1995). Differential localization of cytoplasmic myosin II isoforms A and B in avian interphase and dividing embryonic and immortalized cardiomyocytes and other cell types in vitro. Cell Motil Cytoskeleton 31, 93-112.

Conti, M. A., Even-Ram, S., Liu, C., Yamada, K. M. and Adelstein, R. S. (2004). Defects in cell adhesion and the visceral endoderm following ablation of nonmuscle myosin heavy chain II-A in mice. J Biol Chem 279, 41263-6.

Dawes-Hoang, R. E., Parmar, K. M., Christiansen, A. E., Phelps, C. B., Brand, A. H. and Wieschaus, E. F. (2005). folded gastrulation, cell shape change and the control of myosin localization. Development 132, 4165-78.

Egelhoff, T. T., Naismith, T. V. and Brozovich, F. V. (1996). Myosin-based cortical tension in Dictyostelium resolved into heavy and light chain-regulated components. J Muscle Res Cell Motil 17, 269-74.

Elul, T. and Keller, R. (2000). Monopolar protrusive activity: a new morphogenic cell behavior in the neural plate dependent on vertical interactions with the mesoderm in Xenopus. Dev Biol 224, 3-19.

Elul, T., Koehl, M. A. and Keller, R. (1997). Cellular mechanism underlying neural convergent extension in Xenopus laevis embryos. Dev Biol 191, 243-58. 
Ezin, A. M., Skoglund, P. and Keller, R. (2003). The midline (notochord and notoplate) patterns the cell motility underlying convergence and extension of the Xenopus neural plate. Dev Biol 256, 100-14.

Ezin, A. M., Skoglund, P. and Keller, R. (2006). The presumptive floor plate (notoplate) induces behaviors associated with convergent extension in medial but not lateral neural plate cells of Xenopus. Dev Biol.

Franke, J. D., Montague, R. A. and Kiehart, D. P. (2005). Nonmuscle myosin II generates forces that transmit tension and drive contraction in multiple tissues during dorsal closure. Curr Biol 15, 2208-21.

Geeves, M. A. and Holmes, K. C. (1999). Structural mechanism of muscle contraction. Annu Rev Biochem 68, 687-728.

Glickman, N. S., Kimmel, C. B., Jones, M. A. and Adams, R. J. (2003). Shaping the zebrafish notochord. Development 130, 873-87.

Golomb, E., Ma, X., Jana, S. S., Preston, Y. A., Kawamoto, S., Shoham, N. G., Goldin, E., Conti, M. A., Sellers, J. R. and Adelstein, R. S. (2004). Identification and characterization of nonmuscle myosin II-C, a new member of the myosin II family. J Biol Chem $279,2800-8$.

Gupton, S. L., Anderson, K. L., Kole, T. P., Fischer, R. S., Ponti, A., Hitchcock-DeGregori, S. E., Danuser, G., Fowler, V. M., Wirtz, D., Hanein, D. et al. (2005). Cell migration without a lamellipodium: translation of actin dynamics into cell movement mediated by tropomyosin. J Cell Biol 168, 619-31. 
Gurdon, J. B. (1987). Embryonic induction--molecular prospects. Development 99, 285-306.

Haigo, S. L., Hildebrand, J. D., Harland, R. M. and Wallingford, J. B. (2003). Shroom induces apical constriction and is required for hingepoint formation during neural tube closure. Curr Biol 13, 2125-37.

Harden, N., Ricos, M., Yee, K., Sanny, J., Langmann, C., Yu, H., Chia, W. and Lim, L. (2002). Drac1 and Crumbs participate in amnioserosa morphogenesis during dorsal closure in Drosophila. J Cell Sci 115, 2119-29.

Hardin, J. and Keller, R. (1988). The behaviour and function of bottle cells during gastrulation of Xenopus laevis. Development 103, 211-30.

Hildebrand, J. D. and Soriano, P. (1999). Shroom, a PDZ domain-containing actin-binding protein, is required for neural tube morphogenesis in mice. Cell 99 , 485-97.

Holmes, K. C. and Geeves, M. A. (2000). The structural basis of muscle contraction. Philos Trans $R$ Soc Lond B Biol Sci 355, 419-31.

Hunt, T. E. (1929). Hensen's node as an organizer in the formation of the chick embryo. Anat. Rec. 42, 22.

Irvine, K. D. and Wieschaus, E. (1994). Cell intercalation during Drosophila germband extension and its regulation by pair-rule segmentation genes. Development 120, 827-41.

Jacinto, A., Woolner, S. and Martin, P. (2002). Dynamic analysis of dorsal closure in Drosophila: from genetics to cell biology. Dev Cell 3, 9-19. 
Jacobson, A. G. (1981). Morphogenesis of the Neural Plate and Tube. In Morphogenesis and Pattern Formation, (ed. T. G. Connelly). New York, NY: Raven Press.

Jacobson, A. G. and Gordon, R. (1976). Changes in the shape of the developing vertebrate nervous system analyzed experimentally, mathematically and by computer simulation. J Exp Zool 197, 191-246.

Jeffery, W. R. (1988). The role of cytoplasmic determinants in embryonic development. Dev Biol (N Y 1985) 5, 3-56.

Katsuragawa, Y., Yanagisawa, M., Inoue, A. and Masaki, T. (1989). Two distinct nonmuscle myosin-heavy-chain mRNAs are differentially expressed in various chicken tissues. Identification of a novel gene family of vertebrate nonsarcomeric myosin heavy chains. Eur J Biochem 184, 611-6.

Kawamoto, S. and Adelstein, R. S. (1991). Chicken nonmuscle myosin heavy chains: differential expression of two mRNAs and evidence for two different polypeptides. J Cell Biol 112, 915-24.

Keller, R. and Danilchik, M. (1988). Regional expression, pattern and timing of convergence and extension during gastrulation of Xenopus laevis. Development 103, 193-209.

Keller, R., Davidson, L., Edlund, A., Elul, T., Ezin, M., Shook, D. and Skoglund, P. (2000). Mechanisms of convergence and extension by cell intercalation. Philos Trans R Soc Lond B Biol Sci 355, 897-922. 
Keller, R., Shih, J. and Domingo, C. (1992a). The patterning and functioning of protrusive activity during convergence and extension of the Xenopus organiser. Dev Suppl, 81-91.

Keller, R., Shih, J. and Sater, A. (1992b). The cellular basis of the convergence and extension of the Xenopus neural plate. Dev Dyn 193, 199-217.

Keller, R., Shih, J., Sater, A. K. and Moreno, C. (1992c). Planar induction of convergence and extension of the neural plate by the organizer of Xenopus. Dev Dyn 193, 218-34.

Keller, R. and Shook, D. (2004). Gastrulation in Amphibians. In Gastrulation From Cells to Embryo, (ed. C. D. Stern), pp. 171-203. Cold Spring Harbor, New York: Cold Spring Harbor Laboratory Press.

Keller, R. E. (1975). Vital dye mapping of the gastrula and neurula of Xenopus laevis. I. Prospective areas and morphogenetic movements of the superficial layer. Dev Biol 42, 222-41.

Keller, R. E. (1976). Vital dye mapping of the gastrula and neurula of Xenopus laevis. II. Prospective areas and morphogenetic movements of the deep layer. Dev Biol 51, 118-37.

Keller, R. E. (1980). The cellular basis of epiboly: an SEM study of deep-cell rearrangement during gastrulation in Xenopus laevis. J Embryol Exp Morpho/60, $201-34$

Keller, R. E. (1981). An experimental analysis of the role of bottle cells and the deep marginal zone in gastrulation of Xenopus laevis. J Exp Zool 216, 81-101. 
Keller, R. E. (1984). The Cellular Basis of Gastrulation in Xenopus laevis: Active, Postinvolution Convergence and Extension by Mediolateral Interdigitation. Amer. Zool. \%R 10.1093/icb/24.3.589 24, 589-603.

Keller, R. E., Danilchik, M., Gimlich, R. and Shih, J. (1985). The function and mechanism of convergent extension during gastrulation of Xenopus laevis. $J$ Embryol Exp Morphol 89 Suppl, 185-209.

Kelley, C. A., Oberman, F., Yisraeli, J. K. and Adelstein, R. S. (1995). A Xenopus nonmuscle myosin heavy chain isoform is phosphorylated by cyclinp34cdc2 kinase during meiosis. J Biol Chem 270, 1395-401.

Kelley, C. A., Sellers, J. R., Gard, D. L., Bui, D., Adelstein, R. S. and Baines, I. C. (1996). Xenopus nonmuscle myosin heavy chain isoforms have different subcellular localizations and enzymatic activities. J Cell Biol 134, 675-87.

Kolega, J. (1998). Cytoplasmic dynamics of myosin IIA and IIB: spatial 'sorting' of isoforms in locomoting cells. J Cell Sci 111 (Pt 15), 2085-95.

Kolega, J. (2003). Asymmetric distribution of myosin IIB in migrating endothelial cells is regulated by a rho-dependent kinase and contributes to tail retraction. $\mathrm{Mol}$ Biol Cell 14, 4745-57.

Kolega, J. (2006). The role of myosin II motor activity in distributing myosin asymmetrically and coupling protrusive activity to cell translocation. Mol Biol Cell $17,4435-45$. 
Koppen, M., Fernandez, B. G., Carvalho, L., Jacinto, A. and Heisenberg, C. P. (2006). Coordinated cell-shape changes control epithelial movement in zebrafish and Drosophila. Development 133, 2671-81.

Kovacs, M., Wang, F., Hu, A., Zhang, Y. and Sellers, J. R. (2003). Functional divergence of human cytoplasmic myosin II: kinetic characterization of the nonmuscle IIA isoform. J Biol Chem 278, 38132-40.

Laevsky, G. and Knecht, D. A. (2003). Cross-linking of actin filaments by myosin II is a major contributor to cortical integrity and cell motility in restrictive environments. J Cell Sci 116, 3761-70.

Lee, J. Y., Marston, D. J., Walston, T., Hardin, J., Halberstadt, A. and Goldstein, B. (2006). Wnt/Frizzled Signaling Controls C. elegans Gastrulation by Activating Actomyosin Contractility. Curr Biol 16, 1986-97.

Lo, C. M., Buxton, D. B., Chua, G. C., Dembo, M., Adelstein, R. S. and Wang, Y. L. (2004). Nonmuscle myosin IIb is involved in the guidance of fibroblast migration. Mol Biol Cell 15, 982-9.

Lodish, H., Berk, A., Zipursky, S. L., Matsudaira, P., Baltimore, D. and Darnell, J. (2001). Molecular Cell Biology. New York: W. H. Freeman and Company.

Matsumura, F. (2005). Regulation of myosin II during cytokinesis in higher eukaryotes. Trends Cell Biol 15, 371-7. 
Maupin, P., Phillips, C. L., Adelstein, R. S. and Pollard, T. D. (1994). Differential localization of myosin-II isozymes in human cultured cells and blood cells. J Cell Sci 107 (Pt 11), 3077-90.

Moore, S. W., Keller, R. E. and Koehl, M. A. (1995). The dorsal involuting marginal zone stiffens anisotropically during its convergent extension in the gastrula of Xenopus laevis. Development 121, 3131-40.

Rayment, I. and Holden, H. M. (1994). The three-dimensional structure of a molecular motor. Trends Biochem Sci 19, 129-34.

Rosenfeld, S. S., Xing, J., Chen, L. Q. and Sweeney, H. L. (2003). Myosin IIb is unconventionally conventional. J Biol Chem 278, 27449-55.

Schechtman, A. M. (1942). The mechanism of amphibian gastrulation. I. Gastrulation-promoting interactions between various regions of an anuran egg (Hyla regilla). Univer. Calif. Publ. Zool. 51, 1-39.

Schoenwolf, G. C. and Smith, J. L. (1990). Mechanisms of neurulation: traditional viewpoint and recent advances. Development 109, 243-70.

Schroeder, T. E. (1970). Neurulation in Xenopus laevis. An analysis and model based upon light and electron microscopy. J Embryol Exp Morphol 23, 427-62.

Shewan, A. M., Maddugoda, M., Kraemer, A., Stehbens, S. J., Verma, S., Kovacs, E. M. and Yap, A. S. (2005). Myosin 2 is a key Rho kinase target necessary for the local concentration of E-cadherin at cell-cell contacts. Mol Biol Cell 16, 4531-42. 
Shih, J. and Keller, R. (1992a). Cell motility driving mediolateral intercalation in explants of Xenopus laevis. Development 116, 901-14.

Shih, J. and Keller, R. (1992b). Patterns of cell motility in the organizer and dorsal mesoderm of Xenopus laevis. Development 116, 915-30.

Spemann, H. (1938). Embryonic development and induction. New Haven, CT: Yale University Press.

Stern, C. D. (2004a). Gastrulation - From Cells to Embryo, (ed. Cold Spring Harbor, New York: Cold Spring Harbor Laboratory Press.

Stern, C. D. (2004b). Gastrulation in the Chick. In Gastrulation - From Cells to Embryo, (ed. C. D. Stern), pp. 219-232. Cold Spring Harbor, New York: Cold Spring Harbor Laboratory Press.

Svitkina, T. M., Verkhovsky, A. B., McQuade, K. M. and Borisy, G. G. (1997). Analysis of the actin-myosin II system in fish epidermal keratocytes: mechanism of cell body translocation. J Cell Bio/ 139, 397-415.

Takeda, K., Kishi, H., Ma, X., Yu, Z. X. and Adelstein, R. S. (2003). Ablation and mutation of nonmuscle myosin heavy chain II-B results in a defect in cardiac myocyte cytokinesis. Circ Res 93, 330-7.

Tam, P. P. L. and Gad, J. M. (2004). Gastrulation in the Mouse Embryo. In Gastrulation - From Cells to Embryo, (ed. C. D. Stern), pp. 233-262. Cold Spring Harbor, New York: Cold Spring Harbor Laboratory Press.

Topczewski, J., Sepich, D. S., Myers, D. C., Walker, C., Amores, A., Lele, Z., Hammerschmidt, M., Postlethwait, J. and Solnica-Krezel, L. (2001). The 
zebrafish glypican knypek controls cell polarity during gastrulation movements of convergent extension. Dev Cell 1, 251-64.

Tullio, A. N., Accili, D., Ferrans, V. J., Yu, Z. X., Takeda, K., Grinberg, A., Westphal, H., Preston, Y. A. and Adelstein, R. S. (1997). Nonmuscle myosin II-B is required for normal development of the mouse heart. Proc Natl Acad Sci U $S A 94,12407-12$.

Tullio, A. N., Bridgman, P. C., Tresser, N. J., Chan, C. C., Conti, M. A., Adelstein, R. S. and Hara, Y. (2001). Structural abnormalities develop in the brain after ablation of the gene encoding nonmuscle myosin II-B heavy chain. $J$ Comp Neurol 433, 62-74.

Waddington, C. H. (1936). Organizers in mammalian development. Nature 138, 125.

Wallingford, J. B. (2005). Neural tube closure and neural tube defects: studies in animal models reveal known knowns and known unknowns. Am J Med Genet C Semin Med Genet 135, 59-68.

Wang, F., Kovacs, M., Hu, A., Limouze, J., Harvey, E. V. and Sellers, J. R. (2003). Kinetic mechanism of non-muscle myosin IIB: functional adaptations for tension generation and maintenance. J Biol Chem 278, 27439-48.

Wilson, P. and Keller, R. (1991). Cell rearrangement during gastrulation of Xenopus: direct observation of cultured explants. Development 112, 289-300. 
29

Wilson, P. A., Otter, G. and Keller, R. (1989). Cell rearrangement and segmentation in Xenopus: direct observation of cultured explants. Development $105,155-66$.

Winklbauer, R. and Schurfeld, M. (1999). Vegetal rotation, a new gastrulation movement involved in the internalization of the mesoderm and endoderm in Xenopus. Development 126, 3703-13.

Xu, X. S., Lee, E., Chen, T., Kuczmarski, E., Chisholm, R. L. and Knecht, D.

A. (2001). During multicellular migration, myosin ii serves a structural role independent of its motor function. Lev Biol 232, 255-64.

Zallen, J. A. and Wieschaus, E. (2004). Patterned gene expression directs bipolar planar polarity in Drosophila. Lev Cell/ 6, 343-55. 
Chapter 2

Myosin IIB is required for convergence and extension during

Xenopus gastrulation

The work presented in this chapter was done in collaboration with Paul Skoglund, who designed the morpholino-oligonucleotides (MOs), performed most of the Western blots, and shared the workload of the in situ hybridizations and the fibronectin adhesion assays. 


\section{SUMMARY}

The dorsal tissues of the Xenopus gastrula undergo convergent extension (CE) movements that are the main force driving both blastopore closure and elongation of the dorsal tissues. CE of the dorsal mesoderm occurs by mediolateral cell intercalation, which is driven by a mediolaterally oriented, bipolar type of cell protrusive activity. Myosin IIB is a motor protein complex expressed predominantly in the dorsal tissues that undergo CE. Reduction of protein levels of myosin heavy chain IIB (MHC-B), an obligatory component of the myosin IIB complex, by means of morpholino-oligonucleotide (MO) knockdown, leads to a dose-dependent phenotype of failure in blastopore closure and/or dorsally flexed trunks, both hallmarks of defective CE. MHC-B morphant cells also exhibit reduced adhesion to one another, as well as to fibronectin extracellular matrix. Analysis of individual morphant cells in a normal embryo background shows that they lose their characteristic mediolateral elongation and orientation, and their mediolaterally polarized protrusive activity. Myosin IIB is thus required for the cell polarity, alignment and motility underlying CE. 


\section{INTRODUCTION}

One of the most important forces driving gastrulation in amphibians is the narrowing and lengthening, or convergent extension (CE), of the dorsal marginal zone of the embryo. This morphogenic movement is the major force driving the normal involution of the dorsal mesoderm, elongation of the dorsal axis, and closure of the blastopore (Keller et al., 1992; Shih and Keller, 1992b). CE is achieved by mediolateral cell intercalation resulting from bipolar, mediolaterally oriented cell protrusive behavior (Shih and Keller, 1992a).

Myosin II is a motor protein complex that functions in a number of aspects of cell motility (Bridgman et al., 2001; Laevsky and Knecht, 2003; Lo et al., 2004) and, as described above, it is necessary for the cell intercalation driving Drosophila germ band extension (Bertet et al., 2004; Zallen and Wieschaus, 2004). Xenopus has at least two different myosin II isoforms, IIA and IIB (BhatiaDey et al., 1993; Kelley et al., 1995). These proteins have distinct biochemical properties, with myosin IIA having a faster rate of ATP-driven actin movement than myosin IIB, which moves actin filaments at a slower rate and spends more time of its cycle tightly bound to actin (Kelley et al., 1996). In Xenopus embryos, more than $90 \%$ of the total myosin II expressed is the IIA form (Bhatia-Dey et al., 1998), which is expressed more or less evenly throughout the embryo (see Chapter 4). Myosin IIB, on the other hand, despite being expressed at low levels everywhere in the embryo before gastrulation, is upregulated in the dorsal 
mesoderm at the onset of gastrulation, as well as in activin-treated animal caps that are induced to form dorsal mesoderm (Bhatia-Dey et al., 1998).

In this chapter, I examine the role of myosin IIB in Xenopus gastrulation. I show that knock-down of myosin heavy chain IIB (MHC-B) results in defects in blastopore closure and dorsal CE. At a cellular level, MHC-B depletion affects cell shape, motility and polarity, as well as adhesion to fibronectin. 


\section{MATERIALS AND METHODS}

\section{Embryos and microsurgery}

Xenopus laevis embryos were obtained and dejellied by standard methods (Sive et al., 2000) and staged according to Nieuwkoop and Faber (1994). Neuraldeep-over-mesoderm explants, consisting of the deep layer of the neural plate with the underlying mesoderm, were made according to Elul and Keller (2000).

\section{Whole-mount immunofluorescence}

Albino embryos or explants were fixed in MEMFA for 2 hours at room temperature and stored in methanol at $-20^{\circ} \mathrm{C}$ for an overnight period or longer. For imaging transverse section, whole-embryos were bisected transversely with a scalpel after rehydration, and prior to immunostaining. MHC-B was detected using a polyclonal isoform-specific primary antibody (Covance, Berkeley, CA) at 1:50 dilution and a rhodamine-conjugated goat anti-rabbit secondary antibody (Jackson Immuno Research, West Grove, PA) at 1:200. Fibronectin was detected using a monoclonal primary antibody (4H2) (Davidson et al., 2004) at 1:200 dilution and an fluorescein-conjugated goat anti-mouse secondary antibody (Jackson Immuno Research) at 1:200. Embryos and explants were dehydrated in methanol and cleared in 2:1 benzyl benzoate:benzyl alcohol. Confocal images were collected using a BioRad Radiance2100 system and processed using ImageJ software. 


\section{Western blotting}

Western blots were performed as described (Skoglund et al., 2006), using stage 19 embryo extracts, run on $5 \%$ acrylamide gels. Detection was with antirabbit HRP, using Supersignal reagents (Pierce, Rockford, IL). Densitometry was performed as described in Skoglund et al. (2006).

\section{Morpholino oligonucleotide}

A morpholino-oligonucleotide $(\mathrm{MO})$ directed against the start site of $\mathrm{MHC}$ B (CTTCCTGCCCTGGTCTCTGTACAT) was produced, and a control MO that varies at five nucleotides (CTTgCTcCCCTGcTCTCTcTAgAT) (Gene Tools, Philomath, OR). Two-cell stage embryos were injected with $1.25,2.5$ or 5 pmol of MHC-B MO per blastomere to obtain final MO concentrations of $2.5,5$ and $10 \mu \mathrm{M}$, respectively. Four-cell stage embryos were injected in two dorsal or ventral blastomeres with 1 pmol MHC-B MO per blastomere to obtain a final MO concentration of $4 \mu \mathrm{M}$. 32-cell stage embryos were injected in scattered dorsal blastomeres with $0.312 \mathrm{pmol}$ of MHC-B MO per blastomere to obtain final MO concentration of $5 \mu \mathrm{M}$.

\section{In situ hybridization}

In situ hybridizations were made according to Harland (1991) with probes against Sonic Hedgehog (Yokotal et al., 1995) and Brachyury (Amaya et al., 1993). 
Fibronectin adhesion assays

Fibronectin adhesion assays were similar to the cadherin adhesion assays described in Brieher and Gumbiner (1994), but $20 \mu \mathrm{g} / \mathrm{ml}$ fibronectin was used as . a substrate for plating the cells. The cells assayed were dorsal marginal zone cells obtained by dissecting dorsal marginal zone tissues from morphant or control embryos at stage $11.5-12$, and dissociating them in calcium-magnesium free media for a few minutes until the majority of the cells were individuals, with few clumps of two or more cells. 


\section{RESULTS}

\section{Myosin IIB expression}

Myosin IIB localization in the embryo was analyzed by whole-mount immunostaining using the MHC-B specific antibody. At tailbud stages, MHC-B is detected in the dorsal region of the embryo, with particularly strong staining in the areas surrounding the notochord and at the intersomitic boundaries, as well as in anterior regions of brain, eye, and branchial arches (Fig. 2-1A). To get a higher resolution image of MHC-B localization in notochordal cells, neural-deep-overmesoderm explants, which consist of the dorsal mesoderm and neural deep layers of the embryo (Elul and Keller, 2000), were immunostained. These explants allow better antibody penetration and easier access for imaging the region of interest. The staining at the outer ends of notochordal cells, as well as staining at the basal ends of the somitic mesodermal cells, show MHC-B in a fibrillar pattern (Fig. 2-1B), reminiscent of fibronectin localization (Davidson et al., 2004). Indeed, MHC-B and fibronectin have overlapping localizations in the embryo and in explants (see Chapter 3).

\section{MHC-B depletion blocks morphogenesis}

To investigate the role of myosin IIB in Xenopus early morphogenesis, a morpholino-oligonucleotide (MO) against the start site of the MHC-B gene was designed that effectively reduces expression of this protein in a dose-dependent 
fashion (Fig. 2-1F). A control MO, mispaired at five sites, has no effect on MHC-B levels (Fig. 2-1F). At a dose of $10 \mu \mathrm{M}$, the MHC-B MO causes a more than $90 \%$ reduction in protein levels (Fig. 2-1F) and a highly penetrant phenotype of blastopore closure failure (Fig. 2-1E). This results in embryos in which there is no involution of mesoderm or elongation of the body axis (Fig. 2-1D). Also, morphant embryos show a loss of adhesion phenotype, as indicated by the shedding of cells at control stages of neurulation (Fig. 2-1D, see vegetal pole of embryo lacking cells), until they eventually dissociate into individual cells by the control early stage 20 s. These shed, dissociated cells nevertheless continue to show motile behavior, indicating that they are not necrotic (data not shown). An equal dose of control MO, on the other hand, does not affect blastopore closure (Fig. 2$1 \mathrm{E})$, and the injected embryos are morphologically similar to uninjected embryos (not shown). This indicates that the phenotypes observed in MHC-B morphant embryos are due to loss of MHC-B protein. The defects in morphant embryos appear only after the onset of gastrulation, at about stage $10-10 \frac{1}{4}$, after

substantial bottle cells have formed. At these stages, morphant and control embryos are morphologically indistinguishable (Fig. $2-3, t=0$ ), indicating that pregastrulation events are not affected by MHC-B depletion.

\section{MHC-B MO does not alter dorsal mesodermal cell fates}

To determine if failure of morphant embryos to close their blastopores and undergo CE results from morphogenic impediments, rather than failure of 
specification of the dorsal mesodermal tissues that execute these movements, embryos were stained for the dorsal mesodermal markers Sonic Hedgehog, which marks notochord and floor plate (Yokotal et al., 1995), and Brachyury, which marks presumptive notochord late and all early, pre-involution mesoderm (Amaya et al., 1993) by whole-mount RNA in situ hybridization. Morphant embryos express both these markers, in patterns consistent with failure of normal morphogenic movements of CE and involution (Fig. 2-2).

\section{MHC-B MO affects morphogenesis in a dose dependent manner}

Injection of MHC-B MO at lower doses reveals a dose response to MHC-B depletion. Time-lapse videorecordings of gastrulation in control and different degree morphants show that by stage 10 morphant and control embryos look similar, with bottle cells forming on the dorsal lip of the blastopore in all groups (Fig. 2-3A-D, $t=0$ ). Throughout gastrulation, bottle cell formation progresses to the ventral lip in all morphant and control embryos (Fig. 2-3A-D, $t=2.5$ ), and the number of bottle cells formed is similar in control, $2.5 \mu \mathrm{M}$ and $5 \mu \mathrm{M} \mathrm{MHC}-\mathrm{B}$ morphant embryos, and only slightly reduced in some $10 \mu \mathrm{M}$ MHC-B morphant embryos. By stage 12 (Fig. 2-3A-D, $t=2.5$ ), a clear difference in blastopore size can be detected. Most morphant embryos at $2.5 \mu \mathrm{M}$ MHC-B MO eventually close their blastopores, although closure is delayed compared to controls, sometimes as late as control stage 17 , and their site of blastopore closure is located more dorsally than in control embryos (Fig. 2-3B, $t=7.5$ ). When these embryos are 
examined at later stages they exhibit a dorsal flexure phenotype, which is typical of embryos in which dorsal CE is reduced, and thus the dorsal axis is shorter than normal (Fig. 2-3 F). A few morphant embryos at $5 \mu \mathrm{M} \mathrm{MHC-B} \mathrm{MO}$ also successfully close their blastopores, and these will later exhibit even more pronounced failure of dorsal extension (Fig. 2-3G). Other defects observed in MHC-B morphant embryos are malformed heads, absence of eyes, and reduced melanophores (Fig. 2-3F, G) (see Chapter 3).

\section{MHC-B MO defects are specific to the dorsal tissues}

To confirm that myosin IIB is required specifically for CE of the dorsal tissues, MHC-B MO was injected at a concentration of $4 \mu \mathrm{M}$ in either the dorsal or the ventral blastomeres at the four-cell stage. When MHC-B MO is targeted to dorsal tissues, the embryo shows severe dorsal flexure (Fig. 2-4B), similar to that observed when MHC-B MO is present everywhere in the embryo (Fig. 2-3F, G). On the other hand, if the MO is targeted to the ventral side, the embryos display a straight body (Fig. 2-4C), similar to uninjected control embryos (Fig. 2-4A), with the exception of a shorter tailbud (Fig. 2-4C, pointers). Despite being a dorsal structure of the post-neurulation embryo, the tailbud, including the posterior mesoderm, is of ventral origin in the 4-cell stage embryo (Keller, 1991; Lane and Sheets, 2000) and therefore is targeted by ventral injection of MO. Accordingly, in the dorsally MHC-B depleted embryos, the tailbud is similar in length to control embryos (Fig. 2-4B, pointers) because it has normal levels of MHC-B. 
MHC-B depletion causes aberrant cell shape and motility

To investigate the cellular basis of the blastopore closure and CE defects observed in morphant embryos, MHC-B MO was targeted to scattered cells in the dorsal region of the embryos by injection of $\mathrm{MO}$, at a final concentration of $10 \mu \mathrm{M}$ per cell, and rhodamine-labeled dextran into single dorsal blastomeres at the $32-$ cell stage. Control injections result in scattered labeled cells that exhibit normal cell and tissue-specific morphology at stage 12 , such as epithelial cell shape in the endoderm and outer ectoderm layer, or elongated cell shape in the dorsal mesoderm (Fig. 2-5A), whereas MHC-B morphant cells show aberrant rounded shapes, and many become excluded from the tissue instead of being evenly scattered throughout the germ layers (Fig. 2-5B), presumably due to loss of adhesion. To further analyze the defects caused by myosin IIB depletion, the concentration of MHC-B MO in scattered dorsal cells was decreased to $5 \mu \mathrm{M}$. These partially myosin IIB depleted cells are still integrated into the axial mesodermal tissues at early neurula stages (Fig. $2-5 \mathrm{C}, \mathrm{t}=0$ ), but have abnormal protrusive behavior. Normal axial mesoderm cells have a mediolaterally elongated shape, with a bipolar mode of protrusive behavior, in which they mainly restrict their protrusive activity to their medial and lateral ends, except when one of the ends enters in contact with the notochord/somite boundary, where it becomes "captured", i.e., it stops lamelliform protrusive behavior; these cells also never cross the notochordal/somitic mesodermal boundary (Shih and Keller, 1992a; Shih and Keller, 1992b). MHC-B morphant cells, on the other hand, 
extend large bleb-like protrusions that fail to respect the notocord/somite boundary (Fig. 2-5C). Eventually, these cells are excluded from the notocord and come to lie in the sulcus formed by the notocordal/somitic mesodermal boundary, where they conform to the available space, which in this case leads to their antero-posterior elongated morphology (Fig. $2-5 \mathrm{C}, \mathrm{t}=75^{\prime}$ ), orthogonal to the typical medio-lateral elongation that normal notocordal cells exhibit. They continue to express protrusive behavior, which occurs in many directions (not shown, see Skoglund et al., in preparation).

MHC-B morphant embryos have reduced levels of fibrillar fibronectin, as well as decreased adhesion to this molecule

Normal embryos immunostained for fibronectin at stage 14 show staining of tissue boundaries, both between and within divisions of the different germ layers (Davidson et al., 2004) (Fig. 2-6A). In contrast, embryos injected at 2-cell stage with $5 \mu \mathrm{M}$ MHC-B MO, and processed for fibronectin immunostaining in parallel with controls, show reduced levels of fibrillar fibronectin (Fig. 2-6B).

Dorsal cells of stage 11 embryos were dissociated and plated onto a fibronectin substrate and assayed for substrate adhesion. Morphant cells have markedly decreased adhesion to fibronectin substrates compared to controls, and this decrease occurs in a dose-dependent manner, with an adhesion index at $5 \mu \mathrm{M}$ MHC-B of roughly half that of control cells, and $20 \%$ of control cells at $10 \mu \mathrm{M}$ MHC-B MO (Fig. 2-6C). 


\section{DISCUSSION}

In this chapter, I show that myosin IIB is expressed in the dorsal embryonic tissues that undergo $\mathrm{CE}$, and that it is required for these morphogenic movements that drive blastopore closure and dorsal axis elongation by affecting cellular adhesion, shape, polarity and protrusive behavior.

Several observations implicate myosin IIB in CE. Firstly, its depletion leads to failure in blastopore closure, a process that, in normal embryos, is mainly a result of $\mathrm{CE}$ of the dorsal tissues, resulting in asymmetric ventrally biased blastopore closure (Keller et al., 1992). Even in embryos partially depleted of MHC-B, in which the blastopore achieves closure, it is delayed and occurs in an abnormal dorsally skewed location. Secondly, these partially morphant embryos display a dorsally-flexed body axis, a hallmark of defective CE. Finally, myosin IIB requirement is specific to the dorsal tissues, as demonstrated by the fact that dorsal targeting of MHC-B MO results in dorsal flexure, whereas ventral targeting produces straight embryos similar to controls. Additional evidence for involvement of myosin IIB in CE of dorsal tissues is presented in Chapter 4 of this thesis.

Myosin IIB depletion causes morphant embryos to dissociate into individual cells, due to decreased cadherin adhesion of morphant cells (Skoglund et al., in preparation). In cultured mammalian epithelial cells, myosin II is necessary for cadherin-mediated adhesion (Shewan et al., 2005), and regulated C-cadherin-mediated cell adhesion is necessary for Xenopus CE (Brieher and 
Gumbiner, 1994; Lee and Gumbiner, 1995; Zhong et al., 1999). Myosin IIB depleted cells also have decreased adhesion to fibronectin. Furthermore, morphant embryos assemble reduced levels of fibronectin matrix, a fact consistent with observations that fibronectin matrix assembly requires tension exerted by cells dependent on RhoA and its effectors Rok and myosin II (Baneyx et al., 2002; Yoneda et al., 2006; Zhong et al., 1998). A fibronectin matrix substrate is, in turn, necessary for dorsal mesoderm cells to exhibit correct mediolateral protrusive behavior, cell elongation, and intercalation (Davidson et al., 2006; Goto et al., 2005). Defects in both cell-cell and cell-matrix adhesion are thus part of the reason for failure in $\mathrm{CE}$ of MHC-B morphant embryos.

At lower doses of MHC-B MO, which cause partial depletion of the protein, defects in cell adhesion are less pronounced and tissue integrity is maintained. However, such partially morphant embryos still display CE defects. Analysis of cell shape and motility in morphant cells scattered in otherwise normal embryos shows that myosin IIB is necessary for maintenance of the mediolaterally elongated cell shape and bipolar protrusive behaviors that drive mediolateral intercalation of cells during dorsal morphogenesis, besides its roles in regulating adhesion. Analysis of the actin cytoskeleton in dorsal mesoderm cells depleted of myosin IIB show that this protein is necessary for maintaining the network of actin cables that comprise the cortical cytoskeleton (Skoglund et al., in preparation), and it is likely that the functions of myosin IIB in dorsal CE are due 
to its role in cross-linking and/or causing contraction of the cortical actin network (for further discussion on this issue see Chapter 6).

Analysis of the defects caused by MHC-B depletion at lower MO levels in whole-embryos indicates additional roles of myosin IIB in morphogenic events other than CE of dorsal mesoderm. In Chapter 3, I investigate the roles of myosin IIB in neural CE and in other neural morphogenic events. 
Figure 2-1. MHC-B is expressed in dorsal axial tissues and is required for blastopore closure.

(A) A tailbud stage embryo immunostained with MHC-B antibody shows high levels of expression in the dorsal tissues - somites (S) and notochord (No), as well as in the brain, eye and branchial arch (BA) regions.

(B) The notochord region of a neural-deep-over-mesoderm explant immunostained with MHC-B antibody shows the characteristic fibrillar staining of this protein in the basal ends of notochordal and somitic cells.

(C-D) A stage 17 uninjected control (C) and an embryo injected at 2-cell stage with $10 \mu \mathrm{M}$ MHC-B MO (D) are shown. The latter has an open blastopore and CE has failed.

(E) A graph shows the percentage of open blastopore (BP) obtained by injection of $10 \mu \mathrm{M}$ of MHC-B MO, control $\mathrm{MO}$, and uninjected (UI) embryos.

(F) A Western blot shows reduction of MHC-B protein levels in embryos injected with 5 or $10 \mu \mathrm{M}$ MHC-B MO. 

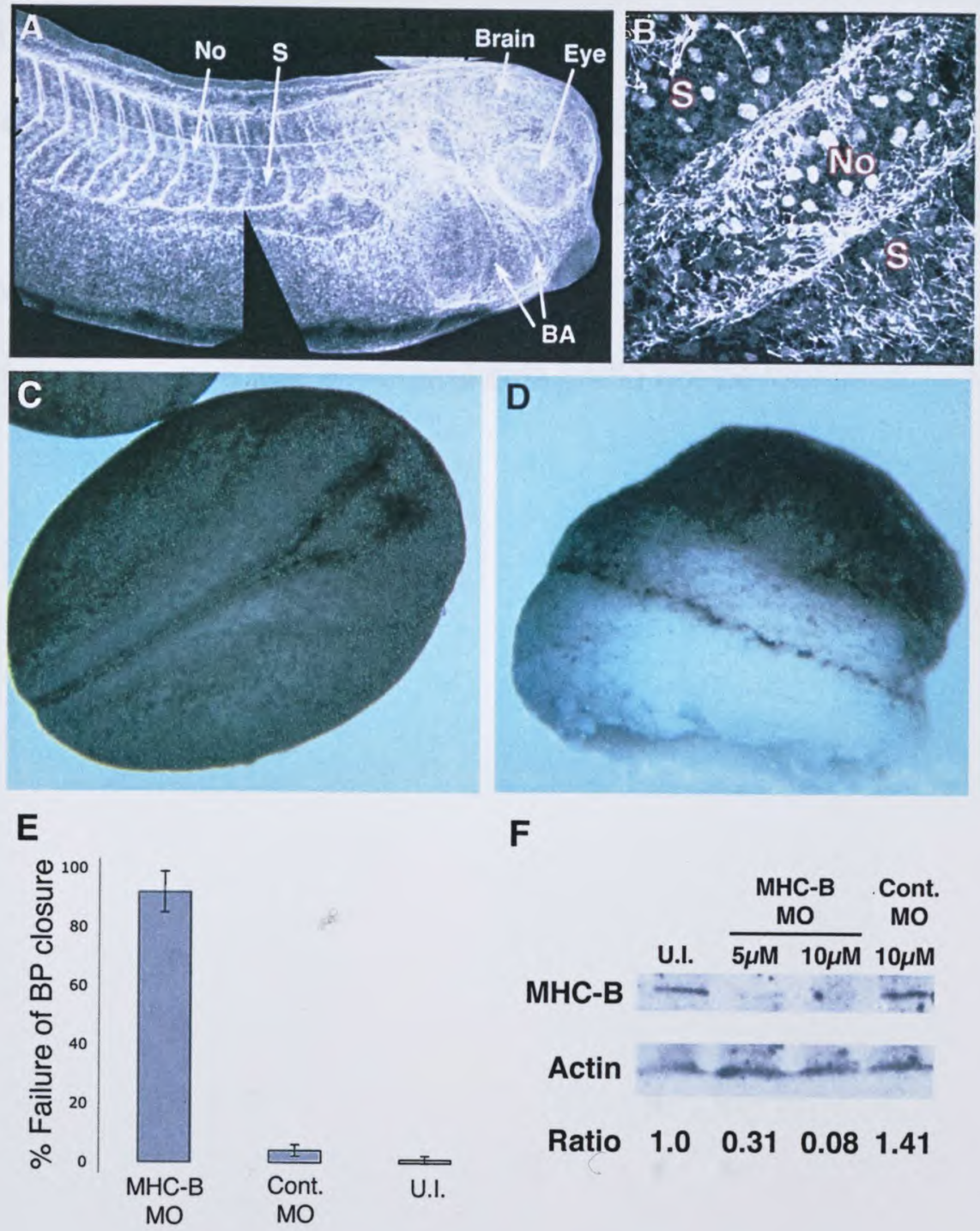

F

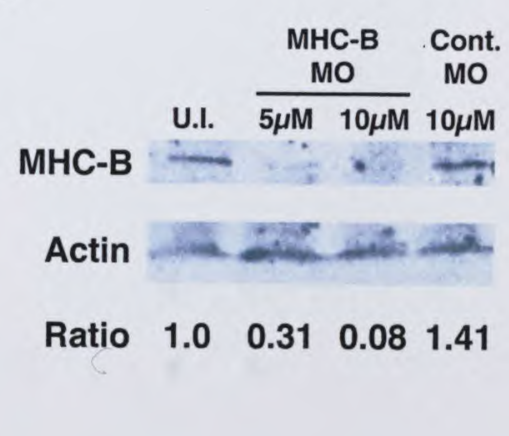


Figure 2-2. MHC-B MO does not alter dorsal mesodermal cell fates.

Normal (A-B) and morphant (C-D) stage 13 embryos were probed by RNA in situ hybridization for Sonic Hedgehog, which marks the notochord and the notoplate (A, C) and Brachyury, which marks notochord and presumptive somites (B, D). Morphant embryos express these markers in patterns consistent with failure of morphogenic movements. All embryos are oriented with the anterior end up, and with the dorsal side facing the camera, except for (D), where morphogenesis was so severely compromised that the dorsal side could not be identified. 

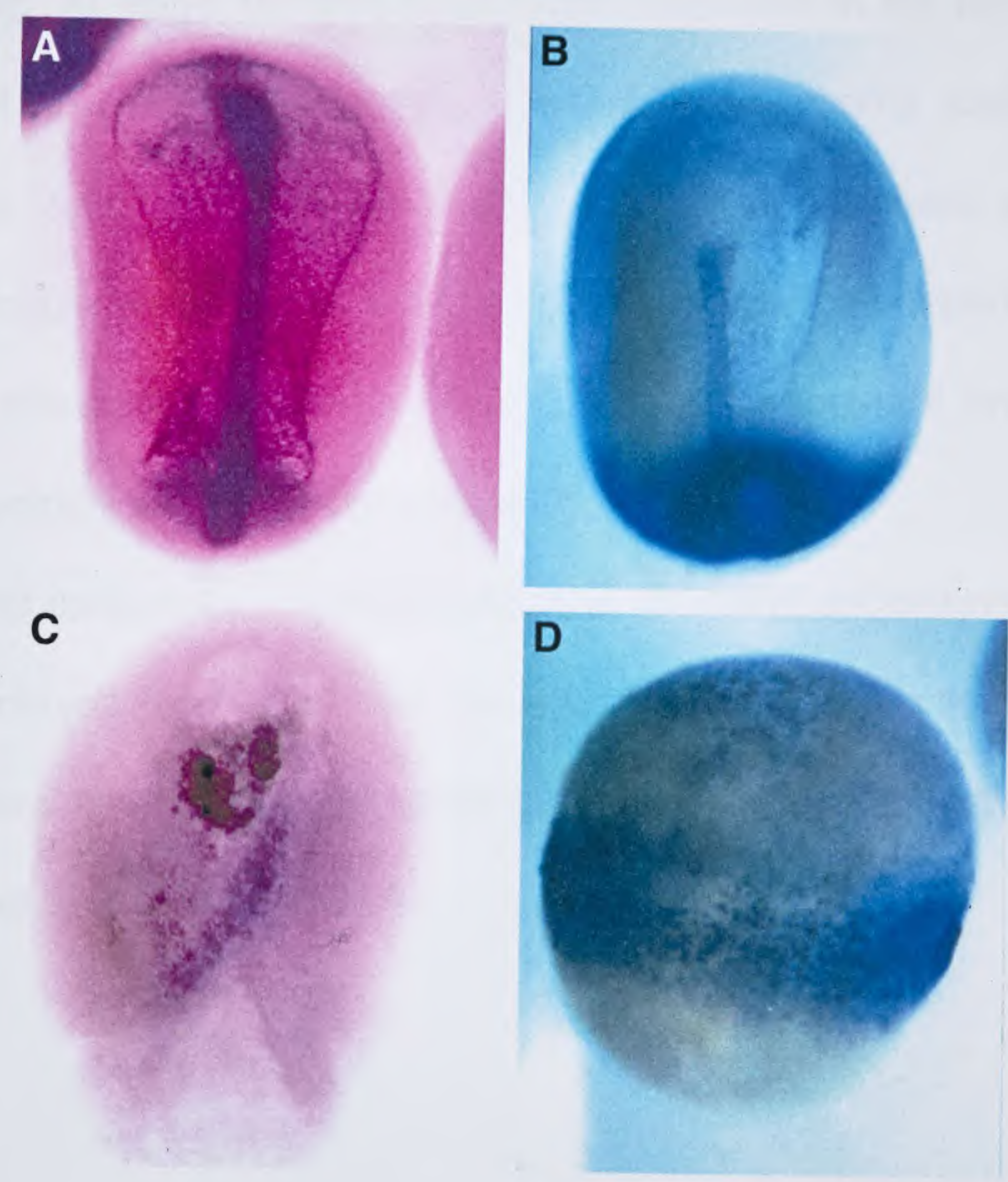
Figure 2-3. MHC-B MO causes a dose-dependent phenotype.

(A-D) Still images from simultaneous time-lapse videorecordings show vegetal views of gastrulation of control (A) and morphant embryos injected with $2.5 \mu \mathrm{M}$ (B), $5 \mu \mathrm{M}(\mathrm{C})$ and $10 \mu \mathrm{M}$ (D) of MHC-B MO. All embryos are oriented with their dorsal side up. At stage $10^{+}-10 \frac{1}{4}(t=0)$ bottle cells form in the dorsal lip of the blastopore of all control and morphant embryos. By control stage $12(t=2.5)$ ventral bottle cells have formed in all control and morphant embryos, but blastopore closure is delayed in morphant embryos in a dose-dependent manner. The site of blastopore closure in $2.5 \mu \mathrm{M}(\mathrm{B}, \mathrm{t}=7.5)$ morphant embryos is not located as ventrally as in control embryos $(\mathbf{A}, \mathrm{t}=7.5)$.

(E-F) Stage 38 control (E), $2.5 \mu \mathrm{M}(\mathbf{F})$ and $5 \mu \mathrm{M}(\mathrm{G})$ morphant embryos are shown. Morphant embryos display arched, dorsally flexed trunks, lack eye structures (pointer, F), and have malformed heads (pointer, G). These phenotypes are more pronounced at $5 \mu \mathrm{M} \mathrm{MHC-B} \mathrm{MO} \mathrm{(G).}$ 

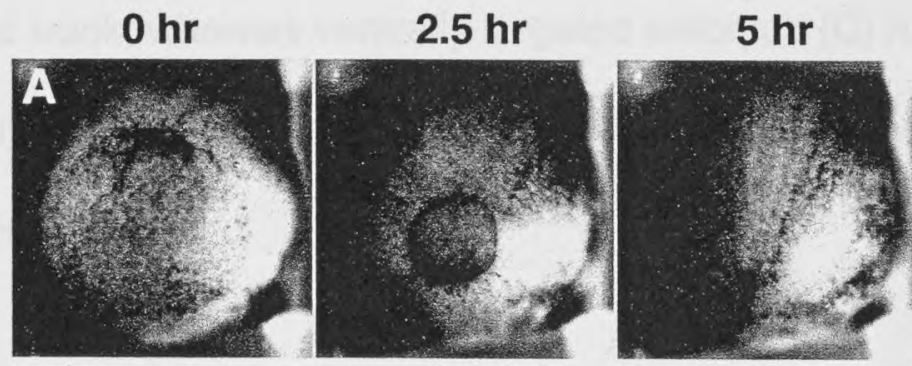

$7.5 \mathrm{hr}$
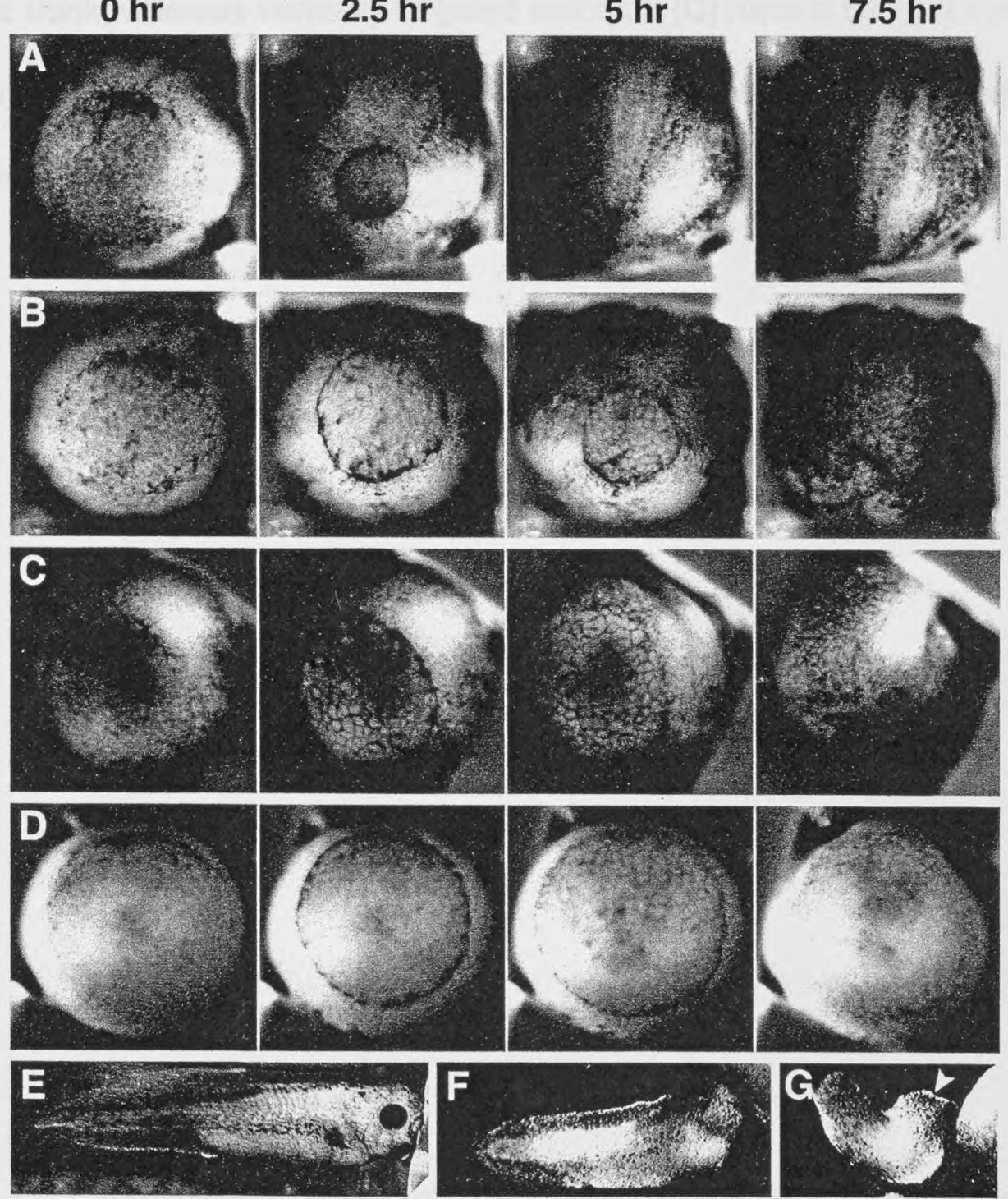
Figure 2-4. Myosin IIB is required in the dorsal tissues.
A stage 32 control (A) and dorsally
(B) and ventrally
(C) targeted morphant embryos are shown. Dorsally targeted morphant embryos (B) display a dorsally arched trunk, whereas ventrally targeted embryos (C) have a straight trunk that is similar to controls, except for a shorter tailbud (cf. distance between pointers, see text for details). 

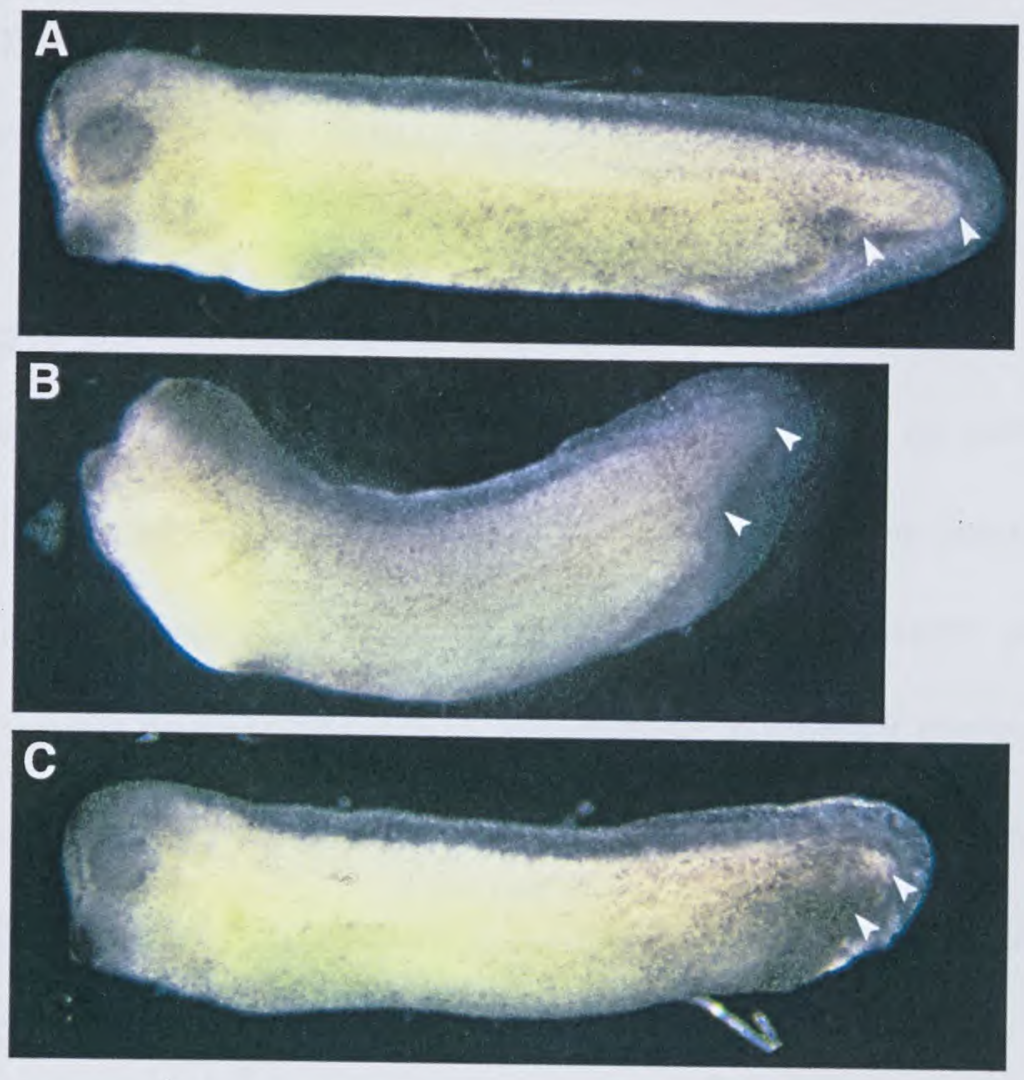
Figure 2-5. MHC-B depleted cells have aberrant morphology and motility.

(A-B) Confocal projections of stage 12 embryos bearing scattered labelled cells with rhodamine-dextran $(\mathbf{A})$, or labeled with rhodamine-dextran and bearing MHC-B MO at $10 \mu \mathrm{M}(\mathbf{B})$ are shown. In control embryos (A) the scattered cells contribute to all three germ layers and display normal layer-specific morphology, whereas morphant cells $(\mathbf{B})$ have aberrant rounded morphologies and many are excluded from the embryo. Ecto - ectoderm; Meso - mesoderm; Endo endoderm.

(C) Still images from a fluorescent time-lapse video-recording of a morphant notocordal cell in a neural-deep-over-mesoderm explant from an embryo bearing scattered cells injected with $5 \mu \mathrm{M}$ MHC-B MO and rhodamine-dextran. This cell has large blunt protrusions, in contrast to the normal lamelliform protrusions of normal cells, and it crosses the notocordal-somitic boundary (horizontal line), a boundary that normal cells respect. After $75^{\prime}$, the cell adopts an antero-posterior elongated morphology, accommodating to the space between the notochord (No) and the somitic mesoderm (S). 

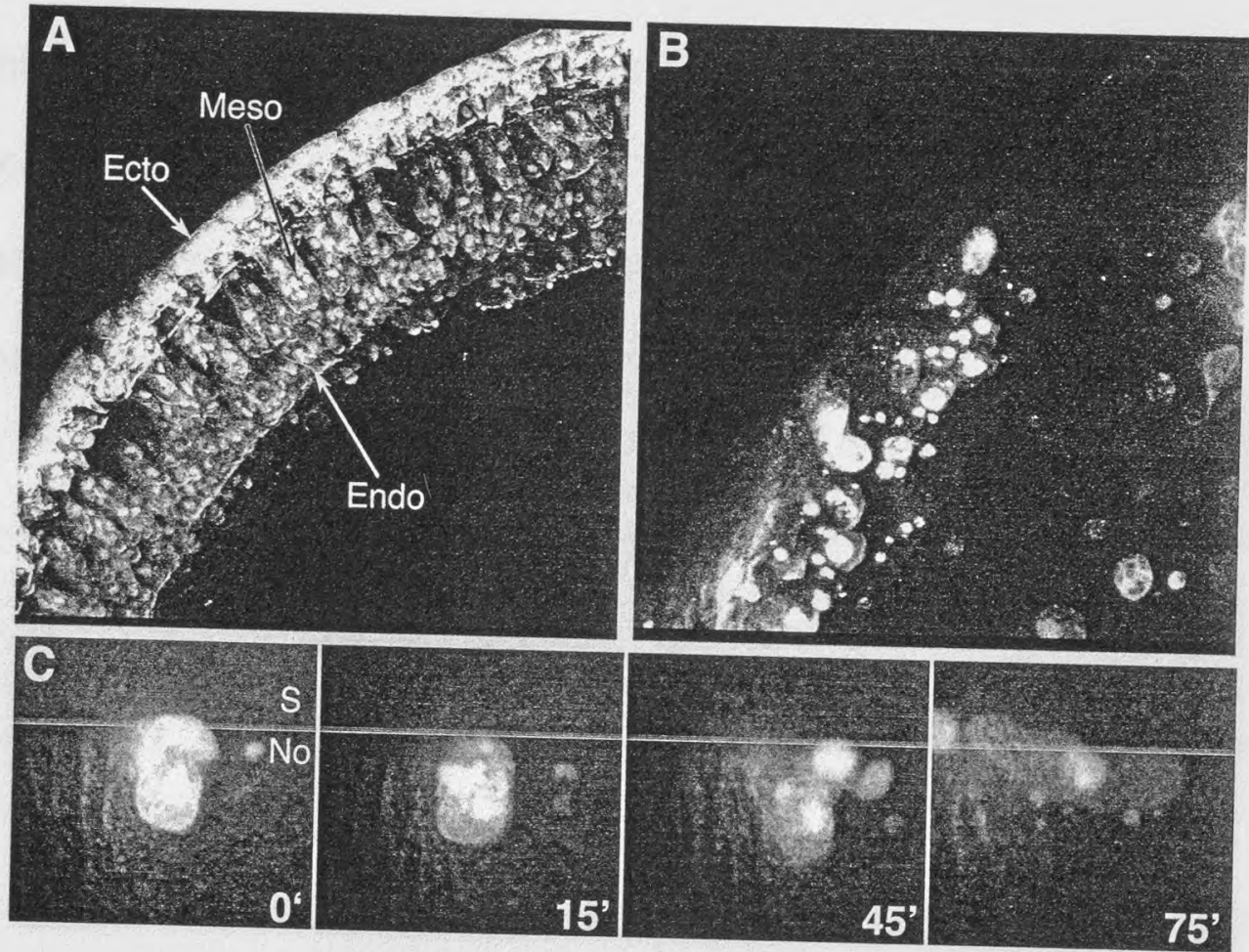
Figure 2-6. MHC-B MO caused reduced levels of fibronectin matrix as well as reduced fibronectin adhesion.

A stage 14 control embryo shows fibronectin immunostaining at tissue boundaries, specifically between the notochordal (No) and somitic (S) mesoderm (A). A morphant embryo injected at 2-cell stage with $5 \mu \mathrm{M}$ MHC-MO displays reduced fibronectin matrix deposition $(\mathbf{B})$; severely compromised morphogenesis in this embryo does not allow identification of the dorsal side and a notochord/somite boundary does not form. The fibronectin (FN) adhesion index of cells dissociated from stage 11 morphant embryos is shown as a percentage of control cell adhesion (C). Error bars are s.e.m. 

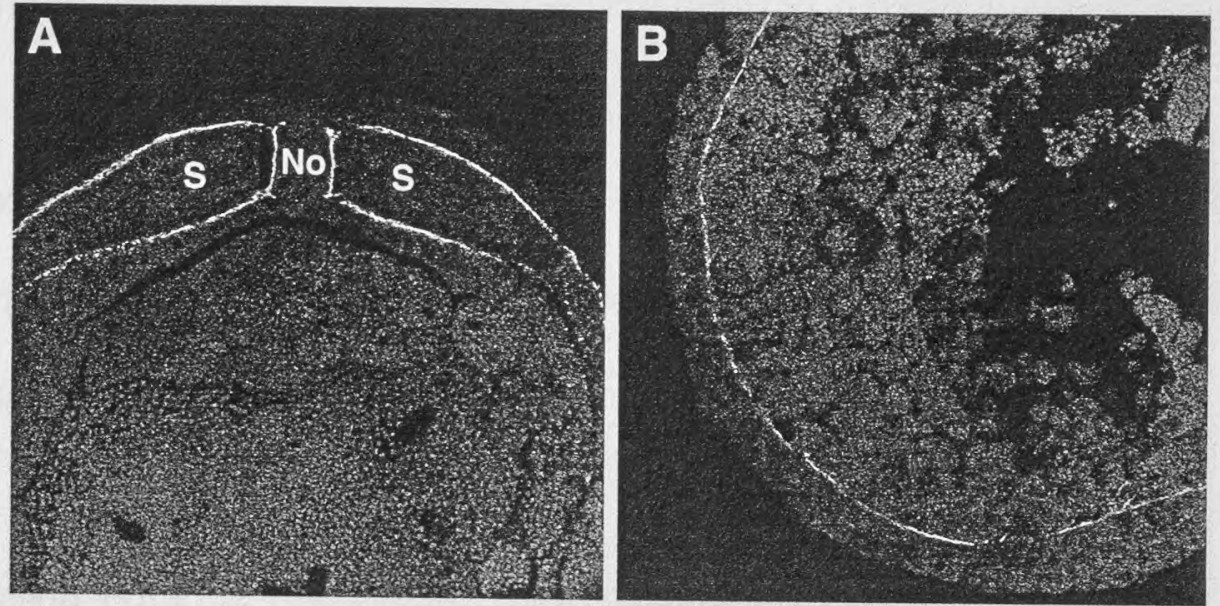

C

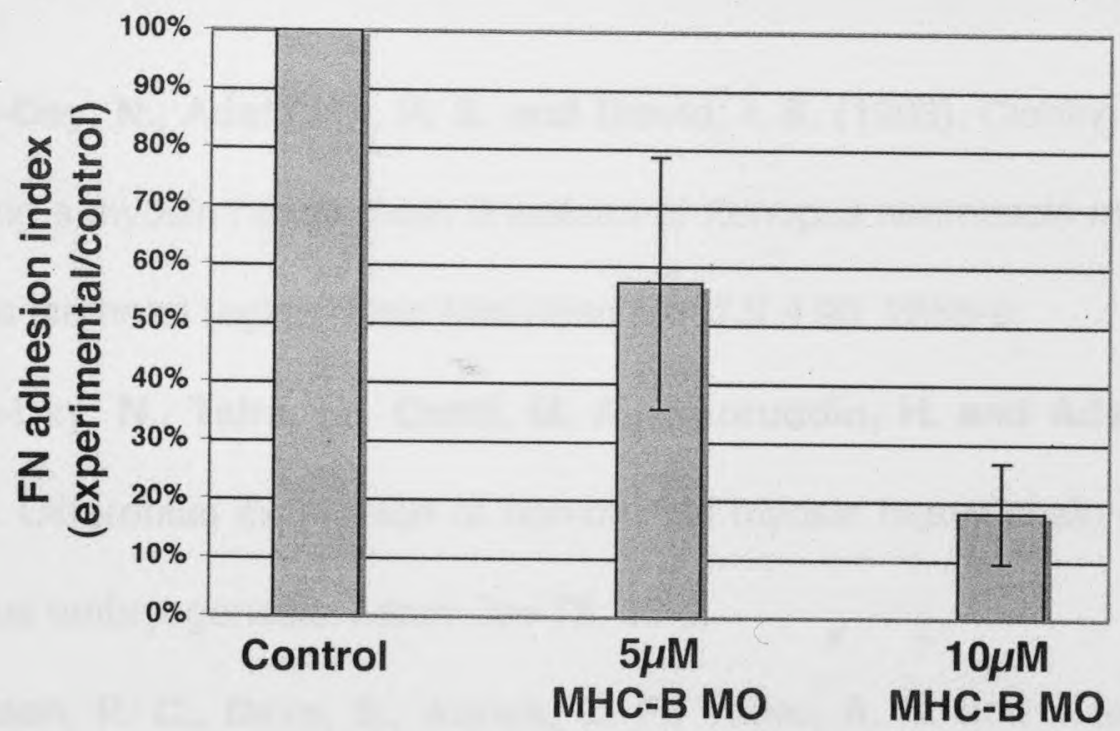




\section{REFERENCES}

Amaya, E., Stein, P. A., Musci, T. J. and Kirschner, M. W. (1993). FGF signalling in the early specification of mesoderm in Xenopus. Development 118, 477-87.

Baneyx, G., Baugh, L. and Vogel, V. (2002). Fibronectin extension and unfolding within cell matrix fibrils controlled by cytoskeletal tension. Proc Natl Acad Sci U S A 99, 5139-43.

Bertet, C., Sulak, L. and Lecuit, T. (2004). Myosin-dependent junction remodelling controls planar cell intercalation and axis elongation. Nature 429, 667-71.

Bhatia-Dey, N., Adelstein, R. S. and Dawid, I. B. (1993). Cloning of the cDNA encoding a myosin heavy chain B isoform of Xenopus nonmuscle myosin with an insert in the head region. Proc Natl Acad Sci U S A 90, 2856-9.

Bhatia-Dey, N., Taira, M., Conti, M. A., Nooruddin, H. and Adelstein, R. S. (1998). Differential expression of non-muscle myosin heavy chain genes during Xenopus embryogenesis. Mech Dev 78, 33-6.

Bridgman, P. C., Dave, S., Asnes, C. F., Tullio, A. N. and Adelstein, R. S. (2001). Myosin IIB is required for growth cone motility. J Neurosci 21, 6159-69.

Brieher, W. M. and Gumbiner, B. M. (1994). Regulation of C-cadherin function during activin induced morphogenesis of Xenopus animal caps. J Cell Biol 126, $519-27$. 
Davidson, L. A., Keller, R. and DeSimone, D. W. (2004). Assembly and remodeling of the fibrillar fibronectin extracellular matrix during gastrulation and neurulation in Xenopus laevis. Dev Dyn 231, 888-95.

Davidson, L. A., Marsden, M., Keller, R. and Desimone, D. W. (2006). Integrin alpha5beta1 and fibronectin regulate polarized cell protrusions required for Xenopus convergence and extension. Curr Biol 16, 833-44.

Elul, T. and Keller, R. (2000). Monopolar protrusive activity: a new morphogenic cell behavior in the neural plate dependent on vertical interactions with the mesoderm in Xenopus. Dev Biol 224, 3-19.

Goto, T., Davidson, L., Asashima, M. and Keller, R. (2005). Planar cell polarity genes regulate polarized extracellular matrix deposition during frog gastrulation. Curr Biol 15, 787-93.

Harland, R. M. (1991). In situ hybridization: an improved whole-mount method for Xenopus embryos. Methods Cell Biol 36, 685-95.

Keller, R. (1991). Early embryonic development of Xenopus laevis. Methods Cell Biol 36, 61-113.

Keller, R., Shih, J. and Domingo, C. (1992). The patterning and functioning of protrusive activity during convergence and extension of the Xenopus organiser. Dev Suppl, 81-91.

Kelley, C. A., Oberman, F., Yisraeli, J. K. and Adelstein, R. S. (1995). A Xenopus nonmuscle myosin heavy chain isoform is phosphorylated by cyclinp34cdc2 kinase during meiosis. J Biol Chem 270, 1395-401. 
Kelley, C. A., Sellers, J. R., Gard, D. L., Bui, D., Adelstein, R. S. and Baines, I. C. (1996). Xenopus nonmuscle myosin heavy chain isoforms have different subcellular localizations and enzymatic activities. J Cell Biol 134, 675-87.

Laevsky, G. and Knecht, D. A. (2003). Cross-linking of actin filaments by myosin II is a major contributor to cortical integrity and cell motility in restrictive environments. J Cell Sci 116, 3761-70.

Lane, M. C. and Sheets, M. D. (2000). Designation of the anterior/posterior axis in pregastrula Xenopus laevis. Dev Biol 225, 37-58.

Lee, C. H. and Gumbiner, B. M. (1995). Disruption of gastrulation movements in Xenopus by a dominant-negative mutant for C-cadherin. Dev Biol 171, 363-73.

Lo, C. M., Buxton, D. B., Chua, G. C., Dembo, M., Adelstein, R. S. and Wang, Y. L. (2004). Nonmuscle myosin $\mathrm{Ilb}$ is involved in the guidance of fibroblast migration. Mol Biol Cell 15, 982-9.

Nieuwkoop, P. D. and Faber, J. (1994). Normal Table of Xenopus laevis (Daudin), (ed. New York: Garland Publishing.

Shewan, A. M., Maddugoda, M., Kraemer, A., Stehbens, S. J., Verma, S., Kovacs, E. M. and Yap, A. S. (2005). Myosin 2 is a key Rho kinase target necessary for the local concentration of E-cadherin at cell-cell contacts. Mol Biol Cell 16, 4531-42.

Shih, J. and Keller, R. (1992a). Cell motility driving mediolateral intercalation in explants of Xenopus laevis. Development 116, 901-14. 
Shih, J. and Keller, R. (1992b). Patterns of cell motility in the organizer and dorsal mesoderm of Xenopus laevis. Development 116, 915-30.

Sive, H. L., Grainger, R. M. and Harland, R. M. (2000). Early Development of Xenopus laevis. Cold Spring Harbor, New York: Cold Spring Harbor Laboratory Press.

Skoglund, P., Dzamba, B., Coffman, C. R., Harris, W. A. and Keller, R. (2006). Xenopus fibrillin is expressed in the organizer and is the earliest component of matrix at the developing notochord-somite boundary. Dev Dyn 235, 1974-83.

Yokotal, C., Mukasa, T., Higashi, M., Odaka, A., Muroya, K., Uchiyama, H., Eto, Y., Asashima, M. and Momoi, T. (1995). Activin induces the expression of the Xenopus homologue of sonic hedgehog during mesoderm formation in Xenopus explants. Biochem Biophys Res Commun 207, 1-7.

Yoneda, A., Ushakov, D., Multhaupt, H. A. and Couchman, J. R. (2006). Fibronectin Matrix Assembly Requires Distinct Contributions from Rho Kinases I and II. Mol Biol Cell.

Zallen, J. A. and Wieschaus, E. (2004). Patterned gene expression directs bipolar planar polarity in Drosophila. Dev Cell 6, 343-55.

Zhong, C., Chrzanowska-Wodnicka, M., Brown, J., Shaub, A., Belkin, A. M. and Burridge, K. (1998). Rho-mediated contractility exposes a cryptic site in fibronectin and induces fibronectin matrix assembly. J Cell Biol 141, 539-51. 
Zhong, Y., Brieher, W. M. and Gumbiner, B. M. (1999). Analysis of C-cadherin regulation during tissue morphogenesis with an activating antibody. $J$ Cell Biol $144,351-9$ 
Chapter 3

Myosin IIB has multiple roles in Xenopus neural morphogenesis 


\section{SUMMARY}

Vertebrate neural tube closure involves dramatic tissue morphogenesis, particularly convergence and extension (CE), which is driven by medio-lateral cell intercalation, and bending and closure of the neural plate, which is driven in part by cellular apical constriction. Myosin IIB is a motor protein that regulates biomechanical properties of cells such as motility, cortical tension and adhesion. Here I show that myosin IIB plays a role in organizing the cortical actin cytoskeleton that maintains cell shape and cortical tension during $\mathrm{CE}$, as well as in bending and closure of the neural plate. Morpholino-oligonucleotide knockdown of myosin heavy chain IIB targeted to the neural plate results in changes in cell shape and organization of the actin cytoskeleton. Although these changes in morphant neural plates of whole embryos result in little impairment of neural $\mathrm{CE}$, the autonomous neural $\mathrm{CE}$ that occurs in morphant explants was substantially inhibited, suggesting that morphant neural plates are pliable and can be passively stretched by the underlying extending mesoderm. These changes in biomechanical properties at the tissue level are consistent with the apparent reduction of cortical tension and adhesion of morphant neural cells. Additional roles for myosin IIB in other independent neurulation events were discovered. Apical constriction of neurepithelial cells is impaired in morphant neural plates, leading to delayed neural tube closure. Myosin IIB depletion also results in defective eye and brain morphogenesis, abnormal motor response to external stimuli, and defective neural cell crest derivatives. 


\section{INTRODUCTION}

The vertebrate dorsal hollow nerve cord, or neural tube, forms from an initially flat, short and broad neural plate which then undergoes dramatic morphogenic events that not only bend and roll it into a tube, but also greatly narrow and lengthen it along its antero-posterior axis (Jacobson and Gordon, 1976; Schoenwolf and Smith, 1990). This narrowing and lengthening of the neural tissue, commonly referred to as convergent extension (CE), is crucial for proper neural tube closure, as it is responsible for bringing the neural folds closer to the midline, where they will meet and fuse (Wallingford and Harland, 2002). In a urodele (tailed) amphibian, Taricha torosus, neural CE is largely dependent on powerful CE movements that occur in the underlying dorsal mesoderm (Jacobson and Gordon, 1976). In the anuran (tailless) amphibian Xenopus laevis, however, a form of neural CE that is mechanically independent of the underlying mesoderm has also been shown to occur (Elul et al., 1997; Keller and Danilchik, 1988; Keller et al., 1992a; Keller et al., 1992b). This mode of neural CE does not require continued vertical signaling interactions with the underlying mesoderm, and can be induced and maintained by planar signals alone (Keller et al., 1992b). However, it occurs by mediolateral cell intercalation of the deep mesenchymal cells of the double layered amphibian neural plate that involves a bipolar protrusive activity similar to that seen in the intercalating presumptive mesodermal cells (Elul et al., 1997). In contrast, in the normal situation, with continued vertical interactions with the underlying mesoderm, this bipolar mode is 
replaced with a monopolar, medially directed protrusive activity and a mode of cell intercalation that is more efficient in producing neural CE (Elul and Keller, 2000; Ezin et al., 2003). This medially-directed protrusive activity is dependent on unknown signals emanating from the midline tissues of notochord and the overlying notoplate (Ezin et al., 2003). CE of the neural plate, as well as CE of the dorsal mesoderm, is dependent on the vertebrate non-canonical Wnt/planar cell polarity (PCP) pathway (Wallingford and Harland, 2001; Wallingford and Harland, 2002). However, the mechanism by which the neural cells are polarized, how they bring about the forces that drive their intercalation between one another and the relative contribution of the autonomous neural $\mathrm{CE}$ movements to the forces that shape the neural plate and roll it into a tube remain unresolved.

Medial movement of the neural folds to close the neural tube is not only dependent on CE, but it also largely facilitated by bending of the neural plate. This process is driven by shape changes in neuroepithelial cells, which undergo apical constriction and assume a wedge or bottle-cell morphology, thus causing the neural sheet to bend (Schoenwolf and Smith, 1990). The actin-binding protein Shroom is a key regulator of apical constriction during Xenopus anterior neural tube closure (Haigo et al., 2003), and in cultured MDCK cells, Shroom causes apical constriction by regulating the apical positioning of a contractile actomyosin network (Hildebrand, 2005).

Myosin II is a motor protein that binds to actin filaments and moves along them by hydrolyzing ATP, and it has also been shown to serve as an actin cross- 
linker (Laevsky and Knecht, 2003; Xu et al., 2001). All vertebrates have at least two genes encoding two different non-muscle myosin II heavy chain proteins MHC-A, MHC-B (Katsuragawa et al., 1989; Kawamoto and Adelstein, 1991; Kelley et al., 1995). A third isoform, MHC-C, has been identified in mouse (Golomb et al., 2004). MHC-A is the predominant isoform expressed in Xenopus early embryonic cells (Kelley et al., 1996), but MHC-B expression is up-regulated in dorsal tissues that undergo CE, and also in activin-treated animal caps, concomitant with the induction of mesodermal markers (Bhatia-Dey et al., 1998). Myosins IIA and IIB have distinct biochemical properties, with IIB having a higher duty ratio, consistent with a role in maintaining cortical tension by cross-linking the cortical actin cytoskeleton (Kovacs et al., 2003; Rosenfeld et al., 2003; Wang et al., 2003). In the mouse, MHC-B plays an important role in neural development, particularly in the migration of certain groups of neurons (Ma et al., 2004; Ma et al., 2006; Tullio et al., 2001), and also in growth cone extension (Bridgman et al., 2001; Brown and Bridgman, 2003). Myosin IIB is necessary for $\mathrm{CE}$ of the dorsal axial and paraxial mesoderm and blastopore closure in Xenopus (see Chapter 2), whereas myosin IIA is necessary for convergent thickening, a movement that occurs in the ventral sector of the gastrula, as well as for elongation of the ventral body axis (see Chapter 4).

Here I examine the role of myosin IIB in Xenopus neural morphogenesis. I show that MHC-B is expressed in Xenopus neural tissues throughout neurulation, and that its knock-down causes several distinct neural defects. These include 
impaired autonomous neural CE in explants, delayed neural tube closure, brain and eye defects, reduced melanophores and abnormal swimming motility. Analysis of neural deep cells depleted of myosin IIB during the process of neural CE reveals defects in cell shape and cortical cytoskeleton integrity that are consistent with reduced cortical tension and changes in the mechanical properties of the neural tissue in the absence of myosin IIB. 


\section{MATERIALS AND METHODS}

\section{Embryos and microsurgery}

Xenopus laevis embryos were obtained and dejellied by standard methods (Sive et al., 2000) and staged according to Nieuwkoop and Faber (1994). Keller sandwiches were made comprising $\sim 100^{\circ}$ of the dorsal marginal zone according to Keller and Danilchik (1988) and neural-deep-over-mesoderm explants were made according to Elul and Keller (2000).

\section{Whole-mount immunofluorescence}

Albino embryos or explants were fixed in Dent's fixative (4:1 methanol:DMSO) for 2 hours at room temperature and stored at $-20^{\circ} \mathrm{C}$ for an overnight period or longer. Whole-embryos were bisected transversely with a scalpel after rehydration, prior to immunostaining. MHC-B was detected using a polyclonal isoform-specific primary antibody (Covance, Berkeley, CA) at 1:50 dilution and a rhodamine-conjugated goat anti-rabbit secondary antibody (Jackson Immuno Research, West Grove, PA) at 1:200. Fibronectin was detected using a monoclonal primary antibody (4H2) (Davidson et al., 2004) at 1:200 dilution and an Alexa488-conjugated goat anti-mouse secondary antibody (Invitrogen - Molecular Probes, Carlsbad, CA) at 1:500. Embryos and explants were dehydrated in methanol and cleared in 2:1 benzyl benzoate:benzyl alcohol. 
Confocal images were collected using a BioRad Radiance2100 system and processed using ImageJ software.

\section{Morpholino oligonucleotide}

A previously described MO against the start site of MHC-B was used (see Chapter 2). 8-cell stage embryos were injected with $0.312 \mathrm{pmol}$ of $\mathrm{MHC}-\mathrm{B} \mathrm{MO}$ per blastomere to obtain final $\mathrm{MO}$ concentration of $2.5 \mu \mathrm{M}$. 32-cell stage embryos were injected with 0.125 or $0.156 \mathrm{pmol}$ of MHC-B MO per blastomere to obtain final $\mathrm{MO}$ concentrations of 2 and $2.5 \mu \mathrm{M}$, respectively.

\section{In situ hybridization}

In situ hybridizations were made according to Harland (1991) with probes against N-CAM (Kintner and Melton, 1987), N- $\beta$-tubulin (Chitnis et al., 1995), Slug (Mayor et al., 1995) and Rx1 (Casarosa et al., 1997).

\section{Phalloidin staining}

Embryos were transversely sectioned with a scalpel blade before staining procedure. Rhodamine-conjugated phalloidin was used (Invitrogen - Molecular Probes, Carlsbad, CA) and staining was done according to Haigo et al. (2003). Embryos were mounted in 1:1 glycerol:PBS. Confocal images were collected using a BioRad Radiance2100 system and processed using ImageJ software. 


\section{Live cell imaging}

Neural deep cells were imaged in neural-deep-over-mesoderm explants made from embryos injected at 2-cell stage with 50 or $200 \mathrm{pg}$ per blastomere of the membrane targeted fluorophores pCS2+/GAP43-GFP or pCS2+/GAP43-RFP (Stubbs et al., 2006), respectively, and at the 32-cell stage with $12.5 \mathrm{pg}$ per blastomere of pCSnucGFP (nuclear targeted GFP) (Kroll and Amaya, 1996) or with 50 pg per blastomere CS107-GFP-Moe (F-actin binding) (Litman et al., 2000), with or without MHC-B MO. Confocal live images were collected using a BioRad Radiance2100 system and processed using ImageJ software. F-actin imaging was done $\sim 2 \mu \mathrm{m}$ deep in the cell cortex using a $60 \mathrm{x}$ oil lens with a numerical aperture of 1.4 . 
RESULTS

Myosin IIB is expressed in the neural plate of Xenopus

MHC-B is expressed predominantly in dorsal mesodermal tissues (BhatiaDey et al., 1998), and so to determine if myosin IIB is involved in neurulation, its expression in neural tissues was investigated by immunostaining using an MHCB specific antibody. By early neurula stages, MHC-B is detected in the dorsal tissues, particularly in the presumptive notochord and at the basal end of the deep layer of the neural plate (Fig. 3-1A). By neural fold stages, MHC-B is strongly present in both layers of the neural plate, and it has a clear cortical subcellular localization (Fig. 3-1B). The basal surface of the deep neural layer is the most strongly labeled region. In the tailbud stages there is particularly strong staining in the outer basal surface of the neural tube, as well as in the neural crest region (Fig. 3-1C). High MHC-B localization occurs in the basal epidermis (Fig. 3-1C) and in scattered cells of the outer epidermis (Fig. 3-1C, asterisks), in addition to confirming strong expression in the notochordal and somitic mesoderm at these stages (Chapter 2) (Fig. 3-1C).

The localization of MHC-B at tissue boundaries is coincidental with extracellular matrix deposition in these regions, and is particularly reminiscent of fibrillar fibronectin localization (Davidson et al., 2004; Goto et al., 2005). To assay co-localization of MHC-B and fibronectin, embryos were co-stained with antibodies against both proteins, confirming localization of fibronectin to tissue 
boundaries (Fig. 3-1D). Co-localization of the two proteins in the outer basal surface of the neural tube, around the neural crest area, around the notochord and in the basal epidermis was observed (Fig. 3-1E). To get a high-resolution en face view of MHC-B and fibronectin localizations at the basal surface of the neural plate (i.e., at the tissue boundary between neural and the underlying somitic tissues), neural-deep-over-mesoderm explants were immunostained. Such explants are deprived of epithelial tissues (Elul and Keller, 2000), therefore allowing better antibody penetration. Also, being cultured and fixed under a coverslip maintains their flat shape, which allows better imaging of the region of interest. As they are in whole embryos, fibronectin and $\mathrm{MHC}-\mathrm{B}$ are co-localized to the boundaries between the notochordal and somitic tissues and at the basal surface of the neural plate in neural-deep-over-mesoderm explants (Fig. 3-1F-H). Likewise, en face images of the neural plate/axial mesoderm interface showed MHC-B in a fibrillar pattern (Fig. 3-1I) that overlapped the fibronectin fibrils (Fig. 3-1J, K). Explants that were stained for MHC-B alone (not shown) showed a pattern similar to that seen in the co-labeling experiment (Fig. 3-1F, I), therefore ruling out the possibility that the overlap between fibronectin and $\mathrm{MHC}-\mathrm{B}$ staining was due to spectral bleed-through rather than co-localization.

\section{MHC-B MO targeted to the neural plate causes multiple neural defects}

A knock-down of myosin IIB in neural morphogenesis was done with a morpholino oligonucleotide (MO) against $\mathrm{MHC}-\mathrm{B}$, which causes gastrulation and 
mesodermal CE defects in whole embryos (Chapter 2). To investigate the role of myosin IIB specifically in the neural tissues, the MHC-B MO was targeted to the neural plate by injection into the dorsal (A- and B-tier) animal blastomeres of 8cell stage embryos. Targeting to the A-tier alone at 32-cell stage did not reach the entire neural tissue, and in particular this injection missed the lateral posterior regions of the neural plate (not shown). However, by selecting 8-cell stage embryos that showed regular cleavage patterns and third cleavage planes located relatively near the animal pole, targeting to the entire neural plate was successful, with minimal contributions to the mesoderm.

The MHC-B MO was injected at a final concentration of $2.5 \mu \mathrm{M}$, at which it causes a mild phenotype on gastrulation (Chapter 2). Injection of higher doses caused loss of cells from the neural plate, implying a loss of cell-cell and perhaps cell-matrix adhesion, as expected from the decrease in cell-cell and cell-matrix adhesion observed at high doses of MHC-B MO (Chapter 2 and Skoglund et al., in preparation). The spaces left by some of these cells were then filled in by wildtype cells (not shown). Targeting was evaluated by visualizing a fluorescent dye co-injected with MHC-B MO, and the criteria for successful cases were stage 12.5 embryos that showed fluorescence in all or most of the neural plate region (Fig. 3-2A') and showed blastopore closure similar to control embryos (Fig. 3-2A), indicating no effect of the $\mathrm{MO}$ on the dorsal mesoderm.

To determine whether injection of MHC-B MO in the neural plate affected neural cell fates, whole-mount RNA in situ hybridization for neural markers was 
done. The MHC-B MO does not cause changes in expression of pan-neural (Fig. 3-3E), neuronal (Fig. 3-3F), neural crest (Fig. 3-3G) or prospective eye markers (Fig. 3-3H).

\section{Delayed neural tube closure}

Time-lapse video-recordings of neurulation in control and neural targeted MHC-B MO embryos revealed a delay in neural tube closure in morphant embryos compared to controls, and this delay was more pronounced in anterior regions (Fig. 3-2B). At stage 19, when all control embryos had fully closed neural tubes, $90 \%(n=11)$ of MHC-B morphants still had displayed open anterior neural plates. Also, at control stage 17-18 areas of darker pigmentation can be seen in the brain region of the neural plate (pointers, Fig. $3-2 B, t=2: 30$ ), which correspond to apical constriction of cells that function in closing the brain region of the neural plate. No such pigment concentration was observed in morphant embryos. To further characterize this phenotype, MHC-B MO was targeted to the neural plate unilaterally (Fig. 3-4). The morphology of the anterior neural fold on the uninjected side (left side, Fig. 3-4A) is developed better and it converges medially faster than its counterpart on the morphant side (right side, Fig. 3-4A). Points on the neural fold region on the uninjected side move towards the midline at $1.76 \pm 0.22 \mu \mathrm{m} \cdot \mathrm{min}^{-1}(\mathrm{n}=5)$, whereas points on the morphant neural fold move at a speed of $0.9 \pm 0.11 \mu \mathrm{m} \cdot \mathrm{min}^{-1}(\mathrm{n}=5)$. Cross-sections through the brain and spinal cord regions of stage 17-18 embryos showed that cells on the morphant side 
failed to constrict their apices, as can be seen by comparing the morphology of the normal superficial cells, which adopt a bottle-cell shape, elongated and with very narrow apices, versus MHC-B MO-containing cells, which have broad apical surfaces (Fig. 3-4C-F). In normal embryos, bottle-cell formation is accompanied by strong apical accumulation of F-actin (Haigo et al., 2003). To confirm the observation that MHC-B depleted cells do not constrict apically, F-actin localization was examined in morphant versus wild-type sides of the same embryo and there was no accumulation of apical actin on the morphant side, contrasting with strong staining on the uninjected side (Fig. 3-4B).

\section{Absent or reduced eyes}

Targeting of MHC-B MO to the neural plate also produced eye defects, consistent with the presence of myosin IIB in the eye (Chapter 2). Morphant embryos either had small eyes with abnormal optic cups (Fig. 3-5B, E; type I phenotype in Fig. 3-5G) or lacked any externally visible eye structures and displayed only a rudimentary optic vesicle (Fig. 3-5C, F; type II phenotype in Fig. 3-5G). Cross-sections through the optic region of control tailbud stage embryos showed well-defined optic cups surrounding the lens (Fig. 3-6B), whereas morphant embryos had abnormal optic cups or rudimentary optic vesicles with no apparent optic cup (Fig. 3-6C, left and right eyes, respectively). The strength of the phenotype seemed to correlate with the amount of MO present (Fig. 3-6D; the more strongly disrupted right eye has higher $\mathrm{MO}$ level, as detected by co- 
injected fluorescent dye). Also, the observed eye defects are likely due to failure in eye morphogenic events rather than in inductive events, given the fact that morphant embryos correctly express the prospective eye marker Rx-1 (Fig. 3$3 G)$.

\section{Defects in melanophore number, spreading and distribution}

By stage 41, wild-type control embryos typically show melanophores dorsally on the head and extending backward, as well as in a lateral row at the level of the pronephros extending from behind the head (Fig. 3-5D). These melanophores originate in the neural crest region, and migrate to their final destinations, where they differentiate. Morphant embryos often show a reduction in the number of melanophores (Fig. 3-5E; type I phenotype in Fig. 3-5G), and in some cases the reduction in melanophores is accompanied by a lack of spreading of the melanin in these cells (Fig. 3-5F; type II phenotype in Fig. 3-5G). These embryos were all kept under the exact same conditions, therefore the pointy appearance of the melanophores in morphant embryos is not due to external stimuli that caused the pigment to condense, since control embryos under the same treatment displayed a spidery morphology, meaning that their pigment granules were spread through the cells. The fact that morphant embryos express the prospective neural crest marker Slug (Fig. 3-3G) indicates that the reduced number of melanophores is likely not due to failure of crest induction but rather to failure of migration. Also, the melanophores that do appear in morphant 
embryos tend to be more broadly distributed, rather than restricted to the upper flank region (cf. Fig.3-5D, E, F).

\section{Brain defects}

Cross-sections through the optic region of control tailbud stage embryos show the hindbrain with a well-defined keyhole shaped ventricle (Fig. 3-6B), whereas sections through the same region of morphant embryos show a more oval hindbrain, with a slit-like ventricle (Fig. 3-6C). Whole brains dissected out of stage 41 morphant embryos are smaller and misshaped (5/5) compared to control brains of the same stage (3/3) (Fig. 3-6A). The reduction in size is more pronounced in the forebrain region, and also apparent in the hindbrain; the midbrain region is closer to the control in terms of size, but defects in shape are evident (Fig. 3-6A).

\section{Diminished touch response}

The end result of successful neural morphogenesis is an operating system of properly connected neurons that can integrate stimuli and produce adequate responses. The ability of morphant embryos to respond to external stimuli was assayed using a simple touch-response assay. When control or morphant tailbud stage embryos were probed gently with a hairloop tool, there were three possible types of response: the animal would squirm several times and swim away, the animal would squirm once or twice but not swim, or there would be no response. 
$94 \%$ of the control embryos squirmed and swam away, whereas the remaining $6 \%$ only squirmed, and none showed no response $(n=17)$. This contrasts with the results obtained for morphant embryos, out of which $82 \%$ squirmed only, $18 \%$ showed no response and none swam $(n=11)$.

\section{Impaired neural CE}

MHC-B reduction caused a dorsal flexure of the trunk, which was classified into two categories: a moderately arched trunk with the head tilted and the rest of the trunk being only slightly bowed dorsally (Fig. 3-5B; type I phenotype in Fig. 3-5G) and a more pronounced arch of the entire trunk (Fig. 35C; type II phenotype in Fig. 3-5G). The reasoning was that these arched trunks result from a defect in neural $\mathrm{CE}$. Both neural and mesodermal tissue undergo active, independent CE (Keller and Danilchik, 1988), and in whole embryos, the extension of the neural tissue occurs in parallel to and is mechanically coupled to the extension of the underlying mesodermal tissues during gastrulation and neurulation. In tailbud stages, the ventral part of the embryo also extends, causing a straightening of the trunk in urodeles (Drawbridge and Steinberg, 2000) and in Xenopus (Larkin and Danilchik, 1999). Thus failure of neural extension, mesodermal extension, or both together could slow extension of the dorsal side relative to the ventral side and result in dorsal flexure. Therefore, one cannot rule out the possibility that the arched phenotype is partly due to presence of MHC-B MO in mesodermal tissues. 
To address this issue, neural CE was assayed in Keller sandwiches, which comprise the dorsal IMZ and NIMZ explanted and sandwiched together at early gastrula stages, and in which the neural and mesodermal tissues extend serially, in opposite directions, with the extension of the neural being mechanically independent of the mesodermal extension (Keller and Danilchik, 1988) (Fig. 3-7A). Neural extension was compared in Keller sandwiches made from normal embryos (Fig. 3-7A), and in those in which MHC-B MO had been targeted to the presumptive neural region (Fig. 3-7B). The neural tissue in morphant explants extended significantly less than in control explants (more than two-fold difference, Fig. 3-7C). The mesodermal extension in morphant explants was close to that observed in control explants (Fig. 3-7C). The slight reduction can be explained by the presence of some $\mathrm{MO}$ in the posterior part of the mesoderm, which is seen by the presence of the fluorescent dye co-injected with the $\mathrm{MO}$ (Fig. 3-7B). If these explants are analyzed individually, the reduction of mesodermal extension correlates with the amount of $\mathrm{MO}$ found in the mesoderm. For example, the two explants on the right in Figure 3-7B show higher fluorescence in the mesoderm and decreased extension of this tissue, when compared to the three explants on the left, all of which have less fluorescence in the mesoderm and greater mesodermal extension. These results show that myosin IIB is essential for neural CE. 


\section{MHC-B reduction causes defects in cell motility and cell shape}

To analyze the cellular basis of the impaired neural CE in morphant embryos, the MHC-B MO was targeted to scattered cells in the neural plate by dorsal injection at the 32-cell stage. Compared to normal cells (Fig. 3-8D), cells at a $\mathrm{MO}$ concentration of $2.5 \mu \mathrm{M}$ are misshapen, flatter, occupy a larger area in the plane of the neural plate, and show abnormal protrusive activity (Fig. 3-8F, G, and movies not shown). Normal cells show sharply defined filiform and lamelliform protrusions with the normal concave marginal profile between protrusions, whereas the morphant cells show large, blunt protrusions, sometimes with multiple lobes, and with convex profiles where they meet the cell body (cf. Fig. 3-8 D, F-G). As the protrusions of the morphant cells extend, their outline appears to accommodate the shape of existing spaces between other cells (movies not shown). This fact and their rounded, multi-lobed morphology and convex profile suggest that the morphant cells have reduced control of the mechanical properties of their cortical region. Eventually, most of these cells are extruded from the tissue (Fig. 3-8 F, G), similar to what happens with mesodermal cells (Chapter 2 and Skoglund et al., in preparation).

When the concentration of $\mathrm{MO}$ is lowered to $2 \mu \mathrm{M}$, the cells have a milder phenotype. They remain in the tissue, and they have the characteristic mediolateral elongation, but they become hyper-elongated. Compared with control cells, which have a length-to-width ratio of $1.69 \pm 0.08(n=43)(F i g .3-8 A)$, morphant cells attain a significantly greater length-to-width ratio of $2.74 \pm 0.13$ 
$(n=43)$ (Fig. 3-8B). However, these elongated morphant cells will round up and undergo mitosis and cytokinesis (Fig. 3-8C), a phenomenon observed regularly, and which also demonstrates that, at least at a concentration of $2 \mu \mathrm{M}$, the MHC-B MO does not affect cytokinesis.

\section{MHC-B reduction causes defects in the actin cytoskeleton}

Analysis of cortical cytoskeleton of normal neural plate cells using an Factin binding GFP probe revealed a well-organized network of actin bundles radiating from one or more foci within the cell, that contracts episodically in conjunction with contractions of the cell body (Fig. 3-8D and movies not shown). This finding raises the possibility that this cortical actin network functions in neural CE. To examine this possiblity, the actin cytoskeleton was analyzed in MHC-B morphant cells. MHC-B depleted cells with a MO concentration of $2.5 \mu \mathrm{M}$ have a less dense, coarser cortical actin network, with fewer, but thicker cables that are curved and rarely straight for any length (Fig. 3-8F). Also, the radiating pattern of cables and their extension into protrusions are lost, and the curved cables flow in the same direction of cell movement, which occurs without apparent episodic contractions of either the cell body or the cytoskeleton (Fig. 38F and movies not shown). In some cases, actin bundles are almost absent (Fig. 3-8G). At the lower $\mathrm{MO}$ concentration of $2 \mu \mathrm{M}$ that produces a milder morphant phenotype of hyper-elongated cells, the actin cytoskeleton is also perturbed, but in a qualitatively different manner. It is not coarsened as it is at higher $\mathrm{MO}$ 
concentrations, but it differs from the cytoskeleton of normal cells in that the actin bundles don't organize in foci, but rather form long straight cables parallel to the direction of cell elongation, that still episodically contract (Fig. 8E and movies not shown), consistent with the level of disruption of cortical actin defining the phenotype seen. 


\section{DISCUSSION}

In this chapter I show that myosin IIB is expressed in Xenopus neural plate and neural tube, and that it is required in these tissues for normal neural morphogenesis, particularly for normal closure of the neural plate, for eye and brain morphogenesis, and for some neural crest cell migration. I further show that myosin IIB is required for autonomous neural CE and that its depletion leads to disruption of the cortical actin cytoskeleton, abnormal cell shape and abnormal protrusive activity. These findings parallel the analysis of myosin IIB in mesodermal $\mathrm{CE}$, which showed that MHC-B reduction in dorsal mesoderm cells leads to similar changes in cytoskeletal organization, cell shape, cell protrusive activity, and cell-cell and cell-matrix adhesion (Chapter 2 and Skoglund et al., in preparation), and they reveal both analogous and novel roles for myosin IIB in neural morphogenesis.

\section{Myosin IIB has multiple roles of varying sensitivity}

How does myosin IIB function in neural morphogenesis? I have shown that neural depletion of MHC-B causes multiple defects, implying several roles for this protein in neurulation. At a cellular level, myosin II has been shown to have several distinct functions in other systems, such as regulation of cell shape and cortical integrity (Egelhoff et al., 1996; Laevsky and Knecht, 2003; Xu et al., 2001), cell motility (Bridgman et al., 2001; Gupton et al., 2005; Lo et al., 2004; Svitkina et al., 1997), and cell adhesion (Shewan et al., 2005). The different 
effects of myosin IIB depletion on neurulation described in this chapter are likely due to several different cell biological functions of this motor molecule.

From the observation that targeting high levels of MHC-B MO to neural plate cells leads to their exclusion from embryonic tissues, I conclude that myosin IIB is essential for neural cell adhesion and tissue integrity, a conclusion that parallels previous work showing that myosin IIB is necessary to maintain proper cell adhesion during CE of the dorsal mesodermal tissues (Skoglund et al., in preparation). In cultured mammalian epithelial cells, myosin II is essential for concentration of E-cadherin at cell junctions during cell adhesion (Shewan et al., 2005), and myosin IIB is essential for both cadherin-mediated adhesion and adhesion to fibronectin extracellular matrix in the Xenopus dorsal mesoderm (Chapter 2 and Skoglund et al., in preparation). Whether myosin IIB plays a similar role in clustering of the cadherins shown to function during neurulation, $\mathrm{N}$ cadherin and F-cadherin (Detrick et al., 1990; Espeseth et al., 1995), is an important, unanswered question.

At lower MHC-B MO levels, which were used for most of the analysis done in this chapter, loss of adhesion does not occur, and neural tissue integrity is maintained, probably because there are residual levels of myosin IIB sufficient for cell adhesion. This partial depletion of myosin IIB in neural tissues reveals additional defects that I believe correspond to other roles of this protein in neurulation, all of which have higher sensitivity to reduction of protein levels than cell adhesion. 
Myosin IIB function plays a role in both the deep and superficial neural plate layers

A delay in neural tube closure can be caused by different factors. Defects in neural CE, which is an active process of the deep layer of the neural plate in Xenopus (Elul et al., 1997; Keller and Danilchik, 1988; Keller et al., 1992a), cause the neural plate to be wider than normal and with neural folds so far apart that they may not meet and thus cannot fuse to form a tube (Wallingford and Harland, 2002). Some part of the delay observed on myosin IIB depletion may be due to failure of active neural $\mathrm{CE}$, and thus convergence of the neural folds falls more on passive stretching of the neural plate by underlying mesoderm, as discussed below. However, most of the delay is probably due to effects of myosin IIB depletion in the superficial, epithelial layer of the neural plate. It does not undergo active mediolateral cell intercalation but instead undergoes passive cell intercalation (Elul et al., 1997; Keller and Danilchik, 1988). Nevertheless, this epithelium plays an important role in neural tube closure since its cells undergo apical constriction, causing the neural plate to converge and bend and thus bring the neural folds to apposition (Burnside and Jacobson, 1968; Haigo et al., 2003; Jacobson and Gordon, 1976; Schoenwolf and Smith, 1990). My results show that myosin IIB is necessary for apical constriction of neural superficial cells, and it is likely that this is the main cause of the delayed neural tube closure observed in MHC-B morphant embryos, given the fact that the defects in CE observed in whole embryos were relatively mild. 
However, when autonomous neural CE was assayed by mechanically separating it from mesoderm CE using the explant system, there was a strong dependence on myosin IIB. In Xenopus, mesodermal CE is stronger than the neural $\mathrm{CE}$, judging from the fact that the former is a much more massive tissue than the latter, and that when the mesodermal and neural extensions are placed in apposition to one another in mechanically confined Keller explants, it is the neural regions that fails to extend or buckles under the compressive force developed by the mesodermal region (R. Keller, unpublished observations; see Moore, 1992). Thus in Xenopus, depletion of myosin IIB has a relatively weak neural phenotype, but this molecule may have a much larger role in other vertebrates in which neural CE may play a relatively larger role, perhaps even larger than mesodermal CE, in axial extension.

\section{Myosin IIB modulates mechanical properties of the neural plate at cellular and tissue levels during $\mathrm{CE}$}

Defects in cell shape have been observed in Dictyostelium cells lacking myosin II, and in this case, it was shown that myosin II regulates cortical integrity and cortical tension by serving as the major actin cross-linker of the cell, with this activity being more relevant than its motor function (Egelhoff et al., 1996; Laevsky and Knecht, 2003; Xu et al., 2001). Interestingly, myosin IIB, when compared to myosin IIA, has an extended duty cycle and a slow rate of translocation on actin 
filaments, properties that are more consistent with it serving primarily as a crosslinker than as a motor in producing actin filament movement (Rosenfeld et al., 2003; Wang et al., 2003). In my experiments, depletion of MHC-B appears to have multiple effects, with more defects appearing at higher levels of depletion. At low MO concentrations, the cytoskeleton is mildly affected, but nevertheless the cells become abnormally elongated along the axis of convergence and along the axis of tensile forces. One explanation for this fact could be that these cells fail to retract their cell bodies as the medial ends protrude and advance towards the midline. However, there's no evidence that these cells need to retract a 'trailing edge' in the same way that cultured cells do, and also depletion of MHC$B$, at least at high levels, decreases adhesion, both to fibronectin and to other cells, indicating that a reduction in myosin IIB levels may ease rather than impede de-adhesion. Another cause for this behavior may be a reduction in cortical stiffness of the cell, the ability to resist stretching. I propose that myosin IIB serves first and foremost as an actin filament cross-linker, which is necessary for maintaining cortical integrity and stiffness. This model is consistent with the progressive effect of increasing doses of MHC-B MO on the cortical actin network and on the cell morphologies. However, a contractile role is not ruled out by my experiments. The apparent decrease in resistance to stretching on MHC-B depletion could be due to weakening of an active, myosin IIB mediated contraction of the cortical actin meshwork, or it could reflect a decreased crosslinking of the actin network, making it easier to stretch in either case. 
At the lower doses of $\mathrm{MO}$ that produce the hyper-elongated cells, the protrusive activity and polarity of the cells does not seem to be affected, but at higher doses both are affected, either directly, or one as a consequence of the other. It is noteworthy that at lower MHC-B MO doses the neural plate cells do remain in the tissue, which indicates that their adhesive properties to other cells and/or to the fibronectin matrix aren't severely compromised. However, they do display a cell shape phenotype, becoming hyper-elongated, which suggests that myosin IIB may have a role in cortical integrity that is more sensitive to MHC-B levels than its adhesion roles. The observation that the cortical actin cytoskeleton is disrupted in MHC-B morphant cells can be explained by myosin IIB having a role in organizing and cross-linking the actin filaments into an organized meshwork that helps regulate cell shape and protrusive activity. The loss of polarity seen at a higher $\mathrm{MO}$ level is consistent with observations in cultured fibroblasts that myosin II regulates protrusive activity and stabilizes cell polarity (Lo et al., 2004). I believe that normal protrusive activity seen at lower doses generates mediolateral tension, though perhaps not as much as in the normal case, and that this tension elongates the individual cells abnormally in the face of weaker cortical tension and/or their inability to adequately respond to this mechanical stretch. This hypothesis is consistent with the fact that myosin IIB depleted cells cultured on traction-measuring substrates do develop traction forces, but fail to respond to mechanical signals (Lo et al., 2004). 
The cytoskeletal disruptions caused by MHC-B depletion and consequent changes in cortical stiffness are also evident at the tissue level. Myosin IIB knockdown in neural plates of whole-embryos leads to a fairly mild phenotype of slight dorsal flexure, contrasting with the strong inhibition of autonomous neural extension that it causes in sandwich explants. I postulate that this results from changes in mechanical properties of the neural tissue, which cause it to become more pliable. These morphant neural plates do not offer substantial mechanical resistance, and will passively stretch in a whole-embryo context due to mesodermal towing. In contrast, when neural CE is blocked by perturbing the Wnt/PCP pathway, the phenotype observed in whole embryos is more dramatic than the one caused by myosin IIB perturbation, with more severe dorsal flexure and resulting open neural tubes (Wallingford and Harland, 2001; Wallingford and Harland, 2002). This is presumably because Wnt/PCP perturbations impair neural CE but do not change the mechanical properties of this tissue, and thus the non-extending neural plate will resist stretching and passive CE due to forces transmitted from the actively extending, underlying mesoderm.

\section{Myosin IIB's roles beyond neural tube closure}

I identify roles of myosin IIB in eye morphogenesis and brain morphogenesis, which are complex processes involving cell shape changes, rearrangements and migrations. It will be of interest in future studies to determine the cell biological and mechanical functions of myosin IIB in these events. 
Likewise, the defective neural crest cell derivatives caused by MHC-B reduction imply a myosin IIB function in their migration, and raise new questions as to how this protein might be involved in this process. In addition to the aforementioned neural morphogenic events, there is a functional requirement for myosin IIB for function of the neural sensory network responsible for the spinal touch reflex. It has been shown that myosin IIB is required for neuronal migration and axon pathfinding both in vivo (Ma et al., 2004; Ma et al., 2006; Tullio et al., 2001) and in vitro (Bridgman et al., 2001; Brown and Bridgman, 2003).

\section{Towards an understanding of the molecular mechanisms of neural morphogenesis}

In this work I explore molecular mechanisms of neurulation by identifying multiple roles for the motor protein myosin IIB. Myosin II is a downstream component of different pathways that control cell morphology, stiffness and adhesion. The different roles unraveled for myosin IIB likely correspond to downstream events regulated by distinct pathways. For example, here I show that myosin IIB is required for both neural $C E$, a process regulated by the Wnt/PCP pathway (Wallingford and Harland, 2001; Wallingford and Harland, 2002), and also for apical constriction of neuroepithelial cells, an event involving the Shroom protein and independent of Wnt/PCP (Haigo et al., 2003). Future challenges in understanding the molecular regulation of neural morphogenesis will include determining how myosin II function is modulated by the different 
molecular pathways that control neurulation events, including what biochemical properties of this molecule are relevant for each process, as well as what cell biological functions are involved. 
Figure 3-1. MHC-B expression in the neural plate.

(A-B) Transverse sections through the mid-trunk regions of embryos stained for MHC-B at stages 12.5 (A) and 16-17.(B) show MHC-B on both the deep and the superficial layers of the neural plate (NP), with strongest labeling in the basal ends of deep neural cells. MHC-B is also present in the mesoderm tissues.

(C-K) A stage 24 embryo (C-E) and a stage 17 neural-deep-over-mesoderm explant (F-K) co-stained for MHC-B (C, F, I) and fibronectin (D, G, H), and the respective merged images $(\mathbf{E}, \mathbf{H}, \mathbf{K})$, coded in red for $\mathrm{MHC}-\mathrm{B}$ and green for fibronectin are shown.

(C-D) A transverse section through the mid-trunk region of a stage 24 embryo shows high MHC-B in the outer basal ends of neural tube (NT) cells, in the neural crest region (NC) and in the deep layer of the epidermis (C), and these areas are coincidental with areas of fibronectin deposition (D, E). MHC-B levels are very high in the notochord (No) (C) (cf. Fig. 2-1) and MHC-B staining is stronger in scattered cells of the outer epidermis (C, marked with asterisks *), which correspond to ciliated cells (se Fig. 5-1).

(F-H) A transverse section through a neural-deep-over-mesoderm explant (obtained by Z-projection of confocal series) shows that, as in whole-embryos, MHC-B is present in the neural and mesoderm tissues, with stronger staining at tissue boundaries (F), which coincide with fibronectin localization $(\mathbf{G}, \mathbf{H})$. (I-K) An en face view (obtained by $X Y$ projections of confocal series) of the boundary between NP and mesoderm in a neural-deep-over-mesoderm explant 
is shown. Some MHC-B has a fibrilar pattern (I) that coincides with fibronectin fibrils (J, K).

NP - neural plate, No - notochord, PS - pre-somitic mesoderm, E - endoderm, S - somitic mesoderm, NT - neural tube, NC - neural crest. 

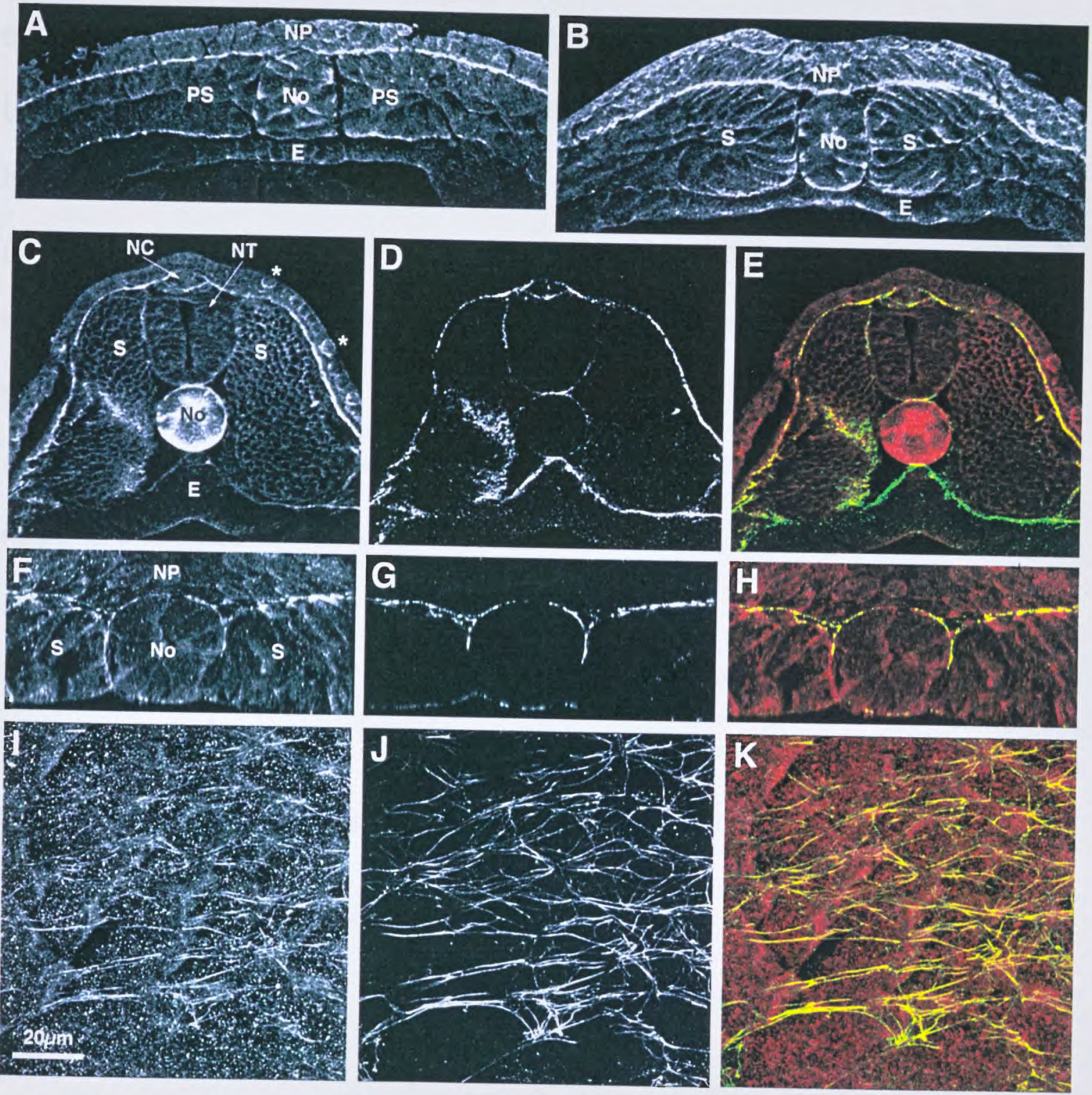
Figure 3-2. Neural targeted MHC-B MO causes delayed neural tube closure.

(A) Stage 12.5 uninjected control (top) and morphant (bottom) embryos injected with MHC-B MO and rhodamine-dextran at the eight-cell stage are shown. The degree of blastopore closure is similar in both groups.

(A') Rhodamine fluorescence of morphant embryos in (A) shows successful targeting to the neural plate.

(B) Still images from a time-lapse video-recording during neurulation stages of the embryos depicted in (A) are shown. The first frame shows dorsal views of stage 13 embryos ( $t=0: 00)$. By stage $17(t=2: 30)$, a delay in neural tube closure can be observed in morphant embryos throughout the neural tissue length, but more pronounced in the anterior region; at this same stage, areas of dark pigmentation can be seen in the anterior neural plate region of control embryos (red pointers), which are absent in morphant embryos. By stage $19(\mathrm{t}=4: 00)$ control embryos have fully closed their neural tubes, whereas morphant embryos display open anterior neural plates. Elapsed time is in hours:minutes. 


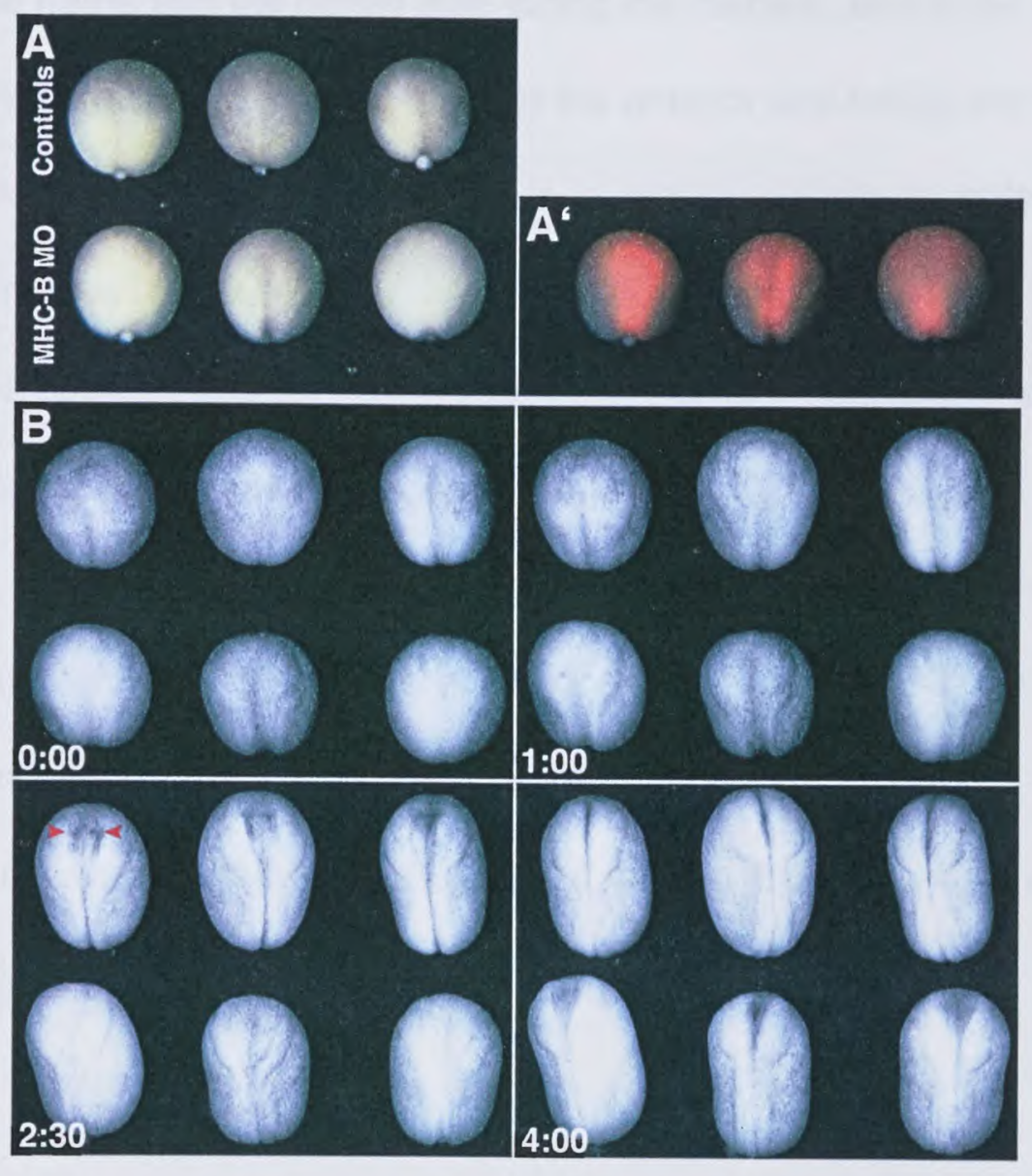


Figure 3-3. Neural targeted MHC-B MO does not alter neural cell fates.

Stage 17 control embryos (A-D) and neural targeted morphants (E-H) stained by in situ hybridization for neural markers show that neural patterning is not affected by MHC-B MO. In (A-C, E-G) the embryos are oriented with the anterior end at the top of the frame and the dorsal side facing the camera, and in (D, H) they are oriented with the dorsal side at the top and the anterior end facing the camera.

(A, E) N-CAM, a pan neural marker, has a similar pattern in control (A) and morphant embryos (E).

(B, F) N- $\beta$-tubulin, a marker for prospective primary neurons, has a similar pattern in control (B) and morphant embryos (F).

(C, G) Slug, a neural crest marker, is present in both control (C) and morphant embryos (G). The stained regions are further apart in morphant embryos (G) because these embryos have delayed neural tube closure.

(D, H) Rx1, an eye-field marker, has a similar pattern in control (D) and morphant embryos (H). 

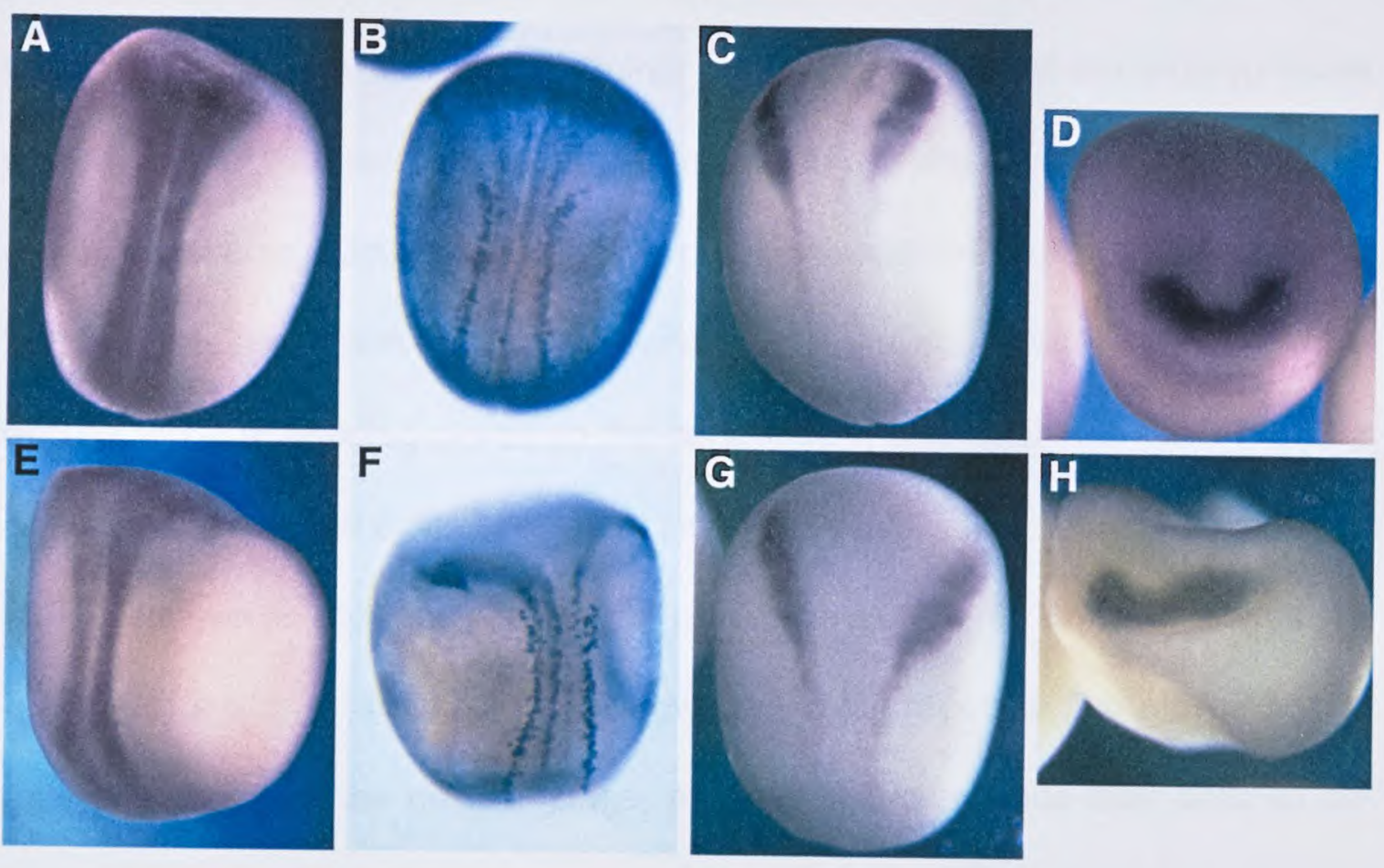
Figure 3-4. Anterior neural tube closure is asymmetrical in unilaterally neural plate targeted morphants.

(A-F) Neural plates unilaterally targeted with MHC-B MO are shown with the injected side on the right.

(A) Still images from a time-lapse video-recording of an anterior view of neural plate closure show colored dots marking points on the embryo surface that were tracked throughout the recording. Points on the control side of the embryo move towards the midline at a faster rate than points on morphant side.

(B) A transverse section through the prospective brain region of a stage 18 embryo stained with rhodamine-phalloidin shows strong apical actin accumulation at bending points on the control side, and no neural plate bending or actin accumulation on the morphant side.

(C-D) Transverse sections through the prospective brain (C) and spinal cord (D) regions of a stage 17 embryo are shown, in which green is fluorescence from dextran injected at the two-cell stage, and red is fluorescence from dextran coinjected with the MHC-B MO.

(E-F) Schematic outlines of the cells shown in (C-D) are represented. The uninjected cells adopt typical bottle cell morphologies, with long thin apices, whereas morphant cells (marked with asterisks *) have broad apical surfaces. 

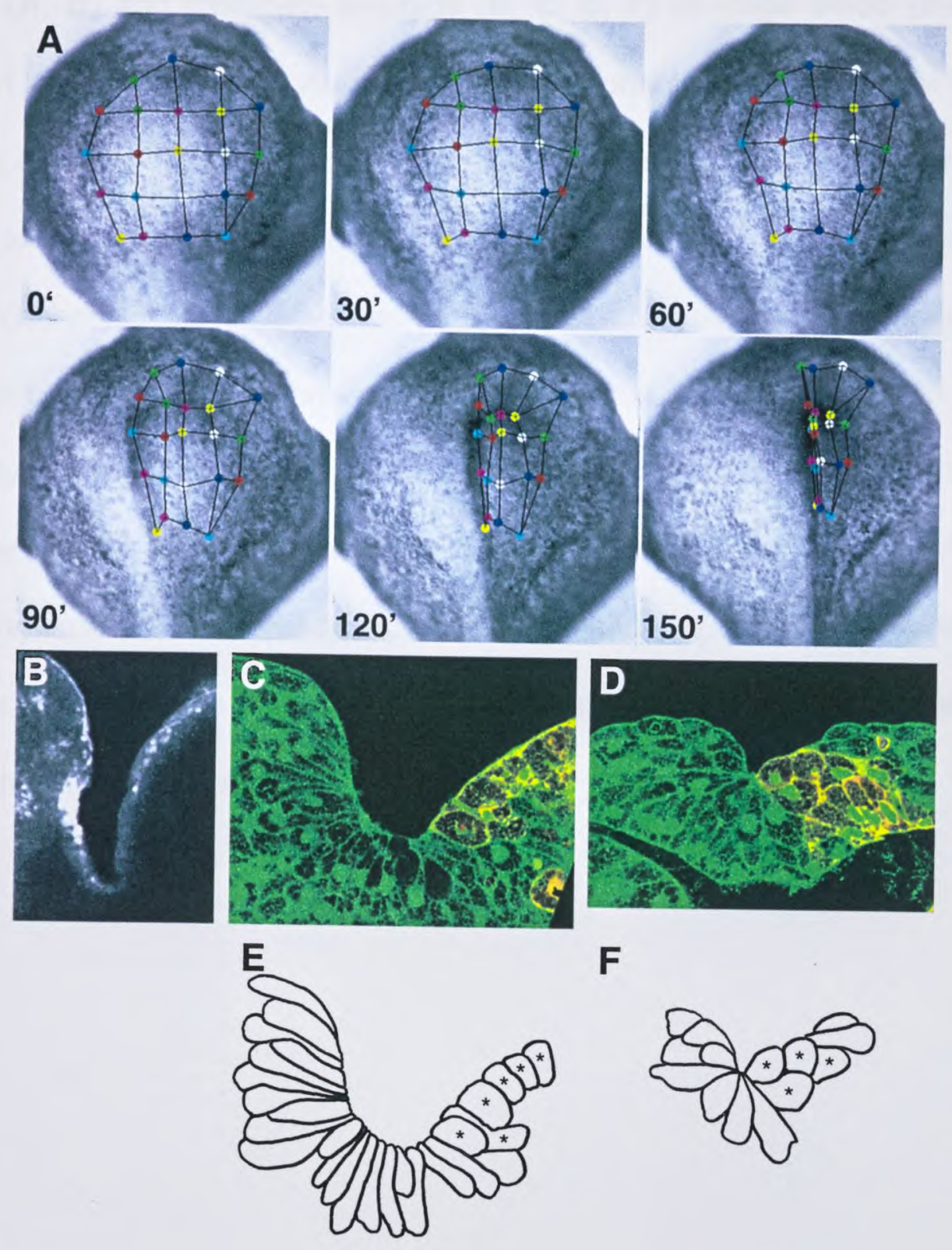

F

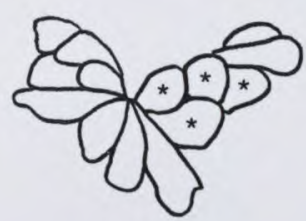


Figure 3-5. Neural targeted MHC-B MO causes dorsal flexure, eye and melanophore defects.

Control (A, D) and morphant embryos (B, C, E, F) at stage 34-35 (A-C) and stage 41 (D-F) are shown. At stage 34-35, morphant embryos display varying degrees of dorsal flexure, classified into 3 categories: similar to wild-type, type I (similar to $\mathbf{B}$ ) and type II (similar to $\mathbf{C}$ ), which are quantified in (G). At this stage, an eye phenotype can be observed in morphant embryos, and it becomes more apparent by stage 41 . Eye phenotypes were classified into 3 categories: similar to wild-type, type I (similar to $\mathbf{B}$ or $\mathbf{E}$ ) and type II (similar to $\mathbf{C}$ or $\mathbf{F}$ ), which are quantified in $(\mathbf{G})$. Stage 41 morphant embryos show defects in the number, spreading, and distribution of flank and head melanophores (D, E, F), divided into 3 categories: similar to wild-type, type I (similar to E) and type II (similar to F), which are quantified in (G). 

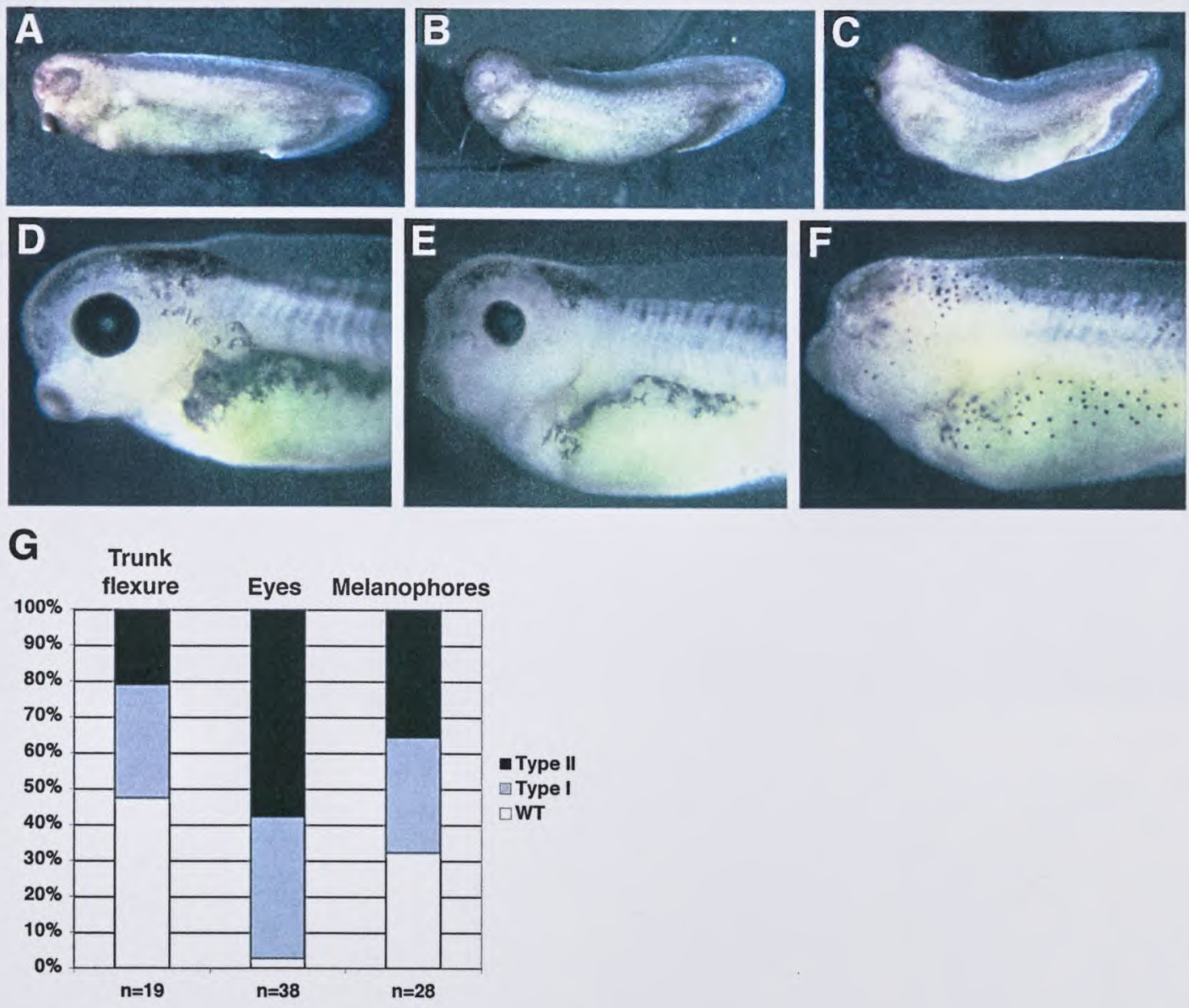
Figure 3-6. Neural targeted MHC-B MO causes brain and eye defects.

(A) Brains dissected from stage 41 morphant embryos (right side) are shorter and misshapen compared to control brains of the same stage (left side). $\mathrm{Fb}-$ forebrain, $\mathrm{Mb}$ - midbrain, $\mathrm{Hb}$ - hindbrain, SC - spinal cord.

(B-D) Transverse sections through the optic region of stage 34-35 embryos are shown, in which green is fluorescence from dextran injected at the two-cell stage, and red is fluorescence from dextran co-injected with the MHC-B MO. Control embryos (B) have well-defined optic cups and brains with key-hole shaped ventricles, whereas morphant embryos (C-D) display malformed optic cups and slit shaped brain ventricles. No - notochord. 

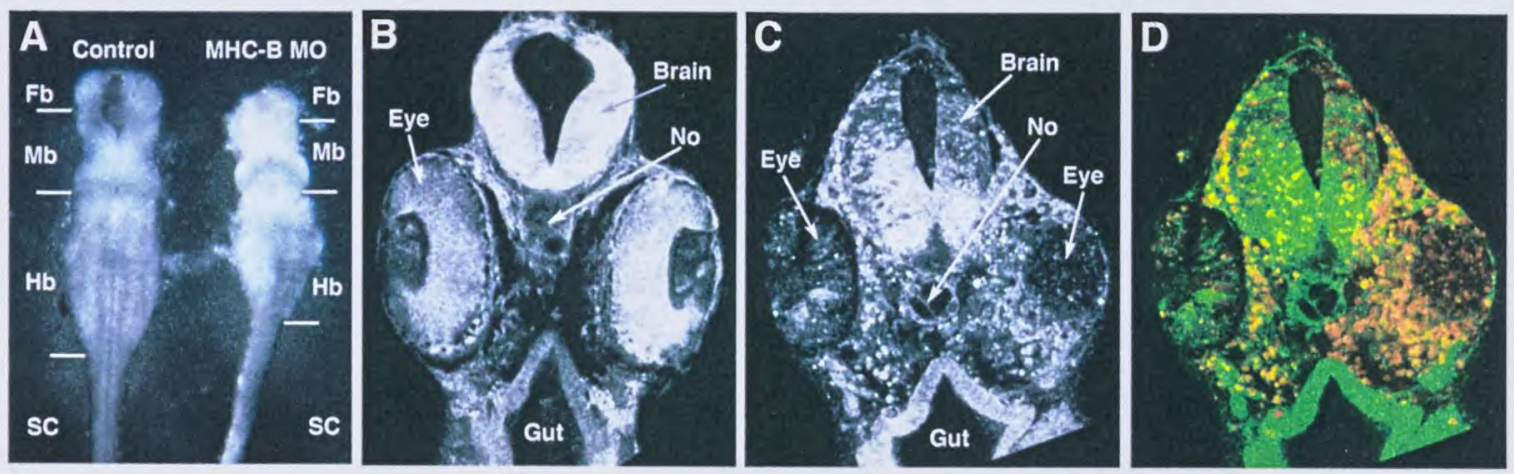
Figure 3-7. Neural targeted MHC-B MO impairs autonomous neural CE.

(A-B) Keller sandwich explants made from control (A) and morphant (B) embryos are shown, with arrows indicating the boundaries between neural (top) and mesodermal (bottom) tissues. (B') Red fluorescence from dextran co-injected with the MO in the morphant embryos in (B) is shown.

(C) The extension of neural and mesodermal tissues in control and morphant Keller sandwiches is measured by the final length of tissues in arbitrary units (AU). Error bars are s.e.m., p-values were calculated using Student's t-test. 

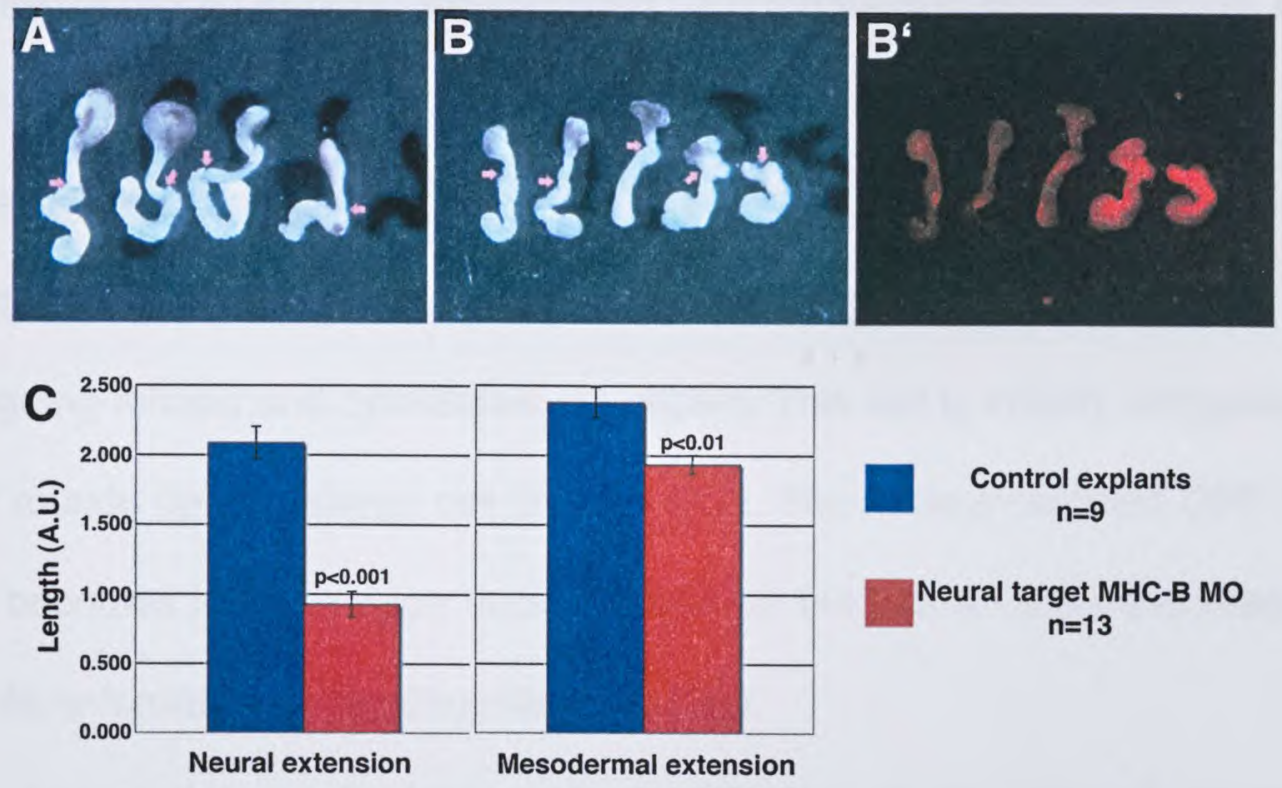
Control explants
$n=9$

Neural target MHC-B MO $n=13$ 
Figure 3-8. MHC-B reduction causes defects in cell shape and in the cytoskeleton.

(A-G) Confocal images of neural deep cells in live neural-deep-over-mesoderm explants are shown.

(A-C) Neural deep cells from embryos injected at the two-cell stage with membrane-targeted GFP mRNA and at the 32-cell stage with nuclear-targeted GFP mRNA alone $(\mathbf{A})$ or nuclear-targeted GFP mRNA and MHC-B MO $(\mathbf{B}, \mathbf{C})$ are shown. Morphant cells (B) are more elongated than control ones (A). Scale bar in (A) also applies to (B).

(C) Still images from a time-lapse video-recording of (B) focusing on a cell undergoing mitosis and cytokinesis are shown. This cell is initially elongated $\left(0^{\prime}\right)$, and it rounds up to undergo cell division (33'). The nuclear-targeted GFP (NLSGFP) becomes invisible upon nuclear envelope breakdown (23') and reappears upon its re-formation in the daughter cells (58').

(D-G) Neural deep cells from embryos injected at the two-cell stage with membrane targeted RFP mRNA and at the 32-cell stage with F-actin targeted GFP mRNA alone (D) or F-actin targeted GFP mRNA and MHC-B MO at $2 \mu \mathrm{M}$ (E) or at $2.5 \mu \mathrm{M}(\mathbf{F}, \mathbf{G})$ are shown. Control cells have well-organized network of actin bundles that radiate from foci within the cell (D). At a MO concentration of $2 \mu \mathrm{M}$, elongated morphant cells have longer actin cables than control cells, and they are not organized in foci and they run parallel to direction of elongation (E). At a $\mathrm{MO}$ concentration of $2.5 \mu \mathrm{M}$, morphant cells have either a few coarse thick actin 
cables (F) or the actin cables are almost absent (G). Scale bar in (D) also applies to $(E-G)$. 

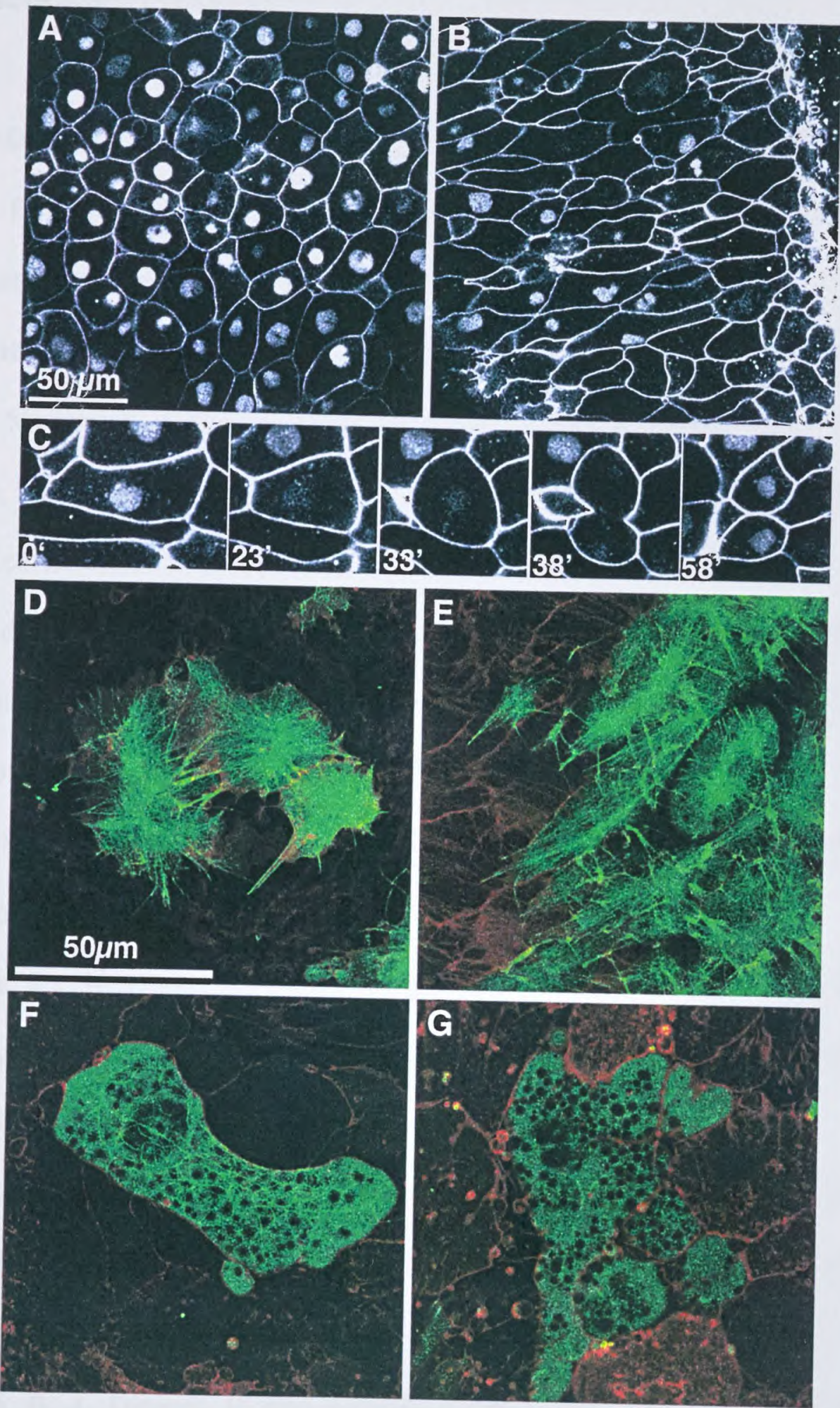


\section{REFERENCES}

Bhatia-Dey, N., Taira, M., Conti, M. A., Nooruddin, H. and Adelstein, R. S. (1998). Differential expression of non-muscle myosin heavy chain genes during Xenopus embryogenesis. Mech Dev 78, 33-6.

Bridgman, P. C., Dave, S., Asnes, C. F., Tullio, A. N. and Adelstein, R. S. (2001). Myosin IIB is required for growth cone motility. J Neurosci 21, 6159-69.

Brown, M. E. and Bridgman, P. C. (2003). Retrograde flow rate is increased in growth cones from myosin IIB knockout mice. J Cell Sci 116, 1087-94.

Burnside, M. B. and Jacobson, A. G. (1968). Analysis of morphogenetic movements in the neural plate of the newt Taricha torosa. Dev Biol 18, 537-52.

Casarosa, S., Andreazzoli, M., Simeone, A. and Barsacchi, G. (1997). Xrx1, a novel Xenopus homeobox gene expressed during eye and pineal gland development. Mech Dev61, 187-98.

Chitnis, A., Henrique, D., Lewis, J., Ish-Horowicz, D. and Kintner, C. (1995). Primary neurogenesis in Xenopus embryos regulated by a homologue of the Drosophila neurogenic gene Delta. Nature 375, 761-6.

Davidson, L. A., Keller, R. and DeSimone, D. W. (2004). Assembly and remodeling of the fibrillar fibronectin extracellular matrix during gastrulation and neurulation in Xenopus laevis. Dev Dyn 231, 888-95.

Detrick, R. J., Dickey, D. and Kintner, C. R. (1990). The effects of N-cadherin misexpression on morphogenesis in Xenopus embryos. Neuron 4, 493-506. 
Drawbridge, J. and Steinberg, M. S. (2000). Elongation of axolotl tailbud embryos requires GPI-linked proteins and organizer-induced, active, ventral trunk endoderm cell rearrangements. Dev Bio/ 223, 27-37.

Egelhoff, T. T., Naismith, T. V. and Brozovich, F. V. (1996). Myosin-based cortical tension in Dictyostelium resolved into heavy and light chain-regulated components. J Muscle Res Cell Motil 17, 269-74.

Elul, T. and Keller, R. (2000). Monopolar protrusive activity: a new morphogenic cell behavior in the neural plate dependent on vertical interactions with the mesoderm in Xenopus. Dev Biol 224, 3-19.

Elul, T., Koehl, M. A. and Keller, R. (1997). Cellular mechanism underlying neural convergent extension in Xenopus laevis embryos. Dev Biol 191, 243-58.

Espeseth, A., Johnson, E. and Kintner, C. (1995). Xenopus F-cadherin, a novel member of the cadherin family of cell adhesion molecules, is expressed at boundaries in the neural tube. Mol Cell Neurosci 6, 199-211.

Ezin, A. M., Skoglund, P. and Keller, R. (2003). The midline (notochord and notoplate) patterns the cell motility underlying convergence and extension of the Xenopus neural plate. Dev Biol 256, 100-14.

Golomb, E., Ma, X., Jana, S. S., Preston, Y. A., Kawamoto, S., Shoham, N. G., Goldin, E., Conti, M. A., Sellers, J. R. and Adelstein, R. S. (2004). Identification and characterization of nonmuscle myosin II-C, a new member of the myosin II family. J Biol Chem 279, 2800-8. 
Goto, T., Davidson, L., Asashima, M. and Keller, R. (2005). Planar cell polarity genes regulate polarized extracellular matrix deposition during frog gastrulation. Curr Biol 15, 787-93.

Gupton, S. L., Anderson, K. L., Kole, T. P., Fischer, R. S., Ponti, A., Hitchcock-DeGregori, S. E., Danuser, G., Fowler, V. M., Wirtz, D., Hanein, D. et al. (2005). Cell migration without a lamellipodium: translation of actin dynamics into cell movement mediated by tropomyosin. J Cell Biol 168, 619-31.

Haigo, S. L., Hildebrand, J. D., Harland, R. M. and Wallingford, J. B. (2003). Shroom induces apical constriction and is required for hingepoint formation during neural tube closure. Curr Biol 13, 2125-37.

Harland, R. M. (1991). In situ hybridization: an improved whole-mount method for Xenopus embryos. Methods Cell Biol 36, 685-95.

Hildebrand, J. D. (2005). Shroom regulates epithelial cell shape via the apical positioning of an actomyosin network. J Cell Sci 118, 5191-203.

Jacobson, A. G. and Gordon, R. (1976). Changes in the shape of the developing vertebrate nervous system analyzed experimentally, mathematically and by computer simulation. J Exp Zool 197, 191-246.

Katsuragawa, Y., Yanagisawa, M., Inoue, A. and Masaki, T. (1989). Two distinct nonmuscle myosin-heavy-chain mRNAs are differentially expressed in various chicken tissues. Identification of a novel gene family of vertebrate nonsarcomeric myosin heavy chains. Eur J Biochem 184, 611-6. 
Kawamoto, S. and Adelstein, R. S. (1991). Chicken nonmuscle myosin heavy chains: differential expression of two mRNAs and evidence for two different polypeptides. J Cell Biol 112, 915-24.

Keller, R. and Danilchik, M. (1988). Regional expression, pattern and timing of convergence and extension during gastrulation of Xenopus laevis. Development 103, 193-209.

Keller, R., Shih, J. and Sater, A. (1992a). The cellular basis of the convergence and extension of the Xenopus neural plate. Dev Dyn 193, 199-217.

Keller, R., Shih, J., Sater, A. K. and Moreno, C. (1992b). Planar induction of convergence and extension of the neural plate by the organizer of Xenopus. Dev Dyn 193, 218-34.

Kelley, C. A., Oberman, F., Yisraeli, J. K. and Adelstein, R. S. (1995). A Xenopus nonmuscle myosin heavy chain isoform is phosphorylated by cyclinp34cdc2 kinase during meiosis. J Biol Chem 270, 1395-401.

Kelley, C. A., Sellers, J. R., Gard, D. L., Bui, D., Adelstein, R. S. and Baines, I. C. (1996). Xenopus nonmuscle myosin heavy chain isoforms have different subcellular localizations and enzymatic activities. J Cell Biol 134, 675-87.

Kintner, C. R. and Melton, D. A. (1987). Expression of Xenopus N-CAM RNA in ectoderm is an early response to neural induction. Development 99, 311-25.

Kovacs, M., Wang, F., Hu, A., Zhang, Y. and Sellers, J. R. (2003). Functional divergence of human cytoplasmic myosin II: kinetic characterization of the nonmuscle IIA isoform. J Biol Chem 278, 38132-40. 
Kroll, K. L. and Amaya, E. (1996). Transgenic Xenopus embryos from sperm nuclear transplantations reveal FGF signaling requirements during gastrulation. Development 122, 3173-83.

Laevsky, G. and Knecht, D. A. (2003). Cross-linking of actin filaments by myosin II is a major contributor to cortical integrity and cell motility in restrictive environments. J Cell Sci 116, 3761-70.

Larkin, K. and Danilchik, M. V. (1999). Ventral cell rearrangements contribute to anterior-posterior axis lengthening between neurula and tailbud stages in Xenopus laevis. Dev Biol 216, 550-60.

Litman, P., Amieva, M. R. and Furthmayr, H. (2000). Imaging of dynamic changes of the actin cytoskeleton in microextensions of live NIH3T3 cells with a GFP fusion of the F-actin binding domain of moesin. BMC Cell Biol 1, 1.

Lo, C. M., Buxton, D. B., Chua, G. C., Dembo, M., Adelstein, R. S. and Wang, Y. L. (2004). Nonmuscle myosin IIb is involved in the guidance of fibroblast migration. Mol Biol Cell 15, 982-9.

Ma, X., Kawamoto, S., Hara, Y. and Adelstein, R. S. (2004). A point mutation in the motor domain of nonmuscle myosin II-B impairs migration of distinct groups of neurons. Mol Biol Cell 15, 2568-79.

Ma, X., Kawamoto, S., Uribe, J. and Adelstein, R. S. (2006). Function of the neuron-specific alternatively spliced isoforms of nonmuscle myosin II-B during mouse brain development. Mol Biol Cell 17, 2138-49. 
Mayor, R., Morgan, R. and Sargent, M. G. (1995). Induction of the prospective neural crest of Xenopus. Development 121, 767-77.

Moore, S. W. (1992). Direct measurement of dynamic biomechanical properties of amphibian embryonic tissues, (ed., pp. 400. Berkeley, CA: University of California at Berkeley.

Nieuwkoop, P. D. and Faber, J. (1994). Normal Table of Xenopus laevis (Daudin), (ed. New York: Garland Publishing.

Rosenfeld, S. S., Xing, J., Chen, L. Q. and Sweeney, H. L. (2003). Myosin Ilb is unconventionally conventional. J Biol Chem 278, 27449-55.

Schoenwolf, G. C. and Smith, J. L. (1990). Mechanisms of neurulation: traditional viewpoint and recent advances. Development 109, 243-70.

Shewan, A. M., Maddugoda, M., Kraemer, A., Stehbens, S. J., Verma, S., Kovacs, E. M. and Yap, A. S. (2005). Myosin 2 is a key Rho kinase target necessary for the local concentration of E-cadherin at cell-cell contacts. Mol Biol Cell 16, 4531-42.

Sive, H. L., Grainger, R. M. and Harland, R. M. (2000). Early Development of Xenopus laevis. Cold Spring Harbor, New York: Cold Spring Harbor Laboratory Press.

Stubbs, J. L., Davidson, L., Keller, R. and Kintner, C. (2006). Radial intercalation of ciliated cells during Xenopus skin development. Development $133,2507-15$. 
Svitkina, T. M., Verkhovsky, A. B., McQuade, K. M. and Borisy, G. G. (1997). Analysis of the actin-myosin II system in fish epidermal keratocytes: mechanism of cell body translocation. J Cell Biol139, 397-415.

Tullio, A. N., Bridgman, P. C., Tresser, N. J., Chan, C. C., Conti, M. A., Adelstein, R. S. and Hara, Y. (2001). Structural abnormalities develop in the brain after ablation of the gene encoding nonmuscle myosin II-B heavy chain. $J$ Comp Neurol 433, 62-74.

Wallingford, J. B. and Harland, R. M. (2001). Xenopus Dishevelled signaling regulates both neural and mesodermal convergent extension: parallel forces elongating the body axis. Development 128, 2581-92.

Wallingford, J. B. and Harland, R. M. (2002). Neural tube closure requires Dishevelled-dependent convergent extension of the midline. Development 129, 5815-25.

Wang, F., Kovacs, M., Hu, A., Limouze, J., Harvey, E. V. and Sellers, J. R. (2003). Kinetic mechanism of non-muscle myosin IIB: functional adaptations for tension generation and maintenance. J Biol Chem 278, 27439-48.

Xu, X. S., Lee, E., Chen, T., Kuczmarski, E., Chisholm, R. L. and Knecht, D. A. (2001). During multicellular migration, myosin ii serves a structural role independent of its motor function. Dev Biol 232, 255-64. 


\section{Chapter 4}

\section{Myosins IIA and IIB have different roles in gastrulation and elongation of the body axis in Xenopus}

The work presented in this chapter was done in collaboration with Paul Skoglund, who designed the morpholino-oligonucleotides (MOs) and did the immunostainings and the Western blots. 
119

SUMMARY

Myosins IIA and IIB have distinct sub-cellular localizations in cultured cells, distinct regional patterns of expression in Xenopus embryos, and different biochemical properties in their ATPase rates, actin binding and actin filament translocation kinetics. Myosin IIB is expressed predominantly in the dorsal tissues of the embryo, and it is required for convergence and extension (CE) movements that provide most of the force driving closure of the blastopore in normal Xenopus embryos. Here I show that myosin IIA is expressed ubiquitously in the embryo, and it is required for the ventral convergent movements that close the ventral blastoporal lip in normal embryos, and that drive blastopore closure in ventralized embryos, which do not undergo CE. Conversely, myosin IIB is dispensable for ventral convergence-driven blastopore closure in ventralized embryos, whereas it is necessary for CE-driven blastopore closure in normal embryos. During antero-posterior elongation of the body axis, myosin IIB is required for elongation of the dorsal aspect of the trunk, which occurs by CE, whereas myosin II A is necessary for elongation of the ventral side of the embryo by a cellular mechanism that is not understood. 


\section{INTRODUCTION}

Studies of morphogenetic movements that drive blastopore closure and shaping of the body plan during early morphogenesis in Xenopus have been mainly focused on the process of convergence and extension (CE) of the dorsal tissues. CE movements have been characterized not only in terms of the cell behaviors that drive its execution (Elul and Keller, 2000; Elul et al., 1997; Ezin et al., 2003; Ezin et al., 2006; Shih and Keller, 1992a; Shih and Keller, 1992b) and see Chapter 1), but also in terms of the molecular pathways that regulate such behaviors (Goto et al., 2005; Goto and Keller, 2002; Tahinci and Symes, 2003; Wallingford et al., 2000). Much less is known about the morphogenetic processes that operate in the ventral tissues of the early embryo, even though they must act in concert with the dorsal processes in order to execute the global shape changes that take in the early embryonic body plan.

In a normal Xenopus embryo, blastopore closure is mainly driven by $\mathrm{CE}$ movements occuring in the dorsal marginal zone, leading to an anisotropic, ventrally located site of blastopore closure (Keller et al., 1992). CE is also responsible for lengthening of the dorsal tissues of the embryo (Keller et al., 1992; Shih and Keller, 1992a; Wilson and Keller, 1991). Thus, perturbations in molecular pathways necessary for CE generally lead to phenotypes consisting of open blastopores and/or dorsally bent trunks (Chen and Gumbiner, 2006; Choi and Han, 2002; Ewald et al., 2004; Goto et al., 2005; Nutt et al., 2001; Skoglund 
and Keller, 2006; Tahinci and Symes, 2003; Wallingford et al., 2000; Winklbauer et al., 2001).

A less well-characterized morphogenic event occurs in the ventral marginal zone of the gastrula, and contributes to closure of the ventral blastopore lip (Keller and Danilchik, 1988; Keller and Shook, 2004). This ventral movement converges the ventral marginal zone, but does so without extension, producing thickening instead, and thus it has been called convergent thickening $(C T)$ (Keller and Danilchick, 1988). In UV-ventralized embryos, in which dorsal tissues do not develop and therefore CE does not occur (Scharf and Gerhart, 1983), the blastopore nevertheless closes (Scharf and Gerhart, 1980) and it is likely that it does so by CT of the entire marginal zone (this Chapter and Shook et al., in preparation).

After gastrulation and blastopore closure the embryo undergoes dramatic anteroposterior elongation. Both the dorsal and ventral sectors of the embryos have to extend in concert in order to achieve a straight body axis (Wallingford and Harland, 2001), but the dorsal and ventral elongations are independent of one another (Larkin and Danilchik, 1999).

Myosin IIB is an actin-based motor protein expressed predominantly in the dorsal tissues of the embryo and necessary for CE of the dorsal mesoderm and neural tissue, as described in Chapters 2 and 3 . In this Chapter I examine the roles of myosin IIA in Xenopus morphogenesis, and compare it with myosin IIB. I show that myosin IIA is expressed ubiquitously in the embryo, and it is required 
for ventral morphogenetic processes of CT during blastopore closure, as well as for ventral elongation. 


\section{MATERIALS AND METHODS}

\section{Embryos and UV-treatment}

Xenopus laevis embryos were obtained and dejellied by standard methods (Sive et al., 2000) and staged according to Nieuwkoop and Faber (1994). Embryos were UV-treated according to Sive et al. (2000), for 6' within 30' of fertilization with an UV-transilluminator (Fotodyne, Hartland, WI).

\section{Whole-mount immunostaining and Western blotting}

MHC-A was detected with an MHC-A isoform specific antibody (Covance, Berkeley, CA).

For whole-mount immunochemistry albino embryos were fixed in MEMFA for 2 hours at room temperature and stored in methanol at $-20^{\circ} \mathrm{C}$ for an overnight period or longer. Primary antibody was used at 1:100 and anti-rabbit alkaline phosphatase conjugated secondary antibody (Invitrogen - Molecular Probes, Carlsbad, CA) at 1:250. Detection was done using NBT/BCIP reagents (Sigma, St. Louis, MO).

Western blots were performed as described (Skoglund et al., 2006) using stage 12 embryo extracts, which were concentrated and dialyzed with Centricon 100 collumns (Millipore, Bedford, MA) and run on 5\% acrylamide gels. Primary antibody was used at 1:250, secondary anti-rabbit alkaline phosphatase antibody (Invitrogen - Molecular Probes, Carlsbad, CA) was used at 1:500, and a tertiary 
124

anti-alkaline phosphatase alkaline phosphatase antibody (Roche - BMB, Indianapolis, IN) was used at 1:50 for amplification of signal. Densitometry was done as described (Skoglund et al., 2006).

Morpholino oligonucleotides

A morpholino-oligonucleotide (MO) directed against the start site of MHCA (CTTGTCCACATCTGTTTGTGCCAT) was produced (Gene Tools, Philomath, OR), as well as a control $\mathrm{MO}$ that varies at five nucleotides (CTTcTCCAgATCTCTTTCTGCgAT). MHC-B MO was done as described in Chapter 2. Two-cell stage embryos were injected with 5 or $10 \mathrm{pmol}$ of MHC-A $\mathrm{MO}$ per blastomere to obtain final $\mathrm{MO}$ concentrations of 10 or $20 \mu \mathrm{M}$, respectively. Two-cell stage embryos were injected with $3.75 \mathrm{pmol}$ of MHC-B MO per blastomere to obtain a final $\mathrm{MO}$ concentration of $7.5 \mu \mathrm{M}$. Four-cell stage embryos were injected in two dorsal or ventral blastomeres with 5 mol MHC-A $\mathrm{MO}$ per blastomere to obtain a final MO concentration of $20 \mu \mathrm{M}$. 


\section{RESULTS}

\section{Myosin IIA is expressed ubiquitously and functions in several} morphogenic events

Myosin IIA localization in the embryo was analyzed by whole-mount immunostaining using the MHC-A specific antibody. At tailbud stages, MHC-A is detected ubiquitously in the embryo (Fig. 4-1A), whereas MHC-B is expressed predominantly in the dorsal tissues (see Figs. 2-1 and 3-1).

Injection of a $\mathrm{MO}$ against the start site of the MHC-A gene at a final concentration of $20 \mu \mathrm{M}$ in both blastomeres of the 2-cell stage embryo results in a $75 \%$ reduction in protein levels (Fig. 4-1B). A control MO, mispaired at five sites, does not affect development when injected at concentrations up to $20 \mu \mathrm{M}$, but causes defects above that concentration (not shown). Therefore $20 \mu \mathrm{M}$ was the maximal dose used for the MHC-A MO. At half-maximal dose $(10 \mu \mathrm{M})$, the MHC-A MO causes no apparent defects (not shown). At maximal dose (20 $\mu \mathrm{M}), \mathrm{MHC}-\mathrm{A}$ morphant embryos are similar to control embryos up until the onset of gastrulation, when the first defect, a reduction and delay in formation of areas of dark pigmentation at the forming dorsal blastoporal lip (Fig. 4-3A, $C, t=0$ ), becomes apparent. These darkly pigmented areas correspond in more than $95 \%$ of the cases to the formation of bottle cells (Hardin and Keller, 1988). Bottle cells are not necessary for blastopore closure (Hardin and Keller, 1988; Keller, 1981), and indeed most (80\%) MHC-A morphant embryos successfully close their 
blastopores (Fig. 4-3E), although they are delayed compared to controls (Fig. 4$3 A, C)$. Another way that blastopore closure differs from controls in morphant embryos is the extreme ventral position at which it occurs (Fig. 4-3A, $C, t=7.5$, arrowheads), suggesting that it is mostly achieved by the dorsal processes of $\mathrm{CE}$, and that the ventral convergence is diminished.

Later in development, at early tailbud stages, morphant embryos exhibit shorter body axes and a very pronounced ventral flexure compared to controls (Fig. 4-1C, D), indicating that elongation of the ventral tissues is more affected than dorsal elongation. Other defects include reduced eyes and malformed heads (Fig. 4-1D, pointer), indicating that myosin IIA is required in multiple morphogenic processes. At late tailbud stages a cell adhesion defect becomes apparent, and morphant embryos start to shed cells and eventually dissociate into individual cells (not shown).

\section{MHC-A MO defects are more pronounced when targeted to ventral tissues}

To differentiate the roles of myosin IIA in dorsal and ventral morphogenesis, MHC-A MO was injected in either the dorsal or the ventral blastomeres at the 4-cell stage. When MHC-A MO is targeted to dorsal tissues the morphant embryos are shorter than controls, with relatively straight bodies and malformed heads and eyes (Fig. 4-2B). When targeted to the ventral side, MHC-A MO causes the embryos to be even shorter (about half the length of 
control embryos, if measured in a straight line from head to tailbud) and curved ventrally (Fig. 4-2C).

\section{MHC-A MO prevents blastopore closure in UV-ventralized embryos}

Irradiation of the vegetal pole of embryos with UV light at the 1-cell stage disrupts microtubules and blocks cortical rotation, a process necessary for the specification of dorsal tissues (Scharf and Gerhart, 1980), and thus UV-treated embryos do not express dorsal tissue specific markers (Smith and Knowland, 1984). Most of these embryos ( 90\%) successfully close their blastopores (Figs. 4-3E and 4-4E), however the mechanism used is distinct from normal embryos in that it occurs in an isotropic fashion (Figs. 4-3A, B, and 4-4A, B) (also see Shook et al., in preparation). Blastopore lip formation is delayed in ventralized embryos, and it only begins when ventral bottle cells start to appear in control embryos and occurs simultaneously all around the blastopore at this time (Figs. 4-3A, B and 4$4 \mathrm{~A}, \mathrm{~B}, \mathrm{t}=2.5$ ). Then blastopore closure proceeds at the same rate all around the marginal zone, which leads to a central site of blastopore closure that is neither ventrally nor dorsally biased (Figs. 4-3A, $B$, arrowheads, and 4-4A, $B, t=7.5$ ). Since the entire marginal zone of these embryos is ventral in character, blastopore closure is thought to occur by expression of CT all around the blastopore, instead of just on the ventral side (Keller and Danilchik, 1988).

The extreme ventral position at which the blastopore closes in MHC-A morphant embryos (Fig. 4-3C) suggests an involvement of myosin IIA in ventral 
convergence. To test this idea, ventralized embryos were injected with MHC-A MO and assayed for blastopore closure. This treatment greatly reduces the number of embryos that close their blastopores (Fig. 4-3D, E), consistent with myosin IIA being necessary for the ventral mode of blastopre lip closure.

\section{UV treatment rescues blastopore closure in MHC-B morphants}

In Chapter 2, I showed that myosin IIB is necessary for CE of the dorsal marginal zone and thus for blastopore closure, most of which is driven by CE in normal embryos, but it does not appear to be involved in convergence of the ventral marginal zone in these experiments. To confirm this hypothesis, ventralized embryos were injected with MHC-B MO at $7.5 \mu \mathrm{M}$ and assayed for blastopore closure. At a concentration of $7.5 \mu \mathrm{M}$, most (70\%) MHC-B morphant embryos do not close their blastopores (Fig. 4-4C, E), but the same concentration of MHC-B MO injected into ventralized embryos allows blastopore closure at levels similar to non-morphant ventralized embryos (Fig. 4-4D, E). This is consistent with the fact that ventralized embryos close their blastopores by CT, which doesn't require myosin IIB. These double-treated, ventralized and MHC-B morphant embryos will, however, display cell adhesion defects later in development and fall apart into single cells (not shown), consistent with a role of myosin IIB in cell adhesion described in Chapter 2. This phenotype is not restricted to the dorsal regions of the embryo, commensurate with the broader use of myosin IIB later in development. 
Myosins IIA and IIB are both required for and act synergistically in cell adhesion

To examine whether myosins IIA and IIB have overlapping functions, both MHC-A and MHC-B MOs were injected simultaneously, at concentrations at which either $\mathrm{MO}$ alone produces little or no defects in morphogenesis. These concentrations are $8 \mu \mathrm{M}$ for MHC-A and $2 \mu \mathrm{M}$ for MHC-B. When coinjected, the two MOs cause a completely penetrant failure in blastopore closure (Fig. 4-5B), whereas neither $\mathrm{MO}$ alone at these concentrations affects blastopore closure by itself. Also, double morphant embryos start to shed cells at late gastrula/early neurula stages (not shown), and late neurula embryos, when removed from their vitelline membranes, readily dissociate into individual cells (Fig. 4-5D, arrows). These results indicate that myosins IIA and IIB have synergistic functions at gastrulation, particularly in terms of their roles in adhesion. 


\section{DISCUSSION}

In this Chapter, I show that myosin IIA is expressed broadly throughout the embryo, in contrast with myosin IIB, which is predominantly expressed in dorsal tissues (see Chapters 2 and 3). I show that myosin IIA has several roles in morphogenesis, and that most of them are distinct from the roles of myosin IIB. MHC-A reduction causes a delay and reduction in formation of dark areas of concentrated pigment at the blastopore lip at gastrulation, a phenotype that suggests a defect in bottle cell formation and that is not observed in MHC-B morphant embryos. During blastopore closure, myosin IIA functions predominantly in the process of ventral convergence, whereas myosin IIB functions in dorsal CE. After gastrulation, myosin IIA is required for ventral elongation, which contrasts with myosin IIB requirement for dorsal elongation, described in Chapter 2. Despite having different roles in morphogenesis, myosins IIA and IIB also have overlapping and synergistic functions in blastopore closure and in cell adhesion.

\section{Different roles for myosins IIA and IIB in blastopore closure}

In Chapter 2, I described a role for myosin IIB in CE of the dorsal marginal zone, which is the main force driving blastopore closure in normal embryos (Keller and Danilchik, 1988). Thus, blastopore closure fails or is retarded in MHCB morphant embryos presumably due to perturbations in CE. In this Chapter, I further demonstrate that this is the case, since UV-ventralization can rescue 
blastopore closure in MHC-B morphant embryos that would otherwise not close their blastopores. This is because blastopore closure in ventralized embryos does not involve CE, and it most likely is achieved by CT movements, which do not require myosin IIB.

CT was described as a convergence that produced thickening instead of extension during the convergence of the ventral sector of the blastoporal lip, based on behavior during involution of vital dyed grafts of tissues in this region (Keller and Tibbetts, 1989) and behavior of ventral explants of the Xenopus marginal zone (Keller and Danilchik, 1988). Also, based on the fact that ventralized Xenopus embryos appear to close their blastopore (Scharf and Gerhart, 1980), it has been thought that CT might be solely responsible for this event in ventralized embryos (Keller and Shook, 2004). CT was described at the tissue level, gleaning clues from several papers, and nothing is known of its cellular basis. Thus it has never been clear whether this was a legitimate morphogenetic movement or some passive response to global forces in the embryo. Recently two observations lend support to the notion that this is a real, regional morphogenic movement that deserves investigation at the cellular and molecular level. First, I show here that myosin IIA knockdowns block blastopore closure in UV-ventralized embryos, and that the same manipulation appears to block ventral convergence in non-ventralized embryos, thus resulting in an extreme, abnormal ventral point of closure, solely driven by dorsal CE in these embryos. Moreover, myosin IIA knockdown does not block the dorsal CE. 
Second, myosin IIB knockdowns do not block blastopore closure in ventralized embryos but do block dorsal, CE-mediated closure in normal embryos. Together, these observations strongly suggest a different underlying molecular mechanism for $\mathrm{CT}$ and $\mathrm{CE}$, and thus lends support to the notion that this is a real morphogenetic movement. In addition, involuting marginal zones from ventralized Xenopus embryos can exert tensile forces, which would be circumblastoporal forces in the embryo (D. Shook, unpublished experiments), further lending support to the idea that CT is a legitimate, force-producing mechanism independent of CE.

A more detailed discussion on different mechanisms contributing to blastopore closure in normal, ventralized and morphant embryos is presented in Chapter 6.

Different roles for myosins IIA and IIB in antero-posterior elongation of the dorsal and ventral aspects of the body axis

One of the most striking differences between MHC-A and MHC-B morphant embryos is that, despite the embryo being shorter than controls in both cases, MHC-A morphants display a severe ventral flexure, whereas weaker MHC-B morphants, which can gastrulate, subsequently flex dorsally. This dorsal flexure of MHC-B morphant embryos is explained by a requirement of myosin IIB in $\mathrm{CE}$, which not only drives blastopore closure but also elongates the dorsal tissues of the embryo during neurulation and tailbud stages, as discussed in 
Chapter 2. Myosin IIA, on the other hand, affects ventral elongation, and its reduction results in an embryo curved ventrally. Also, targeting MHC-A to the ventral side of embryos produces a more severe impaired elongation phenotype than dorsal targeting. The mechanism that elongates the ventral half of the embryo is poorly understood. There is evidence that medio-lateral cell intercalation of the ventral mesodermal cells may be involved (Larkin and Danilchik, 1999), but there is no evidence that this intercalation is active, and a role for the endodermal tissues cannot be ruled out. In the urodele, ventral elongation is thought to involve cell rearrangements that occur in the ventral endoderm (Drawbridge and Steinberg, 2000). Future experiments involving targeting of MHC-A MO to the ventral mesoderm or endoderm may help discern the relative contributions of these two tissues for extension of the ventral half of the embryo.

\section{Roles for myosin IIA in dorsal morphogenesis}

Myosin IIA appears to be the main myosin II isoform required in ventral tissues for movements of CT and ventral elongation, but it also contributes to dorsal morphogenetic events, since its decrease leads to defects in brain and eyes. Furthermore, dorsally targeted MHC-A morphants differ from control embryos in having defects in the brain and eyes, and they are also shorter than controls. Therefore a role, overlapping with myosin IIB, in CE is likely. These contributions of myosin IIA for dorsal morphogenesis are not explored in this 
work, but future avenues of research aimed at describing the roles of this protein in $\mathrm{CE}$ and in neural morphogenesis should illuminate the relative contributions of myosin II isoforms in dorsal morphogenesis. In summary, given the defects caused by their depletions and their distributions in the embryo, I postulate that ventral morphogenesis is mostly dependent on myosin IIA, which is the isoform predominantly expressed in ventral tissues, whereas dorsal morphogenesis depends upon both $\mathrm{A}$ and $\mathrm{B}$ myosin isoforms, which are co-expressed in dorsal tissues. 
Figure 4-1. MHC-A is expressed ubiquitously and is required for ventral extension.

(A) A tailbud stage embryo immunostained with MHC-A antibody shows ubiquitous expression of this protein.

(B) A Western blot shows reduction of MHC-A protein levels in embryos injected with 10 or $20 \mu \mathrm{M}$ MHC-B MO.

(C, D) Comparison of early tailbud stage uninjected control (C) and an embryo injected at 2-cell stage with $20 \mu \mathrm{M}$ MHC-A MO (D) shows shorter axis and ventral flexure resulting from defective ventral extension, as well as head and eye defects (pointer) in the latter. 


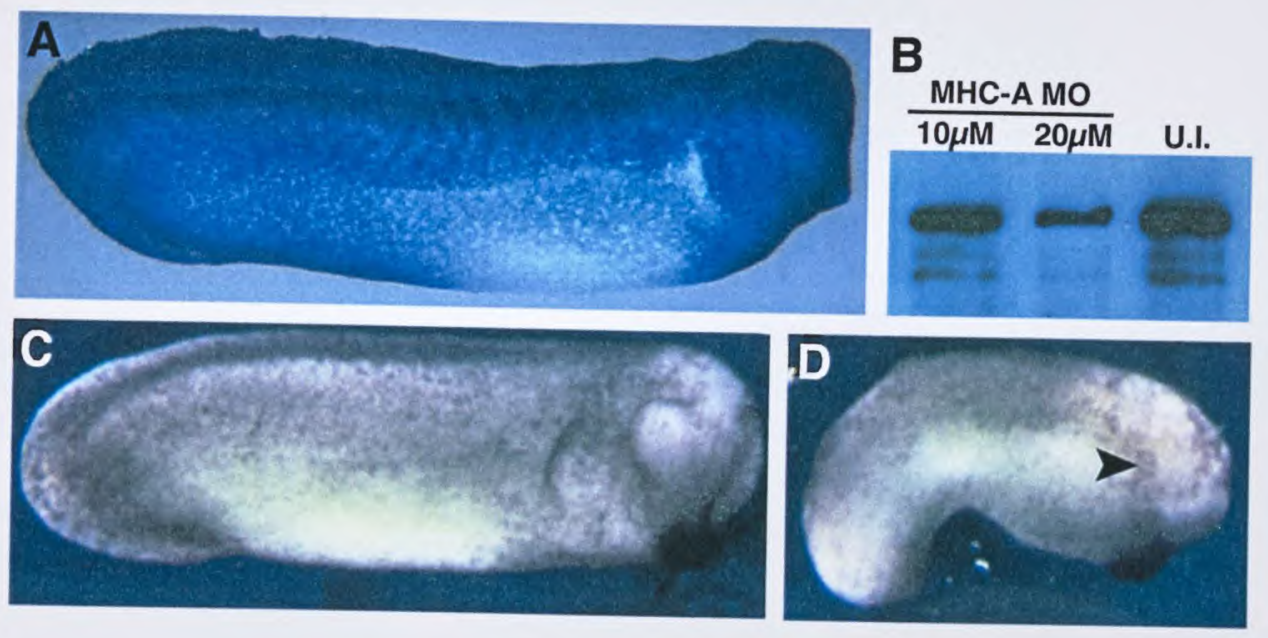


Figure 4-2. MHC-A MO causes worse defects in ventral than in dorsal dorsal tissues.

Early tailbud stage control (A) and dorsally.(B) and ventrally (C) targeted morphant embryos are shown. Dorsally targeted morphant embryos (B) display head defects and a slightly shorter axis than controls, whereas ventrally targeted morphant embryos $(\mathbf{C})$ have a greater reduction in body length. 

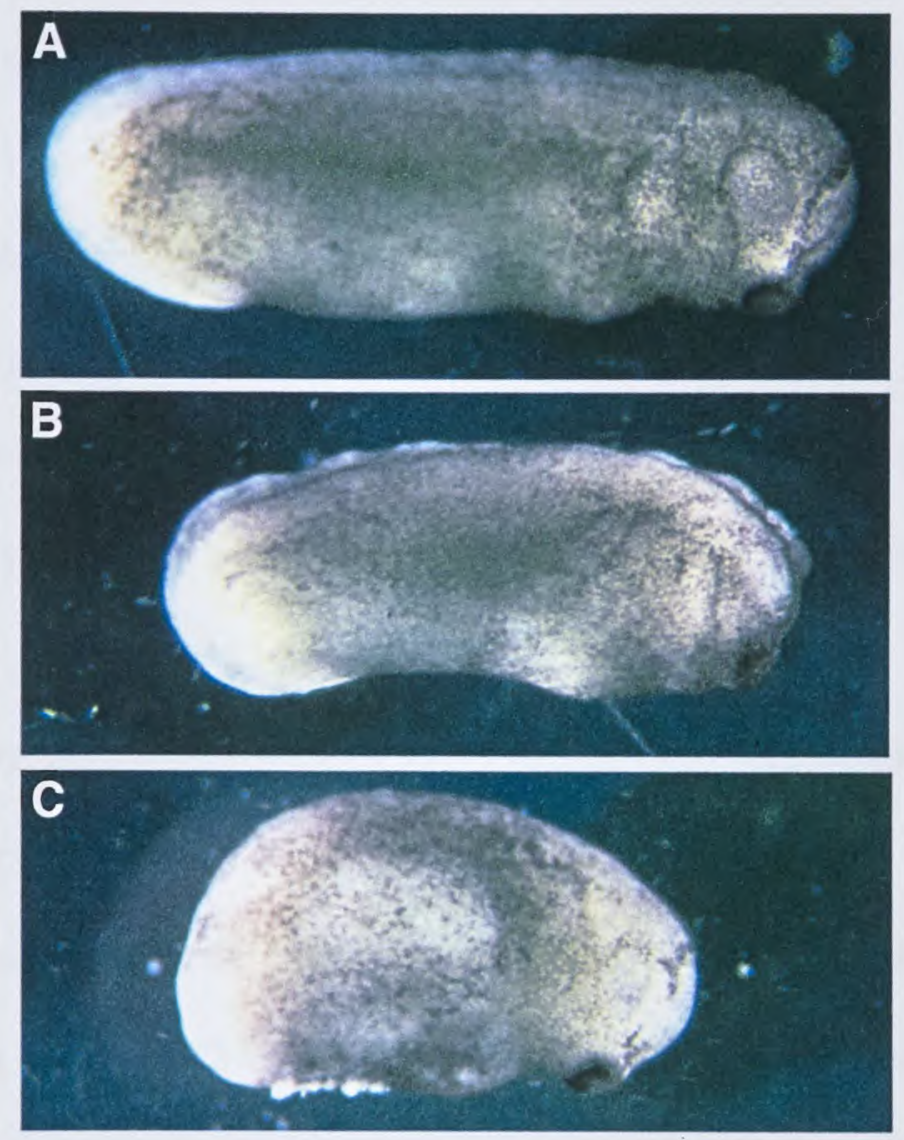
139

Figure 4-3. MHC-A MO prevents blastopore closure in UV-ventralized embryos.

(A-D) Still images from simultaneous time-lapse videorecordings show vegetal views of gastrulation. Non-ventralized embryos are oriented with their dorsal side up. Pointers indicate the site of blastopore closure.

(A) A control embryo shows normal, anisotropic ventrally-biased blastopore closure (pointer).

(B) A UV-ventralized embryo shows isotropic, centrally located blastopore closure (pointer).

(C) A morphant embryo injected with $20 \mu \mathrm{M}$ MHC-A MO shows reduced bottle cell formation as well as a delayed and extremely ventral site of blastopore closure (pointer).

(D) A UV-ventralized morphant embryo injected with $20 \mu \mathrm{M}$ MHC-A MO shows reduced bottle cell formation and failure of blastopore closure.

(E) Frequency of blastopore closure in control, UV-treated, MHC-A MO injected and UV-treated MHC-A MO injected embryos is shown. Error bars are s.e.m.. 

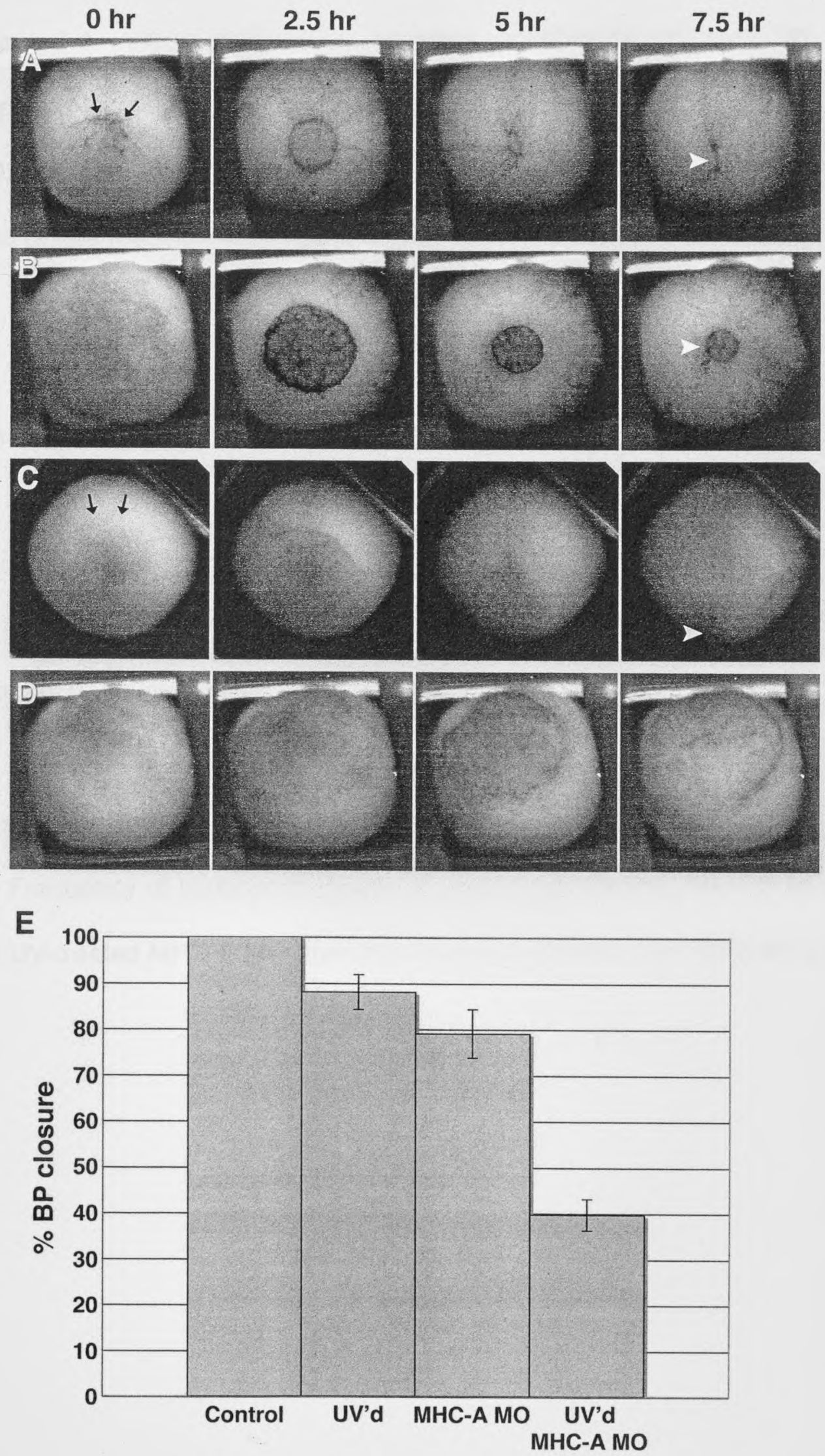
Figure 4-4. UV-ventralization rescues blastopore closure in MHC-B morphant embryos.

(A-D) Still images from simultaneous time-lapse videorecordings show vegetal views of gastrulation. Non-ventralized embryos are oriented with their dorsal side up.

(A) A control embryo shows normal, anisotropic ventrally-biased blastopore closure.

(B) A UV-ventralized embryo shows isotropic, centrally located blastopore closure.

(C) A morphant embryo injected with $7.5 \mu \mathrm{M}$ MHC-B $\mathrm{MO}$ shows failure of blastopore closure.

(D) A UV-ventralized morphant embryo injected with $7.5 \mu \mathrm{M} \mathrm{MHC-B} \mathrm{MO}$ is rescued and shows isotropic, centrally located blastopore closure.

(E) Frequency of blastopore closure in control, UV-treated, MHC-B MO injected and UV-treated MHC-B MO injected embryos is shown. Error bars are s.e.m.. 

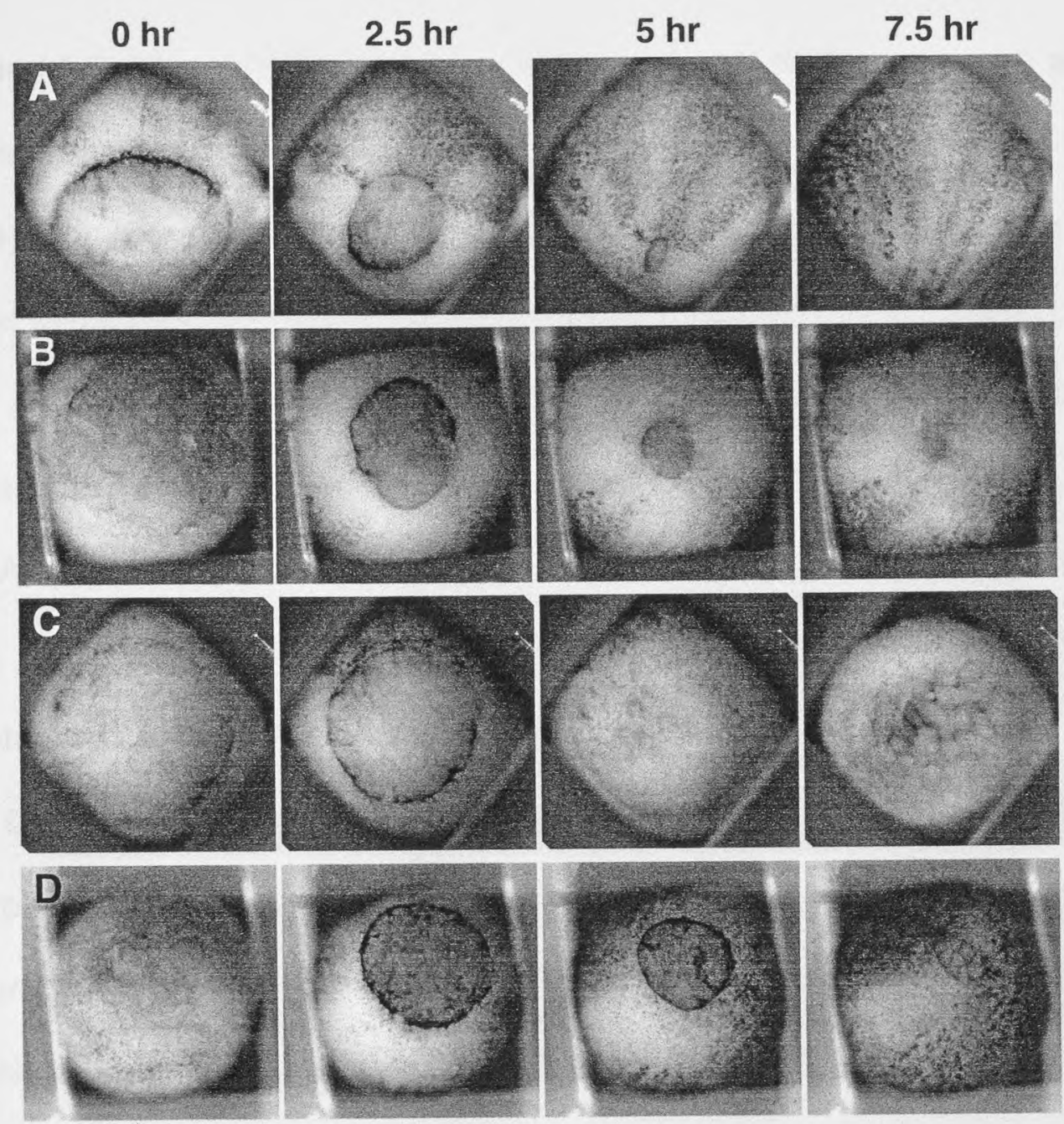

E

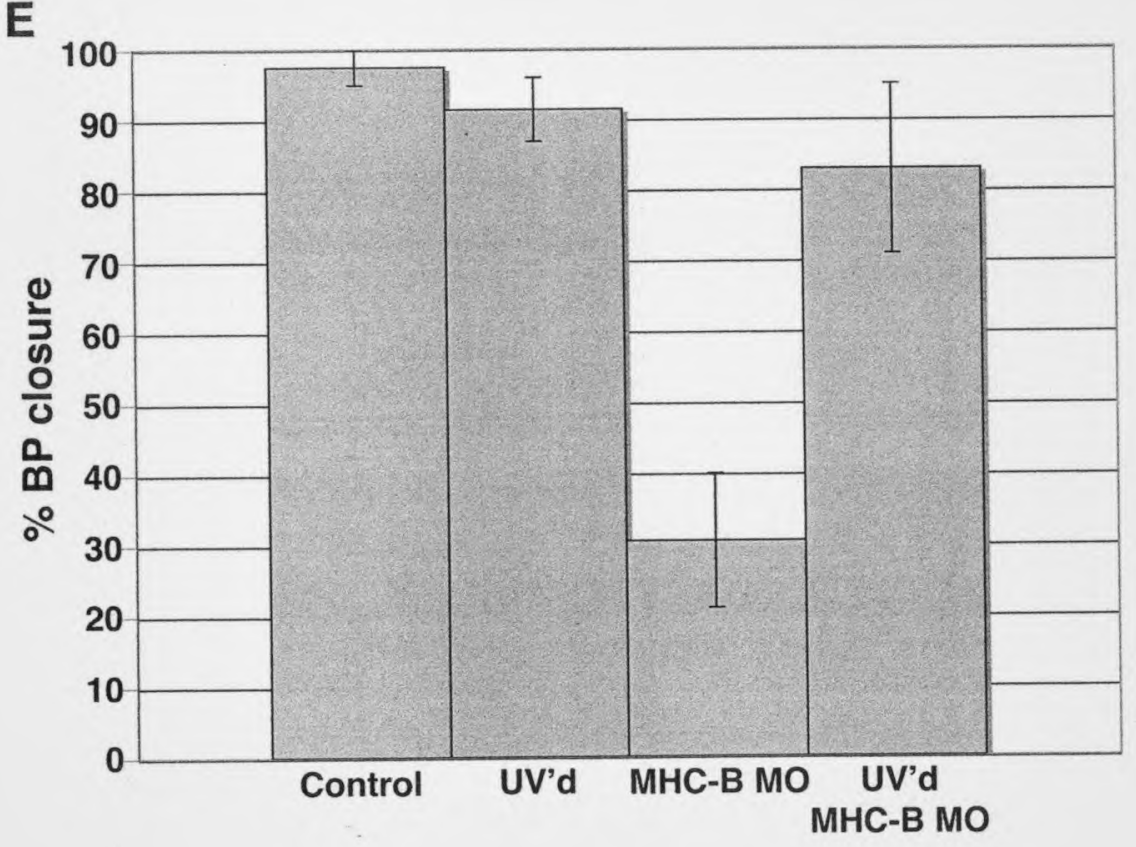


Figure 4-5. Myosins IIA and IIB synergize in blastopore closure and cell adhesion.

(A-B) Still images from simultaneous time-lapse videorecordings show. vegetal views of gastrulation. Both embryos are oriented with their dorsal side up.

(A) An uninjected control embryo shows normal bottle cell formation and blastopore closure.

(B) A double morphant embryo, injected with $8 \mu \mathrm{M}$ MHC-A MO and $2 \mu \mathrm{M}$ MHC-B $\mathrm{MO}$, has delayed and reduced bottle cell formation and fails to close the blastopore.

(C, D) Normal control devitellinized stage 20 embryos (C) and sibling double morphant embryos injected with $8 \mu \mathrm{M}$ MHC-A MO and $2 \mu \mathrm{M}$ MHC-B MO (D) show failure of morphogenesis and dissociate into masses of loose cells when the vitelline membrane is removed (arrows). 

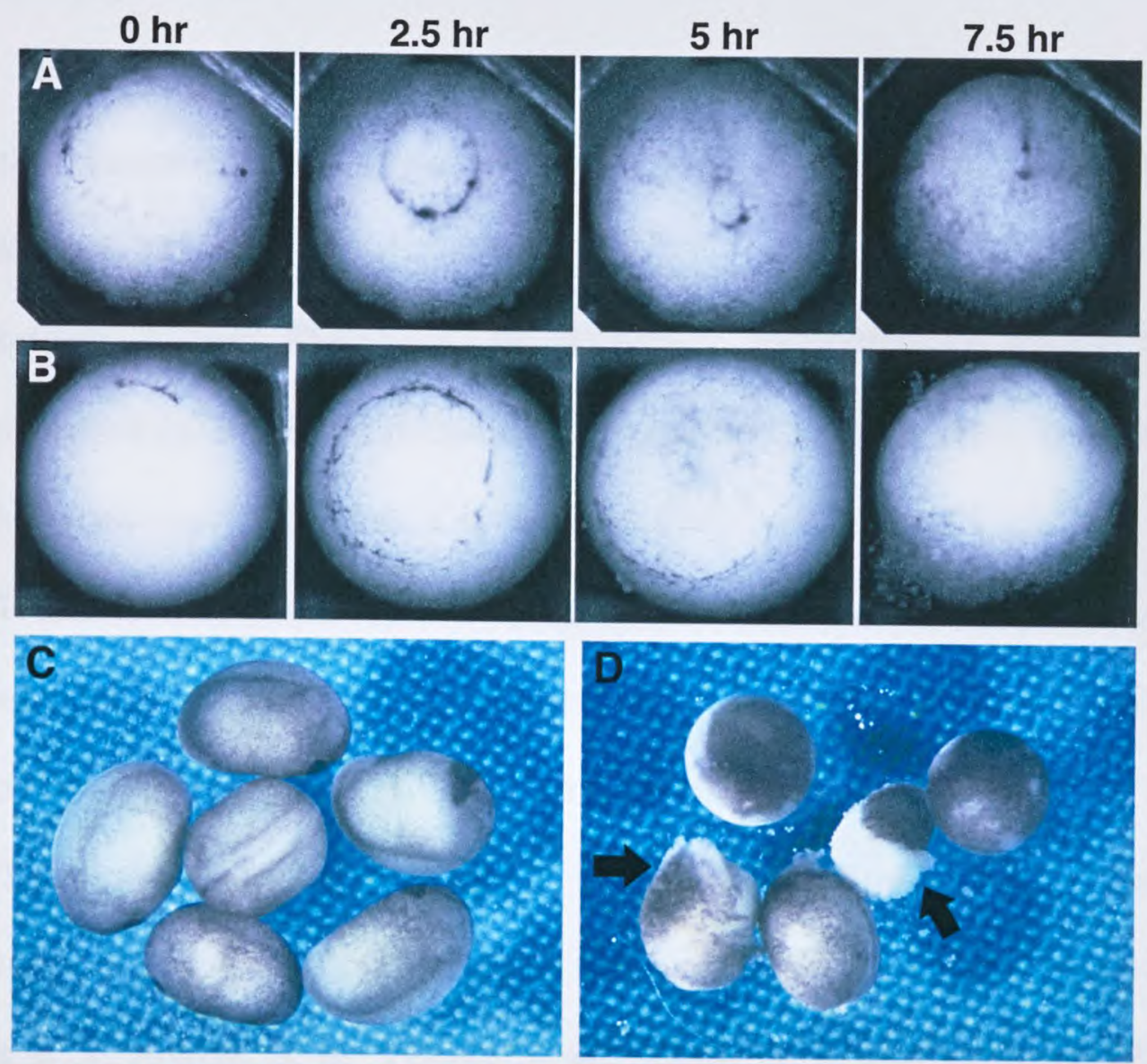


\section{REFERENCES}

Chen, X. and Gumbiner, B. M. (2006). Paraxial protocadherin mediates cell sorting and tissue morphogenesis by regulating $\mathrm{C}$-cadherin adhesion activity. $J$ Cell Biol 174, 301-13.

Choi, S. C. and Han, J. K. (2002). Xenopus Cdc42 regulates convergent extension movements during gastrulation through Wnt/Ca2+ signaling pathway. Dev Biol 244, 342-57.

Drawbridge, J. and Steinberg, M. S. (2000). Elongation of axolotl tailbud embryos requires GPI-linked proteins and organizer-induced, active, ventral trunk endoderm cell rearrangements. Dev Biol 223, 27-37.

Elul, T. and Keller, R. (2000). Monopolar protrusive activity: a new morphogenic cell behavior in the neural plate dependent on vertical interactions with the mesoderm in Xenopus. Dev Biol 224, 3-19.

Elul, T., KoehI, M. A. and Keller, R. (1997). Cellular mechanism underlying neural convergent extension in Xenopus laevis embryos. Dev Biol 191, 243-58.

Ewald, A. J., Peyrot, S. M., Tyszka, J. M., Fraser, S. E. and Wallingford, J. B. (2004). Regional requirements for Dishevelled signaling during Xenopus gastrulation: separable effects on blastopore closure, mesendoderm internalization and archenteron formation. Development 131, 6195-209. 
Ezin, A. M., Skoglund, P. and Keller, R. (2003). The midline (notochord and notoplate) patterns the cell motility underlying convergence and extension of the Xenopus neural plate. Dev Biol 256, 100-14.

Ezin, A. M., Skoglund, P. and Keller, R. (2006). The presumptive floor plate (notoplate) induces behaviors associated with convergent extension in medial but not lateral neural plate cells of Xenopus. Dev Biol.

Goto, T., Davidson, L., Asashima, M. and Keller, R. (2005). Planar cell polarity genes regulate polarized extracellular matrix deposition during frog gastrulation. Curr Biol 15, 787-93.

Goto, T. and Keller, R. (2002). The planar cell polarity gene strabismus regulates convergence and extension and neural fold closure in Xenopus. Dev Biol 247, 165-81.

Hardin, J. and Keller, R. (1988). The behaviour and function of bottle cells during gastrulation of Xenopus laevis. Development 103, 211-30.

Keller, R. and Danilchik, M. (1988). Regional expression, pattern and timing of convergence and extension during gastrulation of Xenopus laevis. Development 103, 193-209.

Keller, R., Shih, J. and Domingo, C. (1992). The patterning and functioning of protrusive activity during convergence and extension of the Xenopus organiser. Dev Suppl, 81-91. 
Keller, R. and Shook, D. (2004). Gastrulation in Amphibians. In Gastrulation From Cells to Embryo, (ed. C. D. Stern), pp. 171-203. Cold Spring Harbor, New York: Cold Spring Harbor Laboratory Press.

Keller, R. and Tibbetts, P. (1989). Mediolateral cell intercalation in the dorsal, axial mesoderm of Xenopus laevis. Dev Biol 131, 539-49.

Keller, R. E. (1981). An experimental analysis of the role of bottle cells and the deep marginal zone in gastrulation of Xenopus laevis. J Exp Zool 216, 81-101.

Larkin, K. and Danilchik, M. V. (1999). Ventral cell rearrangements contribute to anterior-posterior axis lengthening between neurula and tailbud stages in Xenopus laevis. Dev Biol 216, 550-60.

Nieuwkoop, P. D. and Faber, J. (1994). Normal Table of Xenopus laevis (Daudin), (ed. New York: Garland Publishing.

Nutt, S. L., Dingwell, K. S., Holt, C. E. and Amaya, E. (2001). Xenopus Sprouty2 inhibits FGF-mediated gastrulation movements but does not affect mesoderm induction and patterning. Genes Dev 15, 1152-66.

Scharf, S. R. and Gerhart, J. C. (1980). Determination of the dorsal-ventral axis in eggs of Xenopus laevis: complete rescue of uv-impaired eggs by oblique orientation before first cleavage. Dev Biol 79, 181-98.

Scharf, S. R. and Gerhart, J. C. (1983). Axis determination in eggs of Xenopus laevis: a critical period before first cleavage, identified by the common effects of cold, pressure and ultraviolet irradiation. Dev Biol99, 75-87. 
Shih, J. and Keller, R. (1992a). Cell motility driving mediolateral intercalation in explants of Xenopus laevis. Development 116, 901-14.

Shih, J. and Keller, R. (1992b). Patterns of cell motility in the organizer and dorsal mesoderm of Xenopus laevis. Development 116, 915-30.

Sive, H. L., Grainger, R. M. and Harland, R. M. (2000). Early Development of Xenopus laevis. Cold Spring Harbor, New York: Cold Spring Harbor Laboratory Press.

Skoglund, P., Dzamba, B., Coffman, C. R., Harris, W. A. and Keller, R. (2006). Xenopus fibrillin is expressed in the organizer and is the earliest component of matrix at the developing notochord-somite boundary. Dev Dyn 235, 1974-83.

Skoglund, P. and Keller, R. (2006). Xenopus fibrillin regulates directed convergence and extension. Dev Biol.

Smith, R. C. and Knowland, J. (1984). Protein synthesis in dorsal and ventral regions of Xenopus laevis embryos in relation to dorsal and ventral differentiation. Dev Biol 103, 355-68.

Tahinci, E. and Symes, K. (2003). Distinct functions of Rho and Rac are required for convergent extension during Xenopus gastrulation. Dev Biol 259, 318-35.

Wallingford, J. B. and Harland, R. M. (2001). Xenopus Dishevelled signaling regulates both neural and mesodermal convergent extension: parallel forces elongating the body axis. Development 128, 2581-92. 
149

Wallingford, J. B., Rowning, B. A., Vogeli, K. M., Rothbacher, U., Fraser, S. E. and Harland, R. M. (2000). Dishevelled controls cell polarity during Xenopus gastrulation. Nature $405,81-5$.

Wilson, P. and Keller, R. (1991). Cell rearrangement during gastrulation of Xenopus: direct observation of cultured explants. Development 112, 289-300.

Winklbauer, R., Medina, A., Swain, R. K. and Steinbeisser, H. (2001). Frizzled-7 signalling controls tissue separation during Xenopus gastrulation. Nature 413, 856-60. 
Chapter 5

Myosin IIB in ciliated cells of the epidermis 


\section{SUMMARY}

Ciliated cells are a scattered subpopulation of cells in the tailbud embryo epidermis. Polarized beating of the cilia result in a directed fluid flow across the embryonic surface, and also result in a gliding movement on smooth surfaces. These cells originate in the deep, mesenchymal layer of the double-layered Xenopus epidermis, and they enter the superficial layer by intercalating radially between the superficial cells. Embryos with reduced levels of myosin IIB lose their characteristic drifting behavior. Myosin IIB protein levels are higher in ciliated cells than in other cells of the epithelium of the epidermis, suggesting that upregulation of myosin IIB may be necessary for radial intercalation of the ciliated cells. My hypothesis is that lowered levels of myosin IIB in these cells blocks their entry into the epithelium. 
INTRODUCTION

Ciliated cells are a sparse, evenly distributed specialized cell type of the Xenopus tadpole skin. They produce currents of water by coordinated, polarized beating of cilia, producing a flow that facilitates the exchange of oxygen and the spreading of secreted mucus on the epidermis (Niu and Twitty, 1950; Twitty, 1928). These cells originate from precursors in the deep layer of the doublelayered Xenopus non-neural ectoderm (Drysdale and Elinson, 1992). Ciliated cell precursors become specified through the Notch/Delta pathway to become ciliated cells during early neurula stages, and then they intercalate radially into the superficial layer of the ectoderm at around the mid neurula stage (Deblandre et al., 1999; Drysdale and Elinson, 1992), where they subsequently undergo ciliogenesis (Chu and Klymkowsky, 1989). Ciliated cell precursors intercalate into the outer layer by first wedging between the basal ends of the outer epithelial cells, and then insert themselves between the apices of the outer cells at points of contact between three or more outer cells (Stubbs et al., 2006). Here I show that myosin IIB expression is higher in ciliated cells than in non-ciliated epidermal cells, and it may be necessary for intercalation of these cells into the superficial layer of the epidermis. 


\section{MATERIALS AND METHODS}

\section{Embryos}

Xenopus laevis embryos were obtained and dejellied by standard methods (Sive et al., 2000) and staged according to Nieuwkoop and Faber (1994).

\section{Whole-mount immunofluorescence}

Albino embryos were fixed in Dent's fixative (4:1 methanol:DMSO) for 2 hours at room temperature and stored at $-20^{\circ} \mathrm{C}$ overnight or longer. For transverse sections, whole-embryos were bisected transversely with a scalpel after rehydration, prior to immunostaining. MHC-B was detected using a polyclonal isoform-specific primary antibody (Covance, Berkeley, CA) at 1:50 dilution and a rhodamine-conjugated goat anti-rabbit secondary antibody (Jackson Immuno Research, West Grove, PA) at 1:200. Acetylated tubulin was detected using a monoclonal primary antibody (Sigma, St. Louis, MO) at 1:200 dilution and an Alexa488-conjugated goat anti-mouse secondary antibody (Invitrogen - Molecular Probes, Carlsbad, CA) at 1:400. Embryos were dehydrated in methanol and cleared in 2:1 benzyl benzoate:benzyl alcohol. Confocal images were collected using a BioRad Radiance 2100 system and processed using ImageJ software. 


\section{RESULTS}

Starting at stage mid-late 20s, normal Xenopus embryos show a slow drifting or gliding behavior. Because this behavior occurs before the tadpole exhibits swimming movements, and because tadpoles placed in anesthetic still drift in the media, despite cessation of other movements driven by muscle contraction, this phenomenon is not muscle contraction dependent. It is likely that this drifting behavior results from beating of ciliated cells, as described previously for urodeles (Niu and Twitty, 1950; Twitty, 1928). I observed that embryos injected with MHC-B MO at low-intermediate doses $(2.5-5 \mu \mathrm{M})$ at the 2-cell stage have reduced drifting compared to control embryos, and in some cases are completely immotile (not shown). This observation suggests that myosin IIB may be involved in the differentiation, the morphogenesis, or the functioning of these ciliated cells.

Embryos immunostained for MHC-B show higher expression of this protein in cells scattered across the epidermis (Figs. 3-1C and 5-1). High resolution images show that MHC-B is localized mainly to the basal ends of the cells and to an apical junctional ring (Fig. 5-1B). When co-stained for acetylated tubulin, which is a ciliated cell marker (Chu and Klymkowsky, 1989), the cells expressing higher levels of MHC-B coincide with ciliated cells (Fig. 5-1C, D). 


\section{DISCUSSION}

Given the observation that MHC-B is upregulated in ciliated cells of the epidermis and the circumstantial evidence that myosin IIB is necessary for proper functioning of these cells, it is reasonable to infer that myosin IIB is necessary for either the differentiation or the radial intercalation of these cells. It is not likely that myosin IIB is necessary for beating of the cilia, a movement based upon tubulin and dynein. Although possible, it is also unlikely that MHC-B MO affects the specification or differentiation of ciliated cells. A transgenic Xenopus line that expresses GFP in the ciliated cell precursors (Stubbs et al., 2006) and acetylated tubulin staining in morphant embryos should help resolve this issue. Due to myosin II's involvement in many morphogenetic processes (Bertet et al., 2004; Bridgman et al., 2001; Kolega, 2003; Laevsky and Knecht, 2003; Lo et al., 2004; Ma et al., 2004; Ma et al., 2006; Tullio et al., 1997; Tullio et al., 2001; Xu et al., 2001; Zallen and Wieschaus, 2004), it is reasonable to postulate that myosin IIB is necessary for radial intercalation of ciliated cell precursors into the superficial layer of the epithelial epidermis. This is particularly true when it has been shown that myosin II is necessary for E-cadherin localization to epithelial junctions and for cell adhesion (Shewan et al., 2005). When a dominant-negative form of cadherin is expressed in ciliated cell precursors, the cells stall out during intercalation (C. Kintner, personal communication), presumably because they fail to establish cell-cell adhesions with other epithelial cells. One possibility is that MHC-B depletion results in a similar phenotype, given the requirement of myosin 
II for cadherin-mediated epithelial cell adhesion (Shewan et al., 2005) as well as mesenchymal cell adhesion (Skoglund et al., in preparation). Another possibility is that MHC-B morphant ciliated cell precursors fail to stop after intercalating and become excluded from the embryo, a phenomenon observed in cells expressing a dominant-negative Rho GTPase (C. Kintner, personal communication). Experiments are underway (C. Kintner laboratory) to elucidate the role of myosin IIB in the intercalation of ciliated cell precursors into the superficial layer. 
Figure 5-1. MHC-B is highly expressed in ciliated cells of the epidermis.

MHC-B immunostainings of stage 24 embryos (A, B) and MHC-B and acetylated tubulin double staining of stage 32 embryos (C, D) are shown.

(A) A transverse section through the midtrunk region shows high MHC-B levels in scattered cells of the epidermis (asterisks).

(B) A high-resolution image of MHC-B expressing epidermal cells shows localization to the basal end as well as to a circum-apical ring.

(C, D) High levels of MHC-B (red) correspond to cells with apical tufts of cilia, stained for acetylated tubulin (green). 

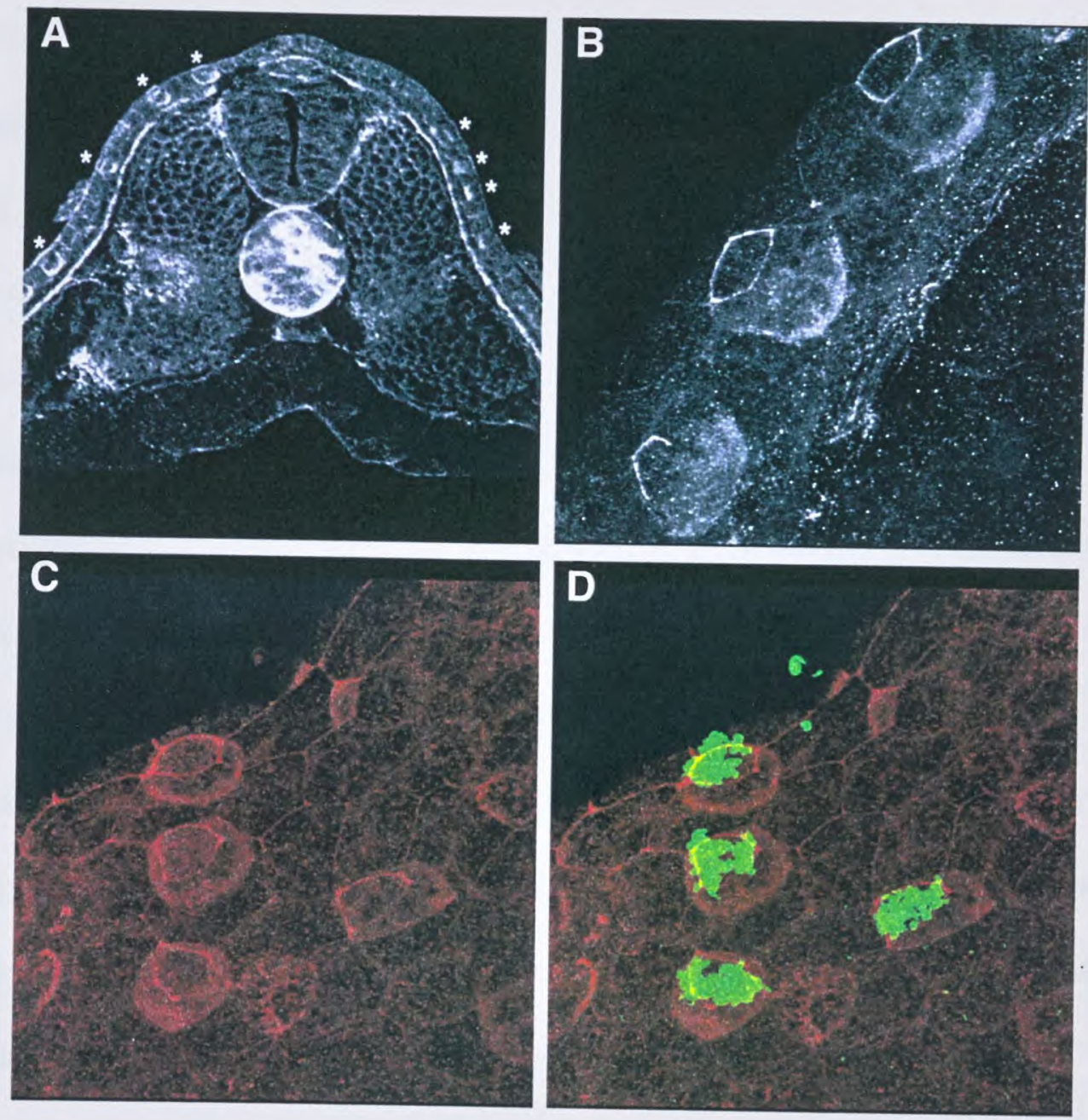


\section{REFERENCES}

Bertet, C., Sulak, L. and Lecuit, T. (2004). Myosin-dependent junction remodelling controls planar cell intercalation and axis elongation. Nature 429, 667-71.

Bridgman, P. C., Dave, S., Asnes, C. F., Tullio, A. N. and Adelstein, R. S. (2001). Myosin IIB is required for growth cone motility. J Neurosci 21, 6159-69.

Chu, D. T. and Klymkowsky, M. W. (1989). The appearance of acetylated alpha-tubulin during early development and cellular differentiation in Xenopus. Dev Biol 136, 104-17.

Deblandre, G. A., Wettstein, D. A., Koyano-Nakagawa, N. and Kintner, C. (1999). A two-step mechanism generates the spacing pattern of the ciliated cells in the skin of Xenopus embryos. Development 126, 4715-28.

Drysdale, T. A. and Elinson, R. P. (1992). Cell Migration and Induction in the Development of the Surface Ectodermal Pattern of the Xenopus laevis Tadpole. (Xenopus/ciliated cell/hatching gland/cement gland/ectodermal differentiation). Development, Growth and Differentiation 34, 51-59.

Kolega, J. (2003). Asymmetric distribution of myosin IIB in migrating endothelial cells is regulated by a rho-dependent kinase and contributes to tail retraction. $\mathrm{Mol}$ Biol Cell 14, 4745-57. 
Laevsky, G. and Knecht, D. A. (2003). Cross-linking of actin filaments by myosin II is a major contributor to cortical integrity and cell motility in restrictive environments. J Cell Sci 116, 3761-70.

Lo, C. M., Buxton, D. B., Chua, G. C., Dembo, M., Adelstein, R. S. and Wang, Y. L. (2004). Nonmuscle myosin $\mathrm{Ilb}$ is involved in the guidance of fibroblast migration. Mol Biol Cell 15, 982-9.

Ma, X., Kawamoto, S., Hara, Y. and Adelstein, R. S. (2004). A point mutation in the motor domain of nonmuscle myosin II-B impairs migration of distinct groups of neurons. Mol Biol Cell 15, 2568-79.

Ma, X., Kawamoto, S., Uribe, J. and Adelstein, R. S. (2006). Function of the neuron-specific alternatively spliced isoforms of nonmuscle myosin II-B during mouse brain development. Mol Biol Cell 17, 2138-49.

Nieuwkoop, P. D. and Faber, J. (1994). Normal Table of Xenopus laevis (Daudin), (ed. New York: Garland Publishing.

Niu, M. C. and Twitty, V. C. (1950). The origin of epidermal melanophores during metamorphosis in Triturus torosus. Journal of Experimental Zoology 113, 633-647.

Shewan, A. M., Maddugoda, M., Kraemer, A., Stehbens, S. J., Verma, S., Kovacs, E. M. and Yap, A. S. (2005). Myosin 2 is a key Rho kinase target necessary for the local concentration of E-cadherin at cell-cell contacts. Mol Biol Cell 16, 4531-42. 
Sive, H. L., Grainger, R. M. and Harland, R. M. (2000). Early Development of Xenopus laevis. Cold Spring Harbor, New York: Cold Spring Harbor Laboratory Press.

Stubbs, J. L., Davidson, L., Keller, R. and Kintner, C. (2006). Radial intercalation of ciliated cells during Xenopus skin development. Development 133, 2507-15.

Tullio, A. N., Accili, D., Ferrans, V. J., Yu, Z. X., Takeda, K., Grinberg, A., Westphal, H., Preston, Y. A. and Adelstein, R. S. (1997). Nonmuscle myosin II-B is required for normal development of the mouse heart. Proc Natl Acad Sci U $S$ A 94, 12407-12.

Tullio, A. N., Bridgman, P. C., Tresser, N. J., Chan, C. C., Conti, M. A., Adelstein, R. S. and Hara, Y. (2001). Structural abnormalities develop in the brain after ablation of the gene encoding nonmuscle myosin II-B heavy chain. $J$ Comp Neurol 433, 62-74.

Twitty, V. C. (1928). Experimental studies on the ciliary action of amphibian embryos. Journal of Experimental Zoology 50, 319-344.

Xu, X. S., Lee, E., Chen, T., Kuczmarski, E., Chisholm, R. L. and Knecht, D. A. (2001). During multicellular migration, myosin ii serves a structural role independent of its motor function. Dev Biol 232, 255-64.

Zallen, J. A. and Wieschaus, E. (2004). Patterned gene expression directs bipolar planar polarity in Drosophila. Dev Cell 6, 343-55. 
Chapter 6

General discussion 
In this work I show that myosin IIA and IIB isoforms function in different morphogenetic movements that occur in different parts of the embryo. Myosin IIB is involved in morphogenesis of the dorsal side of the embryo, whereas myosin IIA functions mainly in ventral morphogenesis. The dorsal and ventral morphogenetic movements in which myosin IIs are implicated function together to produce blastopore closure and elongation of the antero-posterior body axis.

\section{Mechanisms of blastopore closure}

In a normal Xenopus embryo, blastopore closure is driven by two mechanisms, convergent extension (CE) of the dorsal tissues and convergent thickening $(\mathrm{CT})$ of the ventral tissues (see Chapter 1). Because CE produces more convergence than $\mathrm{CT}$, and because it simultaneously extends the dorsal tissues as it converges them, blastopore closure in a normal embryo is asymmetric, biased towards the ventral side (Fig. 6-1A). Due to this fact, and because perturbations that disrupt CE generally result in an open blastopore, $\mathrm{CE}$ is often considered the sole driver of blastopore closure. However, in UVventralized embryos, where CE cannot occur because the dorsal tissues are not specified, blastopore closure nevertheless occurs. We (the Keller lab) think that this is because the entire marginal zone of the ventralized embryo undergoes CT. This CT movement occurs with equal strength all around the blastopore, thus closing it symmetrically (Fig. 6-1B). 
Myosin IIB is expressed predominantly in the dorsal side of the embryo, whereas myosin IIA is expressed ubiquitously (this work and Bhatia-Dey et al., 1998; Kelley et al., 1996). I show here (and also in Rolo et al., in preparation; Skoglund et al. a,b, in preparation) that, in accordance with their distributions, myosins IIA and IIB have different roles in the different morphogenetic movements that operate in dorsal and ventral tissues, with IIB being necessary for dorsal CE but not for ventral CT, and with IIA, the main myosin II isoform in ventral tissues, having a major role in ventral $\mathrm{CT}$.

When myosin IIA is targeted by injection of MHC-A MO, the ventral mechanisms of CT are compromised. However, because CE of the dorsal tissues is functional, blastopore closure is achieved, and it occurs in an extremely ventral location, with a stronger ventral bias than that observed in control normal embryos (Fig. 6-1C). Normally, the presumptive posterior somitic tissue lying at the lateral and ventral aspects of the marginal zone (Keller, 1991; Keller, 1976) undergo CT (Keller and Danilchik, 1988), which moves blastopore closure a small distance dorsally (Fig. 6-1A). However, when this ventral CT does not occur in MHC-A MO injected embryos, this movement never occurs, but the normal process of recruitment of the presumptive posterior somitic mesoderm, which lies at the lateral and ventral sides of the blastopore, into the posterior segmental plate, where they undergo CE, nevertheless takes place. This results in a greater dorsal CE and a more ventral site of blastopore closure. These findings also suggest that CT is not a pre-requisite to CE. Normally, the 
mesoderm in the ventral sectors of the IMZ undergoes CT before CE; whether this happens dorsally in a cryptic manner, it is not known. In any case, it appears that the laterally and ventrally situated presumptive mesoderm does not have to exercise CT in order to do CE.

On the other hand, when myosin IIB is depleted by injection of MHC-B MO at high concentration, then $\mathrm{CE}$, the main force driving blastopore closure, is disrupted, resulting in an open blastopore (Fig. 6-1F). If myosin IIB levels are only mildly reduced by lowering the dose of $\mathrm{MHC}-\mathrm{B} \mathrm{MO}$, then $\mathrm{CE}$ is mildly affected but it still occurs, and in this case the blastopore closes, albeit not as ventrally biased as in the normal situation, given the weakening of the forces produced by dorsal CE (Fig. 6-1E).

The effects on blastopore closure of reducing the levels of myosins IIA and IIB are reversed when done on UV-ventralized embryos. Injecting MHC-A MO disrupts $\mathrm{CT}$, which is the only movement driving convergence of the involuting marginal zone in ventralized embryos, and, accordingly, such embryos do not close their blastopores (Fig. 6-1D). Conversely, injection of high levels of MHC-B $\mathrm{MO}$ into ventralized embryos has no effect on $\mathrm{CT}$, and therefore blastopore closure occurs similarly to that seen in non-morphant ventralized embryos (Fig. $6-1 G)$. This interpretation is also consistent with the idea that failure of blastopore closure in otherwise normal MHC-B morphants is due to a failure of CE.

The asymmetric, ventrally-biased, CE-driven mechanism of blastopore closure seen in the normal Xenopus embryo is typical of anuran amphibians 
having moderate egg size, but other amphibians seem to close their blastopores using convergence only, uncoupled from extension (Keller and Shook, 2004). In Gastrotheca rhiobambae, a South American marsupial frog with a very large egg $(1 \mathrm{~cm}$ in diameter), involution of the marginal zone and blastopore closure are symmetric and occur prior to axial elongation (del Pino, 1996; del Pino and Elinson, 1983), and presumably this process is driven by CT occurring all around the marginal zone (Keller and Shook, 2004). After blastopore closure, the dorsal side of Gastrotheca will extend, elongating the post-involution mesoderm (del Pino, 1996; del Pino and Elinson, 1983), presumably by CE. If the roles for myosins IIA and IIB in morphogenesis are conserved across taxa, then the expected outcome of depleting Gastrotheca embryos of myosin IIA would be an open blastopore, whereas myosin IIB depletion shouldn't affect this process, but instead impede the later, dorsal elongation. These predictions should be tested on species showing a range of relative CE- versus CT-dependent gastrulations.

\section{Myosin IIB in CE}

Given myosin IIB's involvement in CE of the dorsal tissues, two main questions arise. One is how is myosin IIB regulated; what is upstream of myosin IIB in the regulatory cascade that leads from induction of dorsal tissues to the expression of stereotypical polarized cell protrusive behaviors that drive mediolateral cell intercalation? The second question is how does myosin IIB affect these same cell behaviors? 
In regard to the first question, in the last few years, much research has been done in order to identify the molecular pathways that regulate cell behavior during $\mathrm{CE}$, and the non-canonical Wnt/planar cell polarity (PCP) pathway has emerged as a key regulator of CE (Goto et al., 2005; Goto and Keller, 2002; Heisenberg et al., 2000; Tada and Smith, 2000; Veeman et al., 2003; Wallingford and Harland, 2001; Wallingford et al., 2000; Wang et al., 2006). The vertebrate PCP pathway involves the seven-pass transmembrane receptor Frizzled 7 , whose signaling is mediated by the PDZ domain protein Dsh, and downstream of Dsh the pathway bifurcates into two branches that lead to the activation of the small GTPases Rac and Rho (Habas et al., 2003; Tahinci and Symes, 2003). Dsh signals to Rho through the formin-related protein Daam1 (Habas et al., 2001), and Rho in turn signals its target, Rho-kinase (Rok) (Kim and Han, 2005; Marlow et al., 2002). Rok modulates myosin II activity by phosphorylation of the myosin regulatory light chain (MRLC), either directly (Amano et al., 1996), or indirectly through inhibition of MRLC-phosphatase (Kimura et al., 1996). It is therefore likely that part of the mechanism that regulates myosin IIB activity in CE involves the PCP pathway, through Rho and Rok.

In regard to the second question of how myosin IIB regulates the cell behaviors underlying mediolateral cell intercalation, cells actively undergoing intercalation in the dorsal mesoderm (Skoglund et al., in preparation) and in the neural plate (see Chapter 3 ) have a well-organized cortical actin cytoskeleton consisting of bundles that radiate from foci within the cell, and episodic 
contraction of this network correlates with contraction of the cell body. When myosin IIB levels are reduced, the actin network is disrupted. Fewer bundles form, and those that do are coarse and curved, instead of straight. In more severe cases, cables largely disappear, and the cytoskeleton has no apparent organization and no coordinated contraction movements occur. These cytoskeletal defects are accompanied by changes in cell shape and in protrusive activity. At high levels of MHC-B MO, cells that would normally be either monopolar (in the neural tissue) or bipolar (in the mesoderm) protrusive become highly protrusive in all directions, indicating that myosin IIB has a role in polarizing the cell, possibly by inhibiting protrusions on the anterior and posterior surfaces. Also, cell shape changes, particularly the flattening and accommodation to available spaces displayed by MHC-B morphant cells, indicate compromised cortical stiffness. Myosin IIB seems to be necessary for maintenance of a cortical actin network that regulates protrusive activity, episodic cell body contractions and cortical integrity.

In Dictyostelium, myosin II has a role in cortical stiffness and integrity that does not depend on myosin's motor function but instead relies on its activity as an actin cross-linker (Egelhoff et al., 1996; Laevsky and Knecht, 2003; Xu et al., 2001). It is possible that myosin IIB functions in intercalating cells mainly as a cross-linker that maintains the shape of the cortical actin network, particularly given the fact that myosin IIB's biochemical properties indicate that this isoform is suitable for such a function (Rosenfeld et al., 2003; Wang et al., 2003). One way 
to test this hypothesis is to attempt to rescue the MHC-MO phenotype using MHC-B point mutations that affect the motor activity of the head but not the binding to actin. In mouse, animals harboring such a mutation show defects in the migration of certain groups of neurons, but the defects in development are not nearly as severe as in mouse knock-out of myosin IIB (Ma et al., 2004; Tullio et al., 1997; Tullio et al., 2001), indicating that some of myosin IIB's functions may depend mostly on its cross-linking activity. If myosin IIB functions mainly as a cross-linker in dorsal intercalating cells, then another questions arises. Which molecule is responsible for causing the episodic contractions of the cytoskeleton? In this case, myosin IIA would be an obvious candidate, given its biochemical properties that make it suitable for fast movement of actin filaments (Kovacs et al., 2003) and its ubiquitous presence in the embryos. MHC-A morphant embryos do indeed show defects in the dorsal tissues, even though they are able to close their blastopores. However, due to maternal protein and incomplete MO efficiency, myosin IIA is only partially reduced in MHC-A morphants.

\section{Myosin IIA in dorsal morphogenesis}

As mentioned above, the evidence indicates that myosin IIA may also be involved in dorsal morphogenetic movements. Particularly, it will be informative to determine whether myosin IIA is involved in CE, and if so, how does it affect cell behaviors, and how does it function in conjunction with myosin IIB? Do they have complementary or overlapping roles? The first step in this line of research should 
obviously involve more detailed characterization of defects in dorsal morphogenesis caused by the MHC-A MO, given that data suggests that it may be involved in CE, at least at body elongation stages, and also in aspects of neural development, such as eye formation (see Chapter 4). Also, the success or failure of rescuing MHC-B morphant phenotypes with injection of MHC-A protein and vice-versa should provide insight as to whether these proteins overlap in function.

\section{Myosin IIA in ventral morphogenesis}

Myosin IIA is involved in ventral morphogenetic events, particularly CT of the ventral marginal zone at gastrulation and elongation of the ventral aspect of the body at post-neurula stages. However, very little is known about these mechanisms. CT is a movement described at a tissue level (Keller and Danilchik, 1988), and myosin IIA's implication in the process provide the first molecular component described as necessary for it to occur, but nevertheless a huge gap still exists in terms of describing CT at a cellular level. Much is known about CE in terms of cellular rearrangements and protrusive behaviors associated with it, perhaps because it is the main mechanism driving blastopore closure in Xenopus, the model organism of choice for many investigations in amphibian gastrulation. However, as discussed above, other species use different ways to close the blastopore, and CT may be a mechanism widely used, and therefore worth studying in detail. 
One caveat is the fact that in studying less traditional species there are often technical problems posed by difficulty in obtaining and manipulating embryos, as well as the lack of molecular tools, such as antibodies or morpholinos, for example. However, the ventralized Xenopus embryo may be an ideal tool for studying CT, because it has all the advantages of Xenopus as a model organism with a mode of blastopore closure that is independent of CE.

Ventral elongation has been attributed to the activity of the vegetal endoderm in the urodele amphibian (Drawbridge and Steinberg, 2000) and to the behavior of the lateral mesoderm in Xenopus (Larkin and Danilchik, 1999). In the latter case, there is some evidence that cell intercalation transverse to the axis of extension is involved, but no evidence bearing on whether it is active or passive in nature (Larkin and Danilchik, 1999). Again, whether it is the endodermal or mesodermal activities that produce this movement, the fact that it is myosin IIAdependent highlights the importance of describing its cellular basis and myosin IIA's role in this cellular mechanism. 
Figure 6-1. Mechanisms of blastopore closure in normal and perturbed Xenopus embryos.

Models of the forces operating in blastopore closure in normal (A), ventralized (B), myosin II morphant (C, E, F) and double-treated (D, G) embryos are shown, with the dorsal side of non-ventralized embryos oriented up. The forces produced by convergent extension (CE) are represented by wide orange arrows, and the forces produced by convergent thickening (CT) are represented by narrow blue arrows. Arrows with faded color represent weakened forces. 
A Normal embryo

Both CE and CT operate
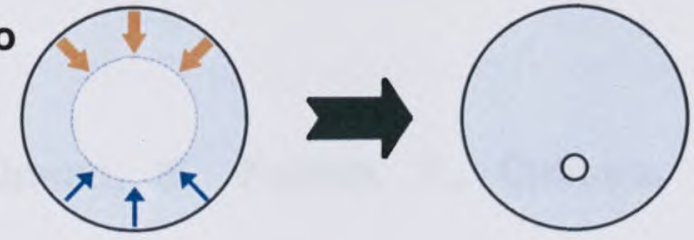

B

\section{Ventralized embryo} No CE; CT occurs all around the marginal zone
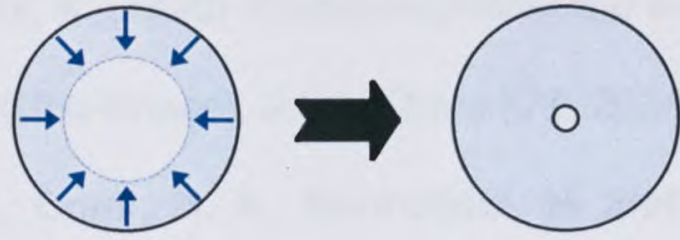

Equal stregth CT all around the BP; symmetric BP closure

C MHC-A MO CE undisturbed; diminished CT
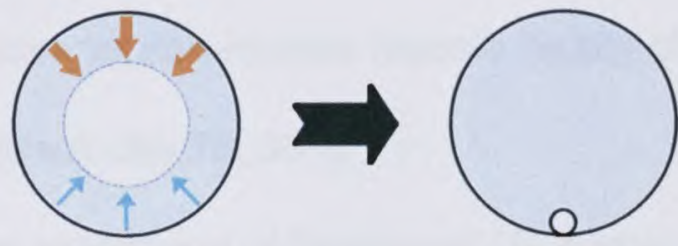

D

$$
\begin{aligned}
& \text { Ventralized } \\
& \text { MHC-A MO } \\
& \text { No CE; diminished } \\
& \text { CT all around the } \\
& \text { marginal zone }
\end{aligned}
$$
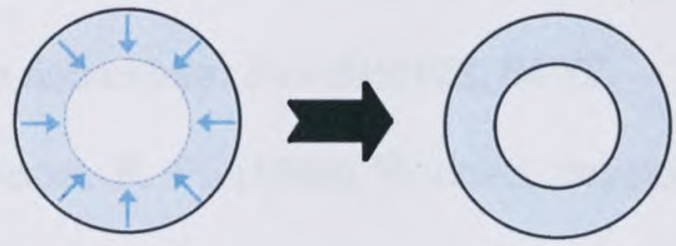

BP closure fails because it solely relies on $\mathrm{CT}$, which is compromised

E Low MHC-B MO Mildly diminished CE; CT undisturbed
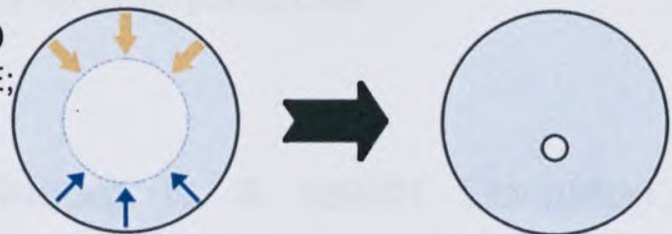

BP closes slightly more dorsal than normal due to weakening of $\mathrm{CE}$

F High MHC-B MO
Severely diminished
CE; CT undisturbed
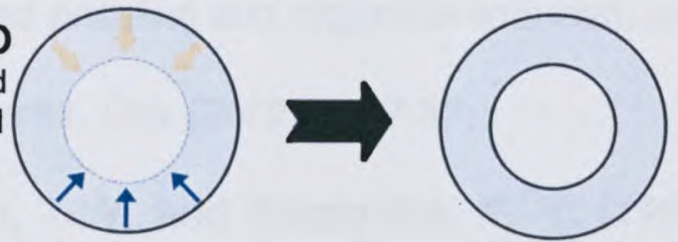

BP closure fails because ventral CT forces alone do not produce enough movement

G

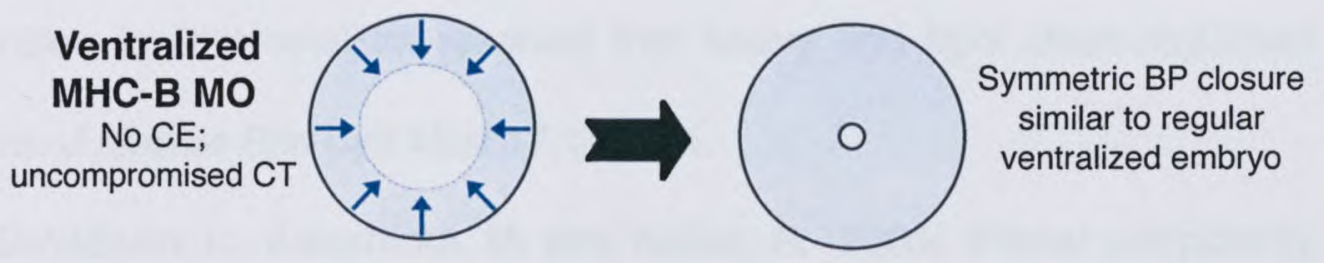




\section{REFERENCES}

Amano, M., Ito, M., Kimura, K., Fukata, Y., Chihara, K., Nakano, T., Matsuura, Y. and Kaibuchi, K. (1996). Phosphorylation and activation of myosin by Rho-associated kinase (Rho-kinase). J Biol Chem 271, 20246-9.

Bhatia-Dey, N., Taira, M., Conti, M. A., Nooruddin, H. and Adelstein, R. S. (1998). Differential expression of non-muscle myosin heavy chain genes during Xenopus embryogenesis. Mech Dev 78, 33-6.

del Pino, E. M. (1996). The expression of Brachyury (T) during gastrulation in the marsupial frog Gastrotheca riobambae. Dev Biol177, 64-72.

del Pino, E. M. and Elinson, R. P. (1983). A novel development pattern for frogs: gastrulation produces an embryonic disk

. Nature 306, 589-591.

Drawbridge, J. and Steinberg, M. S. (2000). Elongation of axolotl tailbud embryos requires GPI-linked proteins and organizer-induced, active, ventral trunk endoderm cell rearrangements. Dev Biol 223, 27-37.

Egelhoff, T. T., Naismith, T. V. and Brozovich, F. V. (1996). Myosin-based cortical tension in Dictyostelium resolved into heavy and light chain-regulated components. J Muscle Res Cell Motil 17, 269-74.

Goto, T., Davidson, L., Asashima, M. and Keller, R. (2005). Planar cell polarity genes regulate polarized extracellular matrix deposition during frog gastrulation. Curr Biol 15, 787-93. 
Goto, T. and Keller, R. (2002). The planar cell polarity gene strabismus regulates convergence and extension and neural fold closure in Xenopus. Dev Biol 247, 165-81.

Habas, R., Dawid, I. B. and He, X. (2003). Coactivation of Rac and Rho by Wnt/Frizzled signaling is required for vertebrate gastrulation. Genes Dev 17, 295309.

Habas, R., Kato, Y. and He, X. (2001). Wnt/Frizzled activation of Rho regulates vertebrate gastrulation and requires a novel Formin homology protein Daam1. Cell 107, 843-54.

Heisenberg, C. P., Tada, M., Rauch, G. J., Saude, L., Concha, M. L., Geisler, R., Stemple, D. L., Smith, J. C. and Wilson, S. W. (2000). Silberblick/Wnt11 mediates convergent extension movements during zebrafish gastrulation. Nature 405, 76-81.

Keller, R. (1991). Early embryonic development of Xenopus laevis. Methods Cell Biol 36, 61-113.

Keller, R. and Danilchik, M. (1988). Regional expression, pattern and timing of convergence and extension during gastrulation of Xenopus laevis. Development 103, 193-209.

Keller, R. and Shook, D. (2004). Gastrulation in Amphibians. In Gastrulation From Cells to Embryo, (ed. C. D. Stern), pp. 171-203. Cold Spring Harbor, New York: Cold Spring Harbor Laboratory Press. 
Keller, R. E. (1976). Vital dye mapping of the gastrula and neurula of Xenopus laevis. II. Prospective areas and morphogenetic movements of the deep layer. Dev Biol 51, 118-37.

Kelley, C. A., Sellers, J. R., Gard, D. L., Bui, D., Adelstein, R. S. and Baines, I. C. (1996). Xenopus nonmuscle myosin heavy chain isoforms have different subcellular localizations and enzymatic activities. J Cell Biol 134, 675-87.

Kim, G. H. and Han, J. K. (2005). JNK and ROKalpha function in the noncanonical Wnt/RhoA signaling pathway to regulate Xenopus convergent extension movements. Dev Dyn 232, 958-68.

Kimura, K., Ito, M., Amano, M., Chihara, K., Fukata, Y., Nakafuku, M., Yamamori, B., Feng, J., Nakano, T., Okawa, K. et al. (1996). Regulation of myosin phosphatase by Rho and Rho-associated kinase (Rho-kinase). Science 273, 245-8.

Kovacs, M., Wang, F., Hu, A., Zhang, Y. and Sellers, J. R. (2003). Functional divergence of human cytoplasmic myosin II: kinetic characterization of the nonmuscle IIA isoform. J Biol Chem 278, 38132-40.

Laevsky, G. and Knecht, D. A. (2003). Cross-linking of actin filaments by myosin II is a major contributor to cortical integrity and cell motility in restrictive environments. J Cell Sci 116, 3761-70.

Larkin, K. and Danilchik, M. V. (1999). Ventral cell rearrangements contribute to anterior-posterior axis lengthening between neurula and tailbud stages in Xenopus laevis. Dev Biol 216, 550-60. 
Ma, X., Kawamoto, S., Hara, Y. and Adelstein, R. S. (2004). A point mutation in the motor domain of nonmuscle myosin II-B impairs migration of distinct groups of neurons. Mol Biol. Cell 15, 2568-79.

Marlow, F., Topczewski, J., Sepich, D. and Solnica-Krezel, L. (2002). Zebrafish Rho kinase 2 acts downstream of Wnt11 to mediate cell polarity and effective convergence and extension movements. Curr Biol 12, 876-84.

Rosenfeld, S. S., Xing, J., Chen, L. Q. and Sweeney, H. L. (2003). Myosin Ilb is unconventionally conventional. J Biol Chem 278, 27449-55.

Tada, M. and Smith, J. C. (2000). Xwnt11 is a target of Xenopus Brachyury: regulation of gastrulation movements via Dishevelled, but not through the canonical Wnt pathway. Development 127, 2227-38.

Tahinci, E. and Symes, K. (2003). Distinct functions of Rho and Rac are required for convergent extension during Xenopus gastrulation. Dev Biol 259, 318-35.

Tullio, A. N., Accili, D., Ferrans, V. J., Yu, Z. X., Takeda, K., Grinberg, A., Westphal, H., Preston, Y. A. and Adelstein, R. S. (1997). Nonmuscle myosin II-B is required for normal development of the mouse heart. Proc Natl Acad Sci U $S$ A 94, 12407-12.

Tullio, A. N., Bridgman, P. C., Tresser, N. J., Chan, C. C., Conti, M. A., Adelstein, R. S. and Hara, Y. (2001). Structural abnormalities develop in the brain after ablation of the gene encoding nonmuscle myosin II-B heavy chain. $J$ Comp Neurol 433, 62-74. 
Veeman, M. T., Slusarski, D. C., Kaykas, A., Louie, S. H. and Moon, R. T. (2003). Zebrafish prickle, a modulator of noncanonical Wnt/Fz signaling, regulates gastrulation movements. Curr Biol 13, 680-5.

Wallingford, J. B. and Harland, R. M. (2001). Xenopus Dishevelled signaling regulates both neural and mesodermal convergent extension: parallel forces elongating the body axis. Development 128, 2581-92.

Wallingford, J. B., Rowning, B. A., Vogeli, K. M., Rothbacher, U., Fraser, S. E. and Harland, R. M. (2000). Dishevelled controls cell polarity during Xenopus gastrulation. Nature 405, 81-5.

Wang, F., Kovacs, M., Hu, A., Limouze, J., Harvey, E. V. and Sellers, J. R. (2003). Kinetic mechanism of non-muscle myosin IIB: functional adaptations for tension generation and maintenance. J Biol Chem 278, 27439-48.

Wang, J., Hamblet, N. S., Mark, S., Dickinson, M. E., Brinkman, B. C., Segil, N., Fraser, S. E., Chen, P., Wallingford, J. B. and Wynshaw-Boris, A. (2006). Dishevelled genes mediate a conserved mammalian PCP pathway to regulate convergent extension during neurulation. Development 133, 1767-78.

Xu, X. S., Lee, E., Chen, T., Kuczmarski, E., Chisholm, R. L. and Knecht, D. A. (2001). During multicellular migration, myosin ii serves a structural role independent of its motor function. Dev Biol 232, 255-64. 